\title{
Present and Future Therapeutic Approaches to Barrier Dysfunction
}

\section{OPEN ACCESS \\ Edited by: \\ Giovanni Barbara, \\ University of Bologna, Italy \\ Reviewed by: \\ Laura Baldomà, \\ University of Barcelona, Spain \\ Linette Willemsen, \\ Utrecht University, Netherlands}

*Correspondence:

Carmen Alonso-Cotoner carmen.alonso@vhir.org

tThese authors have contributed equally to this work and share first authorship

¥ORCID:

Marina Fortea orcid.org/0000-0001-8885-7495

Mercé Albert-Bayo orcid.org/0000-0002-9726-8083

Mar Abril-Gil

orcid.org/0000-0003-0318-6755

John-Peter Ganda Mall orcid.org/0000-0002-2120-7743

Xavier Serra-Ruiz orcid.org/0000-0003-2478-8923

Alejandro Henao-Paez orcid.org/0000-0001-6062-4753

Elba Expósito

orcid.org/0000-0001-6088-3149

Ana María González-Castro orcid.org/0000-0003-3955-3318

Danila Guagnozzi orcid.org/0000-0002-6171-1901

Beatriz Lobo

orcid.org/0000-0003-3391-7125

Carmen Alonso-Cotoner orcid.org/0000-0002-3483-2919

Javier Santos

orcid.org/0000-0002-4798-5033

Specialty section:

This article was submitted to

Nutritional Immunology,

a section of the journal

Frontiers in Nutrition

Received: 31 May 2021

Accepted: 29 September 2021

Published: 28 October 2021

\author{
Marina Fortea ${ }^{1+\neq}$, Mercé Albert-Bayo ${ }^{2 \ddagger \neq}$, Mar Abril-Gil ${ }^{2 \ddagger}$, John-Peter Ganda Mall ${ }^{2,3 \neq}$, \\ Xavier Serra-Ruiz ${ }^{4 \ddagger}$, Alejandro Henao-Paez ${ }^{4 \neq}$, Elba Expósito ${ }^{2 \ddagger}$, \\ Ana María González-Castro ${ }^{2 \ddagger}$, Danila Guagnozzi ${ }^{2,4,5,6 \neq}$, Beatriz Lobo ${ }^{2,4,5 \neq}$, \\ Carmen Alonso-Cotoner ${ }^{2,4,5,6 *}$ and Javier Santos ${ }^{2,4,5,6 \neq}$
}

${ }^{1}$ Laboratory for Enteric NeuroScience, Translational Research Center for Gastrolntestinal Disorders, University of Leuven, Leuven, Belgium, ${ }^{2}$ Laboratory of Neuro-Immuno-Gastroenterology, Digestive System Research Unit, Vall d'Hebron Institut de Recerca (VHIR), Vall d'Hebron Hospital Universitari, Barcelona, Spain, ${ }^{3}$ Department of Biomedical and Clinical Sciences, Linköping University, Linköping, Sweden, ${ }^{4}$ Department of Gastroenterology, Vall d'Hebron Hospital Universitari, Barcelona, Spain, ${ }^{5}$ Facultad de Medicina, Universitat Autònoma de Barcelona, Bellaterra, Spain, ${ }^{6}$ Centro de Investigación Biomédica en Red de Enfermedades Hepáticas y Digestivas (CIBERHED), Instituto de Salud Carlos III, Madrid, Spain

There is converging and increasing evidence, but also uncertainty, for the role of abnormal intestinal epithelial barrier function in the origin and development of a growing number of human gastrointestinal and extraintestinal inflammatory disorders, and their related complaints. Despite a vast literature addressing factors and mechanisms underlying changes in intestinal permeability in humans, and its connection to the appearance and severity of clinical symptoms, the ultimate link remains to be established in many cases. Accordingly, there are no directives or clinical guidelines related to the therapeutic management of intestinal permeability disorders that allow health professionals involved in the management of these patients to carry out a consensus treatment based on clinical evidence. Instead, there are multiple pseudoscientific approaches and commercial propaganda scattered on the internet that confuse those affected and health professionals and that often lack scientific rigor. Therefore, in this review we aim to shed light on the different therapeutic options, which include, among others, dietary management, nutraceuticals and medical devices, microbiota and drugs, and epigenetic and exosomes-manipulation, through an objective evaluation of the scientific publications in this field. Advances in the knowledge and management of intestinal permeability will sure enable better options of dealing with this group of common disorders to enhance quality of life of those affected.

Keywords: epithelial barrier function, intestinal permeability, nutrients, short chain fatty acids, prebiotics, probiotics, mast cell stabilizers, mucoprotectants

\section{INTRODUCTION}

This manuscript belongs to a series of articles dealing with the role of intestinal barrier dysfunction in the origin of chronic inflammatory disorders. Previous papers in this monography review the anatomical, molecular, microbiological, immunological, and pathophysiological bases that link intestinal permeability to the development of chronic conditions within the gastrointestinal tract. Some studies also point to a prominent role of abnormal responses to food and microbial antigens, and toxins, resulting from the alteration of the intestinal epithelial permeability, in the generation of symptoms and signs common to functional diseases of the digestive tract. Although 
the theoretical basis for this hypothesis is apparently solid, it is nonetheless true that translation from pathophysiological alterations to clinical manifestations relies mostly on in vitro and ex vivo studies and preclinical models. Therefore, more evidence from clinical trials is needed to determine their role in the management of these diseases.

Despite outstanding advances on the pathophysiology and molecular mechanisms underlying barrier abnormalities, currently we have no universal standards to accurately determine the magnitude of the problem (see other papers in this monography). In this sense, functional barrier parameters such as lactulose/mannitol ratio and maybe certain blood markers may be more indicative for intestinal barrier function than secondary parameters such as levels of tight junction protein expression. This lack of standardization generates confusion impeding further actions of regulatory agencies and many health-care professionals doubt the validity, usefulness and clinical applicability of the different techniques used for the determination of intestinal permeability.

Closely related to the scant clinical evidence linking permeability alterations with inflammatory disorders of the digestive system and other body systems is the insufficient development of molecules or drugs aimed at controlling this function. This is despite the large number of potential therapeutic targets in which a regulatory role has been evidenced in both the pore pathway and the leak pathway. In addition, the modulation of the microbiota and its metabolites, through nutrition, can also play an important role in the therapeutic armamentarium of altered intestinal permeability.

There are hundreds of publications that have investigated a huge number of molecules involved in intestinal barrier homeostasis, though many data are derived from in vitro or animal studies what may not well-represent the physiologic situation in the human organism and may not correctly mimic human pathology. In this article, we will review the evidence related to the use of those molecules or products that offer greater potential for the clinical management of diseases that have been more consistently associated with intestinal epithelial barrier (IEB) dysfunction. We will focus our review on the paracellular

Abbreviations: AMPK, AMP-activated protein kinase; Arg, Arginine; CD, Celiac Disease; ClC-2, Chloride channel type 2; CLDN, Claudin; CRF, Corticotropin-releasing factor; CRF-R, CRF Receptor; DF, Dietary Fibers; DMM, Dexmedetomidine; DSCG, Disodium cromoglycate; DSS, Dextran sodium sulfate; EcN, Escherichia coli Nissle 1917; EV, extracellular vesicles; FODMAP, Fermentable oligosaccharides, disaccharides, monosaccharides, and polyols; GC, Glucocorticoids; GI, Gastrointestinal; Gln, Glutamine; GLP-2, Glucagon-like peptide 2; GLP-2R, Glucagon-like peptide 2 receptor; GOS, Galactooligosaccharide; GT, Gelatine tannate; IBD, Inflammatory Bowel Disease; IBS, Irritable Bowel Syndrome; IBS-D, Irritable Bowel Syndrome with Diarrea; IEIFG-1R, Epithelial insulin-like growth factor-1 receptor; IEB, Intestinal epithelial barrier; IFN- $\gamma$, Interferon gamma; Ig, Immunoglobulin; IL, Interleukin; LBP, Lubiprostone; LPS, Lipopolysaccharide; LRH-1, Liver receptor homolog-1; MC, Mast cell; MiRNA, Micro-RNA; MLC, Myosin light chain; MLCK, Myosin light chain kinase; NF-KB, Nuclear factor kappa B; NLRP3, NLR family pyrin domain containing 3; OCLN, Occludin; SCFA, Short-chain fatty acids; TEER, Transepithelial electrical resistance; TJ, Tight Junction; TLR, Toll-Like Receptor; TNF- $\alpha$, Tumor necrosis factor; UC, Ulcerative colitis; VDR, Vitamin D receptor; Vit, Vitamin; XenomiRs, xeno-miRNAs; XG, Xyloglucan; Zn, Zinc; ZO, Zonula Occludens. route as the main target of the epithelial barrier breakdown and as an early event whose loss of functional integrity likely facilitates transepithelial antigen penetration, and the stimulation of immunological responses, further increasing paracellular epithelial permeability and promoting the development of lowgrade mucosal inflammation (Figure 1) (1).

The potential market for intestinal permeability regulatory products is unknown but intuitively ample. However, it remains to be established the mechanistic link between alterations in intestinal permeability and specific diseases to estimate how many patients could benefit from better therapies for intestinal permeability and the direct and indirect cost derived from attending these people.

Finally, this manuscript is not intended as a systematic review of the literature concerning intestinal permeability and its management. We just want to raise awareness on the potential of targeting intestinal permeability to improve gut mucosal inflammation and related clinical manifestations. However, we also want to make clear that improving barrier integrity does not mean that inflammation and immune activation are interrupted because this deserves further evidence and possibly complementary approaches to manage microbiome and immune system defects.

\section{APPROACH TO MANAGEMENT}

\section{Nutrients}

Nutrition has a key role in shaping gut microbiota (2) whereas processing of food by gut microbiota releases byproducts and metabolites that influence the functioning of the intestinal barrier and mucus layer integrity $(2,3)$ in health and disease $(4,5)$ (Figure 2).

\section{Dietary Fibers, Prebiotics, and Short-Chain Fatty Acids}

The international CODEX Alimentarius Commission defined in 2009 dietary fibers (DF) as "carbohydrate polymers with 10 or more monomeric units which are not hydrolyzed by the endogenous enzymes in the small intestine of humans" (6). In terms of solubility, DF differ in their chemical properties $(7,8)$. Insoluble fibers mainly contribute to stool bulk whereas soluble fibers are metabolized by the host microbiota, also contributing to maintain eubiosis (9). In fact, many of these fibers can be considered as prebiotics because they are resistant to the acidic $\mathrm{pH}$ of the stomach, not hydrolyzed by mammalian enzymes, not absorbed in the GI tract, but fermented by intestinal microbiota, and selectively stimulate the growth and/or activity of the intestinal microbiota, particularly Bifidobacteria and Lactobacilli $(10,11)$, to improve host's health (12). This may be relevant as bacterial dysbiosis is highly associated with intestinal barrier dysfunction and related pathologies such as Inflammatory Bowel Disease (IBD) (13) (see Table 1). In addition, the outer mucus layer is degraded to glycans by the glycan-consuming microbiota and glycans reused by bacteria in the absence of sufficient DF, as shown in a gnotobiotic mouse model, what may lead to erosion of the colonic mucus barrier, 


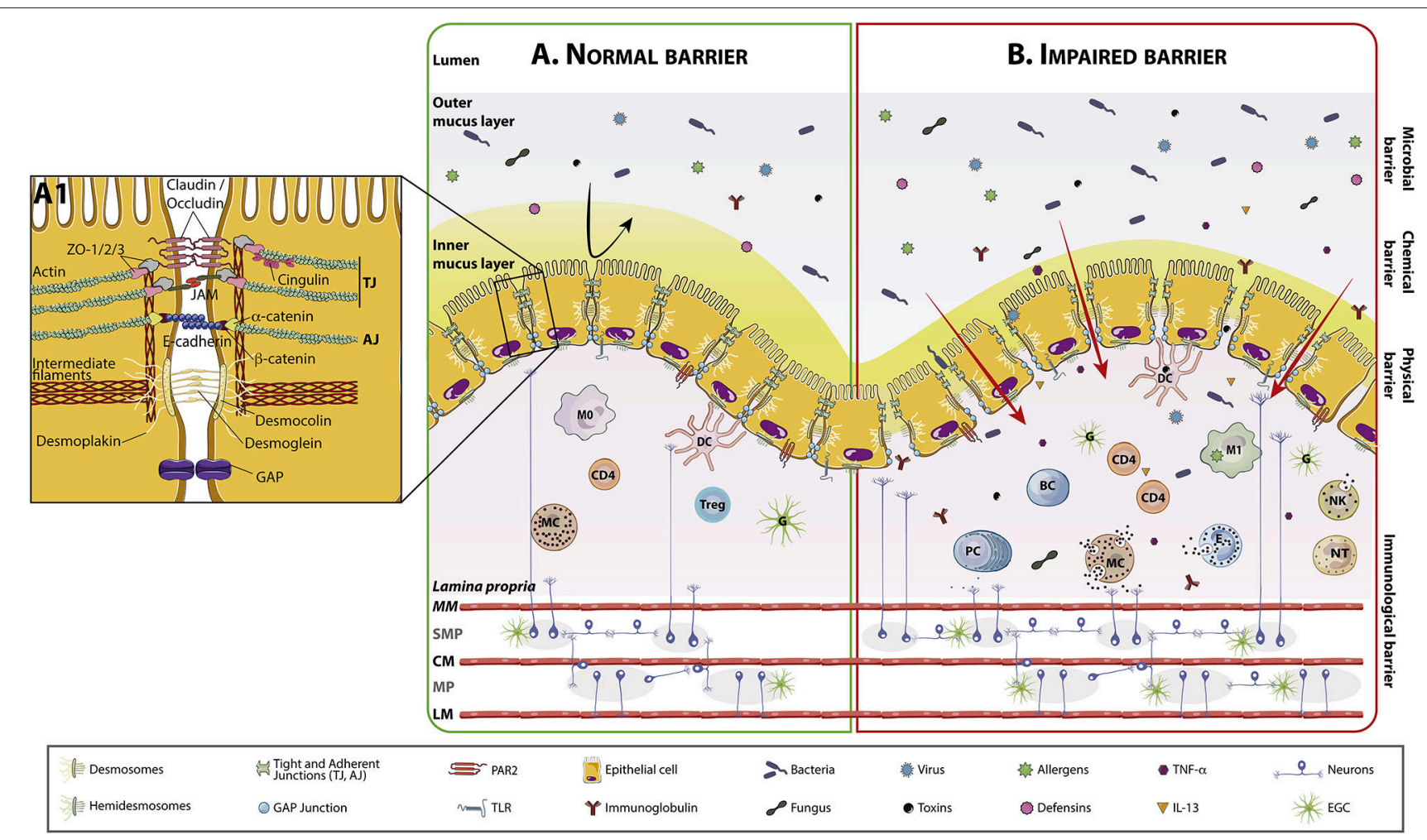

FIGURE 1 | Intestinal barrier anatomy and its components in normal and impaired conditions. The intestinal mucosa comprises a layer of polarized, columnar epithelial cells next to a subepithelial region that contains the lamina propria, the enteric nervous system, connective tissue, and muscular layers. On top of columnar cells there is the mucus layer. Normal mucus is $98 \%$ water, being the rest glycosilated proteins (mucins) and glycolipids. In the colon, mucus has an outer layer, densely colonized by bacteria, fungus, virus, and able to retain toxins and allergens, and a mostly sterile inner layer where immunoglobulins (mostly secretory-lgA), and defensins such as lysozyme are present. The inner mucus layer is dense and attached an $50 \mu \mathrm{m}$ thick and the outer layer is loose and unattached and about $100 \mu \mathrm{m}$ thick. The small intestine has only one single mucus layer, which is much thinner than the mucus layer in the large intestine. The lamina propria includes a diffuse lymphoid tissue constituted by macrophages, dendritic cells, plasma cells, lamina propria lymphocytes, MCs, eosinophils and occasionally, neutrophils. (A) The intestinal barrier in homeostasis, where cells are closely attached by intercellular junctions (TJs, adherens junctions, desmosomes and GAP junctions) represented in detail in (A1). (B) Impaired intestinal barrier, with increased trans and paracellular passage of lumen contents. This increased transport activates the immune system and cell recruitment and degranulation in the lamina propria. MC and PC are able to modulate the ENS interacting with SMP/MP neurons and with EGCs. (A1) Representation of intercellular junctions. Intercellular junctions are primary responsible for nutrient absorption and water and chloride secretion. Intercellular junctional complexes, including TJs, adherens junctions, gap junctions, and desmosomes, are dynamic structures that restrict the passage of molecules: 4-5 $\AA$ at the villus tip to over $20 \AA$ at the base of the crypt in the small bowel. The integrity and structure of epithelial cells are mostly modulated by the cytoskeleton, mainly by actin, myosin, and intermediate filaments. Cells adhere to the basement membrane through hemidesmosomes. TJs are primarily made up of CLDNs, OCLNs, and JAM proteins, which are connected through zonula occludens and cingulin to the cytoskeleton. Adherens junctions include cadherins such as E-cadherin, which binds catenins $(\alpha$ and $\beta$ ) connected to the cytoskeleton. Desmosomes are mainly comprised of desmocollin and desmoglein, which interact with desmoplakin, in turn connected to the intermediate filaments. AJ, Adherens junctions; BC, B Cell; CD4, Lymphocyte T helper CD4+; CLDN, Claudin; CM, Circular muscle; D,

Desmosomes; DC, Dendritic cell; EGC, Enteric glial cell; ENS, Enteric nervous system; IL-13, Interleukin 13; JAM, Junctional adhesion molecule; LM, Longitudinal muscle; MO, Macrophages type 0; M1, Macrophages type 1; MC, Mast cell; MM, Muscularis mucosae; MP, Myenteric plexus; NK, Natural killer; NT, Neutrophil; OCLN, occludin; PC, Plasma cell; SMP, Submucous plexus; TJ, Tight junctions; TNF- $\alpha$, Tumor necrosis factor alpha; Treg, T regulatory lymphocyte.

promoting greater epithelial access, and lethal colitis by mucosal pathogens (38).

These dietary compounds mainly include inulin-type fructans (inulin, oligofructose, and fructooligosaccharides), galactans, galactooligosaccharides (GOS), and other heteropolysaccharides such as chitosan, starch, alginate, pectin, or dextran, among others. These products have been shown to positively impact intestinal barrier function through different mechanisms after their fermentation by non-pathogenic colonic bacteria. Fermentation of DF by gut microbiota releases short-chain fatty acids (SCFAs). SCFAs are carboxylic acids with aliphatic tails of
1-6 carbons, being the most abundant acetate, propionate, and butyrate (39). SCFAs show a wide range of biological functions including anti-inflammatory responses, modulation of colonic contractility and maintenance of both mucosal immune cell activity and integrity of the IEB, among others (see Table 2). SCFAs, specially at low concentrations, increased transepithelial electrical resistance (TEER) in T84 and Caco-2 cells, what immediately enhanced barrier function of the colonic epithelium through cholesterol-rich microdomain in the plasma membrane and decreased inulin permeability $(42,54-56)$. These effects seem to be mediated by AMP-activated protein kinase (AMPK) 


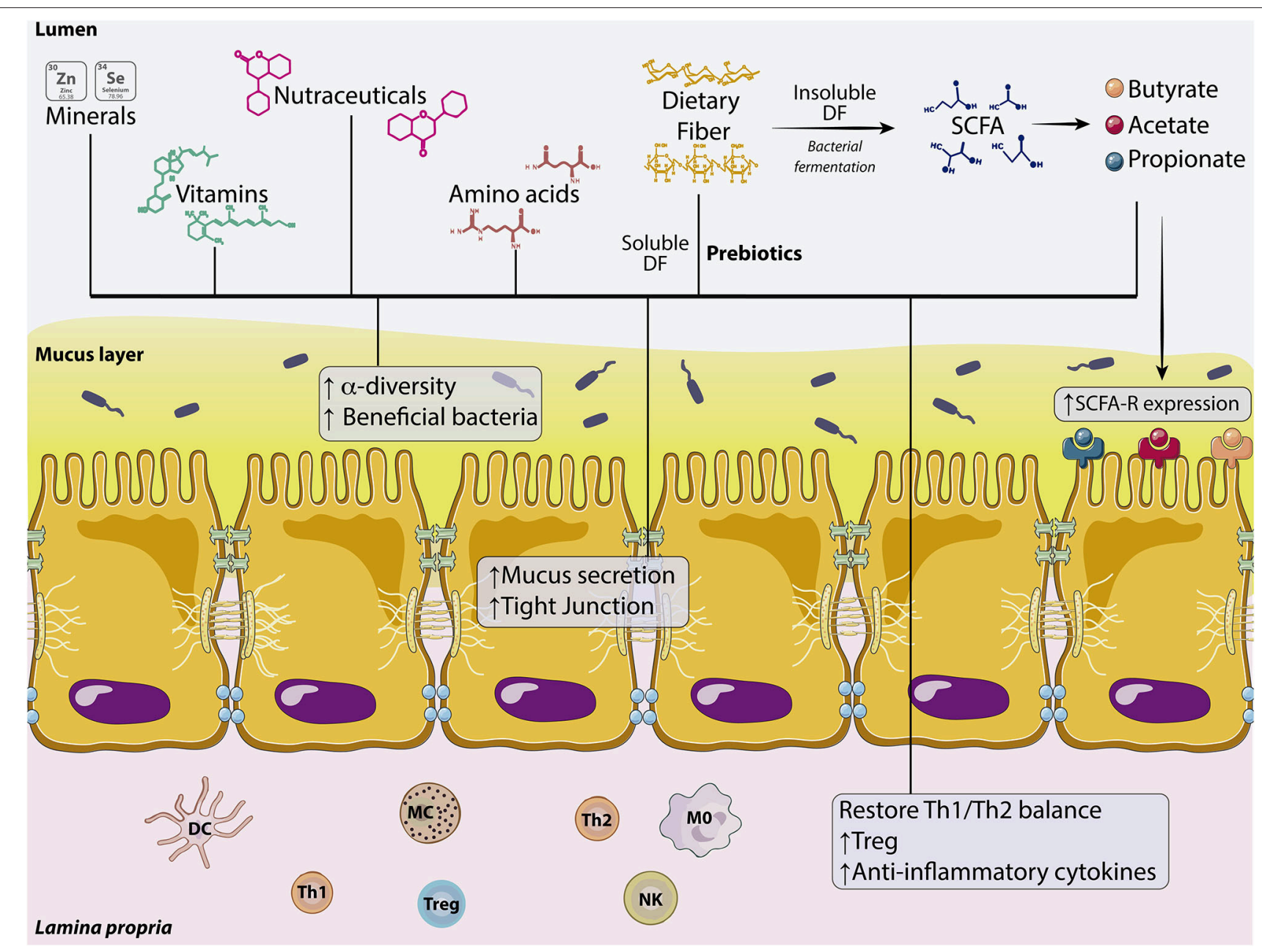

FIGURE 2 | Dietary components involved in the regulation of intestinal permeability. Effects of minerals, vit, nutraceuticals, amino acids, soluble DFs (prebiotics), and SCFAs on the intestinal barrier. These dietary components are capable of affecting the microbiota by increasing $\alpha$-diversity and the number of beneficial bacteria. DFs also enhance mucus secretion from the IEB and increase the expression of TJs proteins. In the lamina propria, dietary compounds increase T reg population, but also the production of anti-inflammatory cytokines restoring the Th1/Th2 balance. Fermentation of insoluble DF to SCFA (butyrate, acetate, and propionate) also increases the expression of SCFA receptors. DC, Dendritic cell; DF, Dietary fiber; IEB, Intestinal epithelial barrier; MO, Macrophage type 0; MC, Mast cell; NK, Natural Killer; Th1, Thelper lymphocyte type 1; Th2, T helper lymphocyte type 2; Treg, T regulatory lymphocyte; SCFA, Short chain fatty acid; Vit, Vitamins.

activity and the accelerated assembly of tight junction (TJ) proteins $(43,44)$.

In vitro studies have shown the ability of DF to attenuate epithelial barrier dysfunction caused by bacterial infection (14, 15) (Table 1). Similar in vitro studies with SCFAs (Table 2) indicate that main SCFAs, butyrate, propionate, and acetate, modulate contractile activity (40), to maintain the circadian rhythm (47). SCFAs are also able to inhibit cytokine production $(16,49)$, activate Tregs (45), enhance IEB, by facilitating TJ assembly via AMPK activation in Caco-2 cell monolayers and through selective upregulation of claudin (CLDN) 3 and 4 , and the activation of $\mathrm{Akt} / \mathrm{mTOR}$ mediated protein synthesis in IPEC-J2 cells (43), increasing TEER (41-44). Interestingly, the activation of NLR family pyrin domain containing (NLRP) 3 inflammasome induces the secretion of proinflammatory cytokines (46), which is linked to intestinal barrier dysfunction (57). In this regard, a study performed in intestinal epithelium cells IEC-6 showed that propionic acid inhibited NLRP3 inflammasome activation and preserved intestinal barrier function (48).

The role of DF and SCFAs in modulating intestinal barrier function and GI inflammation has been also tested in vivo in several preclinical models and in multiple species (Tables 1, 2). In this sense, sodium butyrate has been shown to revert colonic permeability in a rat model of Irritable Bowel Syndrome (IBS) (50). In C57/BL6 mice submitted to chemotherapyinduced mucositis, high fiber diet (pectin-based) decreased the influx of immune cells, improved histopathological parameters and decreased intestinal permeability, compared to those that received the normal diet (58). In obese mice, prebiotics exhibited lower plasma lipopolysaccharide (LPS) and cytokines, and lower intestinal permeability and improved TJ integrity 
TABLE 1 | Dietary fiber role in the recovery of impaired barrier function.

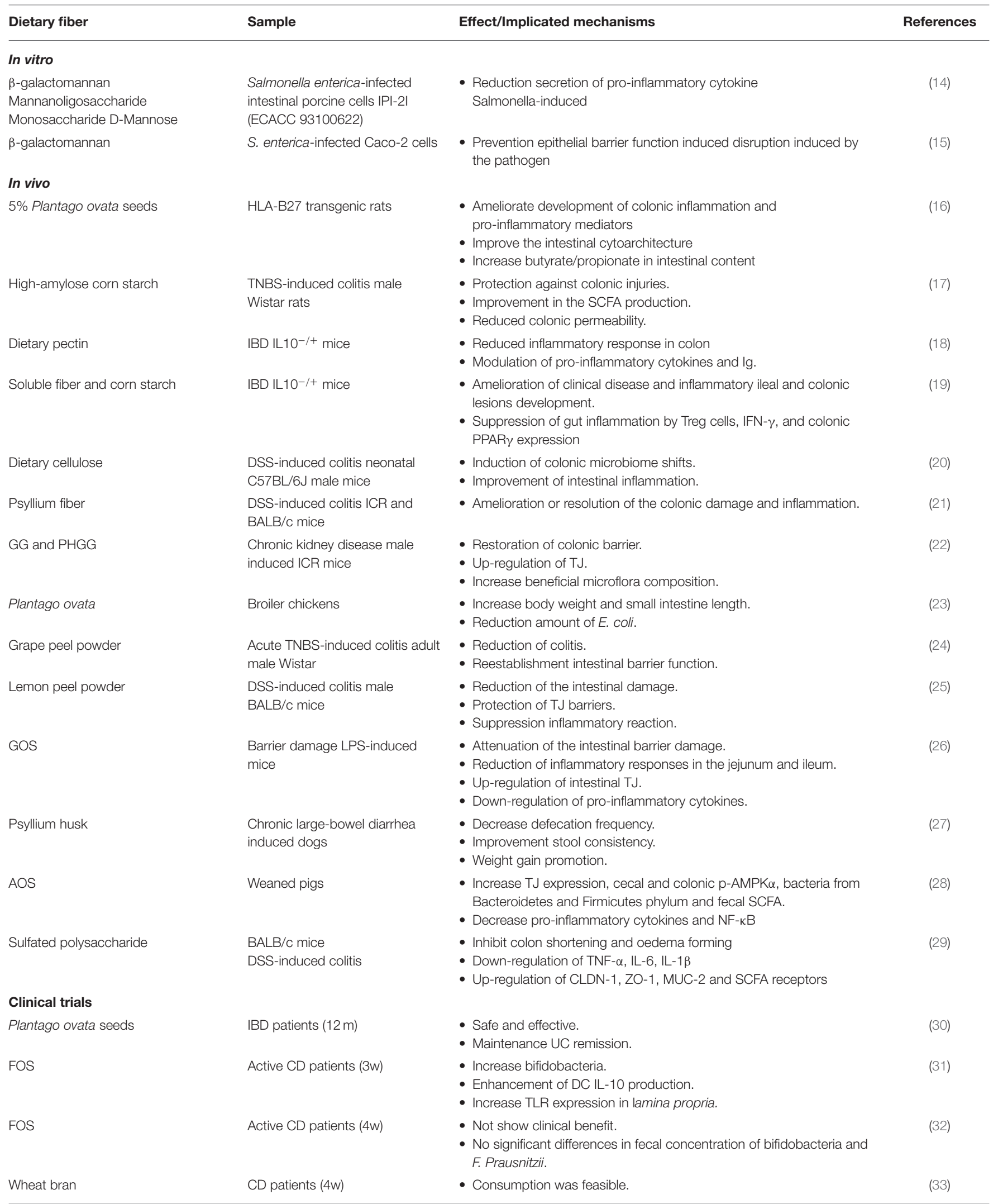


TABLE 1 | Continued

\begin{tabular}{lll}
\hline Dietary fiber & Sample & Effect/Implicated mechanisms \\
\hline & & - No adverse effects. \\
& & - Improvement health-related QoL and Gl function. \\
Low-FODMAP & - Reduction Gl symptoms. \\
Non-digestible polysaccharides & Elderly population with Gl & - Reduction colonic hyperpermeability. \\
Symptoms (biopsies, ex vivo) & - Reduction serum biomarker of permeability. \\
Controlled-fiber diet & NAFLD patients $(6 \mathrm{~m})$ & Positive influence in NAFLD-associated parameters. \\
Low-FODMAP diet & IBS-D patients $(4 \mathrm{w})$ & - Low-FODMAP improved symptoms and QoL. \\
Traditional dietary advice & &
\end{tabular}

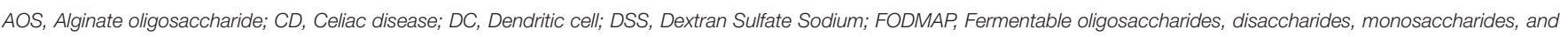

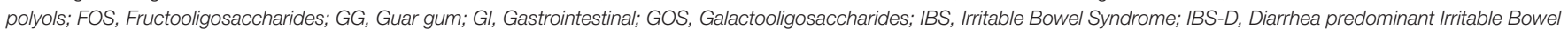

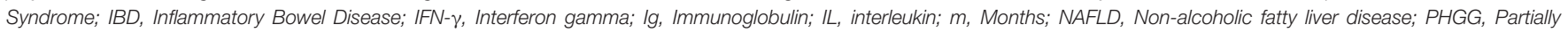

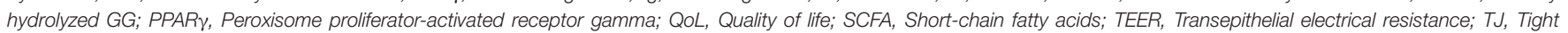
junction; TLR, Toll-like receptor; TNBF, Trinitrobenzene sulfonic acid; Treg, Regulatory Tlymphocyte; UC, Ulcerative Colitis; w, Weeks.

compared to controls (59). Dietary enrichment with psyllium fiber (21), dietary cellulose (20), or lemon peel powder (25) also ameliorated colonic damage and inflammation and decreased TJ protein expression in the dextran sodium sulfate (DSS)induced colitis model in mice, particularly during the infancy. Sulfated polysachharide not only reduced colonic inflammation, but also but inhibited colon shortening and oedema in mice model (29). In this model, DF also ameliorated intestinal barrier dysfunction and inflammation (51). In specific pathogen-free and germ-free mice given DSS, psyllium, pectin, and cellulose fiber reduced the severity of colitis through microbiota-dependent and microbiota-independent mechanisms, including restoration of intestinal permeability (60). Similar studies in rats have disclosed the ability of high-amylose cornstarch diet to protect against 2,4,6 trinitrobenzene sulfonic acid (TNBS)-induced colonic injury, and improve colonic permeability (17). In the same model, high rich DF containing grape peel powder also reduced colitis and reestablished intestinal barrier function in Wistar rats (24). Moreover, apple-derived pectin has been shown to modulate gut microbiota and CLDN-1 expression in obese rats submitted to high-fat diet, to attenuate metabolic endotoxemia, inflammation, and weight gain (61). In other rat models, the addition of cellulose fiber to elemental diet could ameliorate barrier failure in the ileum compared to total parenteral nutrition (62) and pectin supplementation significantly reversed the methotrexateinduced increase in permeability in the distal small bowel and colon (63).

DF was able to restore colonic barrier integrity in a mice model of chronic kidney disease (22) and GOS administration attenuated intestinal barrier damage and inflammatory responses induced by LPS in the jejunum and ileum of mice (26). In other models, particularly in interleukin (IL)-10 knockout mice with IBD, dietary pectin and cornstarch diets downregulated the inflammatory response in colon, but its relation with the regulation of intestinal permeability was not established $(18,19)$.

DF, such as Psyllium husk, was able to decrease bowel movements, and improve stool consistency and weight gain in dogs (27). Moreover, Plantago ovata showed effectiveness in increasing body weight and small intestine length as well as in reducing intestinal $E$. Coli in broiler chickens (23). Recent studies have shown that alginate oligosaccharide is able to increase TJ expression, Bacteroidetes, and Firmicutes phylum bacteria and to decrease pro-inflammatory cytokines in weaned pigs (28).

Regarding SCFA, in a rat model of irritable bowel syndrome (IBS) (50), sodium butyrate has been shown to revert colonic permeability. Also in this model, mixed or alone SCFA have been reported improving IBS symptomatology (52). In neonatal IBSmice model, different concentrations of SCFA were able to reduce the colonic transit alteration in a dose-dependent manner (53).

In humans, conclusions derived from dietary interventions with supplemental fiber have been often inconclusive and weighted down by differences in the design and performance of studies, as highlighted in a recent meta-analysis in IBD population (64). Thus, pectin supplementation (15/day) or daily supplementation (12 g/day) with the DF $\beta$-glucan and wheat arabinoxylan did not affect baseline intestinal barrier function in young and elderly healthy individuals (65) or indomethacin-induced intestinal hyperpermeability in vivo or gut microbiota composition in elderly, respectively (66). Furthermore, oligofructose-enriched inulin ( $8 \mathrm{~g} /$ day) did not improve intestinal permeability in children with diabetes mellitus (67) as did not either oligofructose (6 g/day) in patients with burn injury (68). Plantago ovata seeds have been shown to maintain remission in UC (30), and FOS increased bifidobacteria and IL-10 in CD patients (31), although it has not been supported by further research (32). However, CD patients were shown to achieve an improvement in their quality of life and GI function after wheat bran intake (33). In other study, healthy male volunteers who ingested inulin for 8 weeks (69), had significantly lower lactulose/mannitol $(\mathrm{L} / \mathrm{M})$ ratio and serum zonulin and higher levels of mucosal GLP-2. However, it is important to note that the methods used were suboptimal. On the contrary, a non-digestible polysaccharide-enriched diet reduced colonic hyperpermeability induced by mast cell (MC) activation, as determined in Ussing chambers, in elderly suffering constipation or diarrhea and elevated baseline colonic permeability (35). Similarly, in patients with non-alcoholic fatty liver disease, 6-months of 
TABLE 2 | Short-chain fatty acids role in the recovery of impaired barrier function.

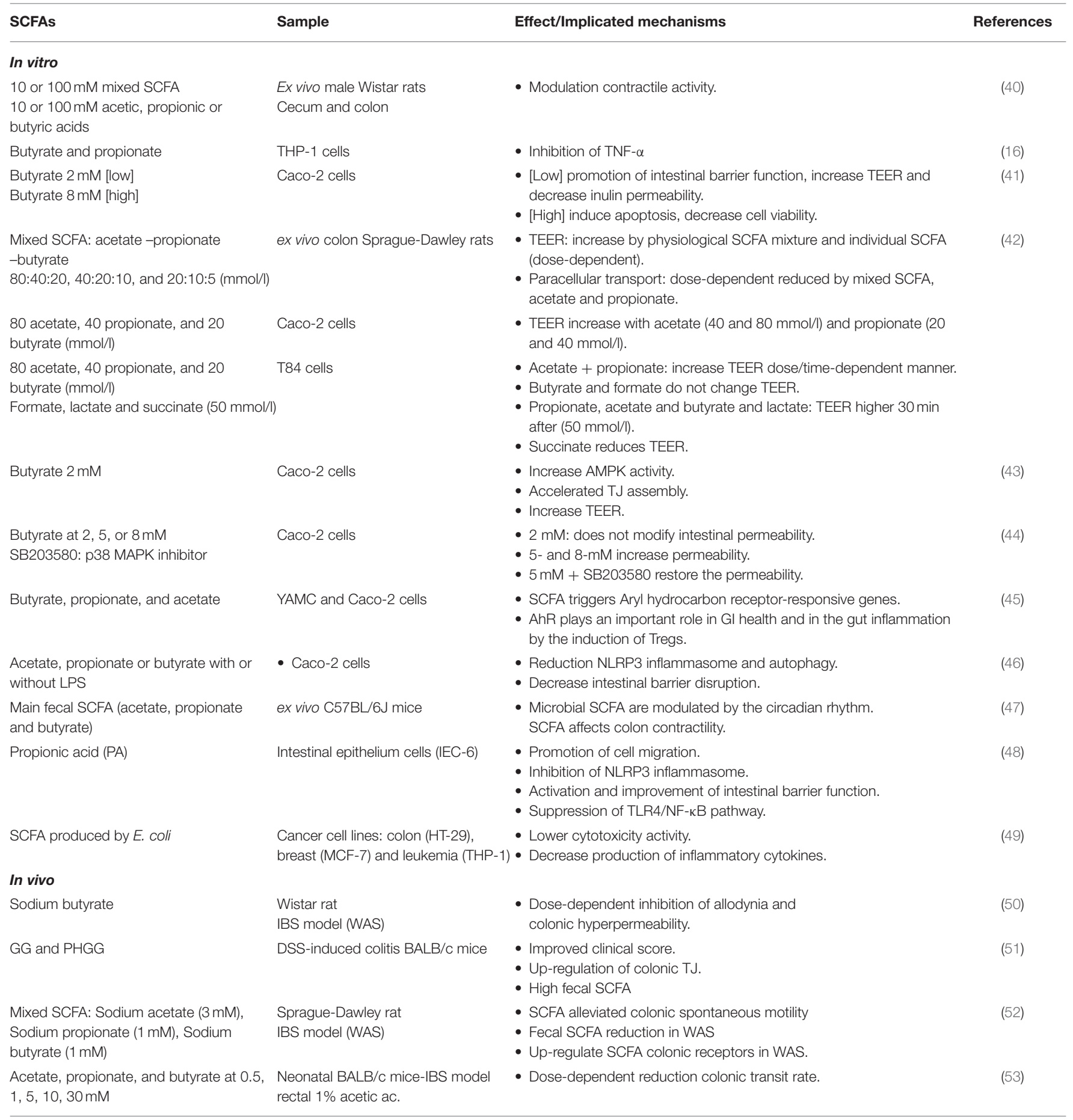

AhR, Aryl hydrocarbon receptor; AOS, Alginate oligosaccharide; CLDN, Claudin; DSS, Dextran Sulfate Sodium; GG, Guar gum; IBS, Irritable Bowel Syndrome; IL, Interleukin; LPS, Lipopolysaccharide; MUC, Mucin; NF-kB, Nuclear factor - kappa beta; NLRP3, NLR family pyrin domain containing 3; $p$-AMPKa, Phosphorylated AMP-activated protein kinase alpha; PHGG, Partially hydrolyzed GG; SCFA, short-chain fatty acid; TEER, Transepithelial electrical resistance; TJ, Tight junction; TLR, Toll-like receptor; TNF- $\alpha$, Tumor necrosis factor alpha; Treg, Regulatory Tlymphocyte; WAS, Water avoidance stress; YAMC, Young adult mouse colonic cells; ZO, Zonula occludens.

fiber intervention demonstrated a reduction in zonulin levels, a purported serum biomarker of permeability (36), and GOS supplementation reduced aspirin-enhanced colonic permeability in obese patients independently of its prebiotic effect (70). The combination of green banana and pectin showed good antidiarrheal properties in children with persistent diarrhea, 
activity that was linked to the reduction in small intestinal permeability (71).

SCFAs are also able to modulate intestinal permeability in humans. Indeed, decrease in gut-derived plasma SCFAs correlated with increased colonic permeability in shift workers (72) and organoid studies based on human colonic mucosal biopsies showed that fermentation of 2' Ofucosyllactose which led to an increase of Bifidobacteria and an increase of SCFAs, in particular butyrate, resulted in CLDN-5 significant upregulation (73).

A diet low in fermentable oligosaccharides, disaccharides, monosaccharides, and polyols (FODMAP) is commonly used in the management of patients with IBS and overall, $52-86 \%$ of patients report significant improvement of their symptoms (34, 37, 74). Moreover, this diet was more effective than others (traditional dietary advice, modified National Institute for Health and Care Excellence guidelines, gluten-free diet and Mediterranean diet and a sham diet) and also nondietary interventions (gut directed hypnotherapy or yoga) (75). Interestingly, this diet improved intestinal permeability in patients with diarrhea-predominant IBS in relation with increased circulating vitamin (vit) D levels (76). However, to date, there is no further demonstration of how low-FODMAP diet may interfere with intestinal permeability.

Recently, a combination of herbs and nutrients including curcumin, aloe vera, slippery elm, guar gum, pectin, peppermint oil, and glutamine (Gln) significantly improved the frequency and severity of upper and lower GI symptoms by $60-80 \%$ in a small sample sized study. This improvement was accompanied by reduction of intestinal permeability, as measured by lactulosemannitol ratios, and by beneficial changes in microbiota composition (77).

Other dietary factors such as the non-sugar prebiotics soy protein hydrolysates have shown promising effects to strengthen the epithelial barrier in response to several barrier disruptors (78).

\section{Vitamins}

Vit $\mathrm{A}$, and vit $\mathrm{D}$ are micronutrients involved in the regulation of TJ molecule expression in the intestinal barrier (79) and mucosal immune system, shaping the microbial populations in the gut $(80,81)$. Both epithelial and immune cells in the GI tract, but not the microbiota, express receptors for vit A (retinoic acid receptor) and vit D (vit D receptor, VDR) (4). VDR protects against mucosal inflammation in experimental colitis and contributes to systemic bile acid homeostasis by regulating expression of fibroblast growth factor (82). Retinoic acid receptor enhances Zonula Occludens (ZO)-2 expression by regulating Toll-Like Receptor (TLR)-4 to improve IEB function in Caco-2 cells, as well as in rat and mouse models, but not in humans (83).

The presence of vit $\mathrm{D}$ increased TEER and preserved the structural integrity of the $\mathrm{TJ}$ in Caco-2 cells treated with DSS (84). In a model of intestinal barrier permeability using IPEC-J2 cells, vit A reverted LPS-induced barrier dysfunction through the enhancement of TEER and TJ protein expression (85). In Caco-2 cells treated with LPS, emulating the barrier damage of necrotizing enterocolitis (NEC), the presence of
1,25-Dihydroxyvitamin D3 -active form of vit D- restored the expression and localization of TJ proteins and reverted LPSinduced down-regulated VDR expression (86). Likely, intestinal damage caused by LPS in IEC-18 line cells and organoids was improved after vit $\mathrm{D}$ treatment, restoring permeability and $\mathrm{TJ}$ (87). Similar findings have been reported in a model of alcoholic liver disease in Caco-2 challenged with ethanol (88). Moreover, vit $\mathrm{D}$ deficiency may compromise mucosal barrier integrity, raising susceptibility to develop IBD, as also shown in Caco-2 cells (89).

In specific-pathogen-free rats, the deficiency of vit A aggravates the severity of diarrhea and intestinal mucosal damage. On the contrary, during the clinical course of diarrhea, supplementation with vit $\mathrm{A}$ relieves diarrhea and improves intestinal damage, increasing the expression of TJ proteins (90). When intestinal epithelial cells from VDR-deficient mice are complemented with a human VDR-encoding trans-gene, the integrity of the mucosal barrier prevents the hyperinflammatory response that is otherwise seen in the lamina propria immune cells of VDR-deficient mice (91).

In humans, several reports indicate insufficient levels of vit D in many inflammatory conditions, including $\operatorname{IBD}(92,93)$ and IBS (94), with more than $50 \%$ of patients affected by hypovitaminosis $(95,96)$. Vit $\mathrm{D}$ deficit has been also related with clinical symptoms and quality of life, but the correlation between the intestinal expression of VDR and CLDN2 remains controversial (97-100). Patients with celiac disease (CD) in remission received a supplementation of vit D -or placeboduring 3 months. The supplemented patients showed higher plasma levels of vit $\mathrm{D}$, improved the results of quality-of-life and kept intestinal permeability as it was at baseline, whereas permeability increased in the placebo group (101). As previously mentioned, a recent study assessed the relation between vit $\mathrm{D}$ levels, intestinal permeability, and a 12-week intervention with low-FODMAP diet in IBS with diarrhea (IBS-D). Those patients with low vit $\mathrm{D}$ levels before the intervention, reduced small bowel permeability, increased vit $\mathrm{D}$ levels and also improved clinical symptoms (76).

\section{Amino Acids}

The pore pathway regulates, through IL-13-mediated expression of CLDN-2, the selective paracellular transport of small-sized $(5-10 \AA)$ ions $(\mathrm{K}+, \mathrm{Na}+)$ and molecules (water) $(102,103)$. In vitro studies in Caco-2 cells with deprived from Gln or after Gln synthetase inhibition, reported reduced TEER, increased permeability and lower TJ protein expression (104-106) which could be reestablished after Gln addition. Gln, and to a lesser extent arginine (Arg), also prevented methotrexate-induced barrier disruption in Caco-2 cells (107). Gln improved intestinal barrier function in a rat model of biliary obstruction (108), and Gln and Arg prevented the mucosal injury in a model of ischemia-reperfusion in rats $(109,110)$. Gln regulated TJ integrity and distribution through calcium/calmodulin-dependent kinase 2 (CaMKK2)-AMP-activated protein kinase signaling in porcine epithelial cells (111). Recently, Gln alleviated IL-13-induced barrier dysfunction by increasing CLDN-1 expression, via 
disruption of the phosphatidylinositol-3-kinase/Akt signaling pathway (112).

In humans, microRNA (miR)-29 has been shown to regulate Gln synthetase, CLDN-1 expression, nuclear factor kappa-light-chain enhancer of activated B cells (NF- $\mathrm{B}$ ) and ultimately tumor necrosis factor (TNF- $\alpha$ ), to regulate the leak paracellular pathway in a series of elegant experiments performed in colonic tissues of IBS-D patients (113). Moreover, in a subsequent randomized, placebo-controlled trial, the same authors showed that supplemental Gln (10 g/day) improved intestinal permeability and major symptoms in post-infectious IBS-D patients (114). In addition, although disputed, enteral Gln supplementation has been shown to improve intestinal permeability in severely thermally injured patients (115). A small randomized trial also showed that Gln and whey protein improved small intestinal permeability and morphology in patients with Crohn's disease (116).

Arg is a semi-essential amino acid that can be metabolized by host arginases and nitric oxide synthases or be consumed by gut bacteria (4). There are few studies related to Arg and protection of the integrity of the epithelial barrier. In heat-stress conditions, pre-treatment with L-Arg partly reverted the decrease on TEER and increased paracellular permeability (117). In a model of hypoxia in jejunal IPEC-J2 cells, Arg prevented the reduction of TEER and increased inulin paracellular permeability (118). A great compilation of the last 30 years of clinical trials performed with Gln and Arg is also available (119), highlighting a reduction of the infection rate and mortality by Gln and a decrease of complications by Arg in surgical patients. Nevertheless, some of these trials have methodologic flaws and many do not evaluate intestinal permeability. Hence, further and well-designed trials are needed for justifying the use of these amino acids.

Tryptophan is an essential amino acid also studied by its potential link between imbalanced gut microbiota, impairment of intestinal immunity and disease development. Recent evidence underlines that the enzyme indoleamine 2,3-dioxygenase 1 expressed by the host is relevant to generate indole metabolites (120), which are involved in the re-establishment of IEB integrity in the context of intestinal inflammatory diseases and metabolic syndrome.

A recent review on amino acid supplementation in weaned piglets, disclosed that several of them (Arg, Gln, tryptophan, sulfur-containing amino acids, and branched-chain amino acids) may have a role in the maintenance and improvement of intestinal morphology and function, increasing proliferation of epithelial cells and preserving intestinal mucosal integrity (121). In mice, radiation-induced intestinal barrier disruption was ameliorated by an amino acid-based oral rehydration solution, enhancing TJ protein expression and improving paracellular permeability (122).

\section{Minerals}

Zinc $(\mathrm{Zn})$ is an essential trace element $[10 \%$ of the human genome encodes Zn-binding proteins (123) that plays an important role in diarrheal diseases and GI infections and it is closely linked to mucosal integrity and IEB (124). Zn deficiency leads to reduced expression of occludin (OCLN) and
ZO-1 proteins in Caco-2 cells (125). Depletion of $\mathrm{Zn}$ induced OCLN-3 proteolysis and decreased CLDN-3 transcription (126) while Zn supplementation increased TEER and ZO-1 expression and decreased CLDN-2 and CLDN-7 expression $(127,128)$, facilitating OCLN and ZO-1 expression in Caco2 and HT29 cells (90). In mice with bacterial infections, Zn supplementation enhanced protection against toxin-induced intestinal dysfunction and leakage (129). The ZRT/IRT-like protein $14, \mathrm{Zn}$ transporter is expressed on plasma membranes and mediates $\mathrm{Zn}$ influx into the cytosol. Mice lacking ZRT/IRT-like protein 14 display increased intestinal permeability associated with altered expression of CLDN-1 and CLDN-2 (130). Other studies have shown that $\mathrm{Cu}$ and $\mathrm{Zn}$ supplementation improved intestinal integrity during the Eimeria spp. Infection in broilers (131). Selenium has also been proposed as a good candidate to prevent changes in intestinal permeability and mitochondrial damage in several species $(132,133)$. In humans, $\mathrm{Zn}$ supplementation is effective in the prevention of diarrhea (134), and has been recommended by The World Health Organization for the treatment of diarrhea (135). Zn also has a beneficial effect on infectious diseases like shigellosis improving IEB, nitrogen absorption, and symptoms (135-137). Finally, zinc carnosine, a health food supplement, stabilizes small bowel integrity and stimulates gut repair processes after indomethacin treatment, as shown in a placebo-controlled trial (138).

\section{Microbiota-Based Factors}

Microbiota exerts many crucial functions (thoroughly reviewed in other papers in this monography) including IEB maintenance $(139,140)$.

\section{Antibiotics}

Antibiotics are recommended to treat bacterial infections. Independently of the origin of the infection, antibiotic administration has adverse effects on the gut indigenous microbial community leading to mid to long term dysbiosis (141) and mycobyosis (142), with some compositional effects lasting for 6 months (143), to ease colonization by pathogens such as Salmonella or Cl. Difficile, and to increase antibiotic resistance $(144,145)$. In addition, many antibiotics induce changes in intestinal permeability that may be linked to alterations in $\alpha$-diversity and relative abundance of specific bacteria within the gut microbiota as shown in rats (146). Moreover, changes in intestinal permeability are accompanied by reduction of SCFAs, and increased activity of NLRP3 inflammasome and autophagy (147). Therefore, the use of some antibiotics in disorders associated with barrier dysfunction may lead to additional complications, though these findings should be translated to the clinic. In addition, bioavailability of antibiotics seems to depend also on the composition of microbiota and on intestinal permeability as well (148).

However, some antibiotics may have a better profile for the microbiota. Rifaximin is a poorly-absorbed broad spectrum oral antibiotic prescribed for GI disorders such as IBS, IBD, small intestine bacterial overgrowth, traveler's diarrhea or diverticular disease (DD) $(149,150)$. Rifaximin seems to exert eubiotic effects on the microbiota, increasing Bifidobacterium, Faecalibacterium 
prausnitzii, and Lactobacillus abundance, with no major change in the overall gut microbiota composition, what may represent a therapeutic advantage in specific clinical settings $(150,151)$. In addition, $\mathrm{Xu}$ et al. (152), showed how oral rifaximin prevented mucosal inflammation, impairment to intestinal barrier function, and visceral hyperalgesia by altering the composition of bacterial communities in the ileum while other antibiotics were not as effective.

\section{Probiotics}

Probiotics are live microorganisms which, when consumed in adequate amounts, confer a health benefit on the host (153). This benefit relates in part to the ability of probiotics to modulate the IEB. A large amount of evidence has accumulated to support the efficacy of probiotics to enhance IEB tightness and integrity, and to modulate intestinal inflammation (154). We will only review here the most representative evidence. For instance, Bifidobacterium was able to adhere to mucus, to inhibit and displace the adhesion of pathogenic bacteria (155) and to increase TJ integrity, protecting them from Escherichia coli O157:H7 (156). Incubation of T84 cell monolayers with multispecies probiotic completely prevented LPS-induced increase in paracellular permeability in a dose dependent manner. This multispecies probiotic also prevented the epithelial disruption induced either by intracolonic infusion of fecal supernatant from IBS patients or by water avoidance stress (WAS) in C57/Bl6 mice. In addition, these formula increased the expression of OCLN and decreased TNF- $\alpha$ secretion in response to LPS (157). Similarly, Lactobacillus rhamnosus CNCM I-3690 prevented changes in intestinal permeability in Caco-2 cells stimulated with TNF- $\alpha$ and in a mouse model of increased colonic permeability, to a similar degree that Faecalibacterium prauznitzii A2-165 in the last (158). In a post-infectious IBS mouse model, probiotic treatment promoted the expression of major TJ proteins CLDN-1 and OCLN in the mouse ileon (159). Similarly, Lactobacillus rhamnosus GG improves intestinal barrier function in the immature murine gut through the induction of CLDN 3 expression (160). In obese and type2 DM mice, Akkermansia. muciniphila treatment increased the intestinal levels of endocannabinoids that control inflammation and gut barrier (161).

Probiotics can also prevent intestinal barrier damage in IBD conditions. Both LGG and a probiotic formulation containing Lactobacillus acidophilus, Bifidobacterium lactis, Lactobacillus plantarum, and Bifidobacterium breve reduced the disruption of barrier function in DSS-induced colitis in mice $(162,163)$. In a similar way, the administration of a probiotic mixture prevented not only the decrease in TJ proteins expression, but also the increase of epithelial apoptotic ratio induced by acute colitis (164). Oral Bifidobacterium infantis conditioned medium administration reduced colonic permeability in IL-10deficient mice in part through enhanced protein expression of CLDN-4, ZO-1, and OCLN, and decreased expression of CLDN-2 (165). Similarly, Escherichia coli Nissle 1917 has been shown to inhibit leaky gut by enhancing mucosal integrity through up-regulation of ZO-1 expression in murine DSS colitis (166). Lactobacillus rhamnosus MTCC-5897 administration before DSS-colitis induction improved intestinal barrier integrity involving transcriptional modulations of TJ genes (ZO-1, OCLN, CLDN-1) (167).

Stress clearly affects intestinal barrier function and probiotics have been shown to prevent some of changes. Weissella paramesenteroides WpK4 ingestion reduced intestinal permeability and reduced anxiety-like and depressive-like behaviors in stressed mice submitted to DSS (168). Lactobacillus farciminis prevented stress-induced gut hyperpermeability and mucus alterations in different animal models $(169,170)$. In rats subjected to partial restraint stress fermented milk containing Bifidobacterium lactis CNCM I-2494 prevented stress-induced increase in intestinal permeability and restored OCLN and JAM-A expressions to control levels (171). More recently, Wang et al. have shown that Lactobacillus casei Zhang significantly increased jejunum villus height, villus height-crypt depth ratio, muscle thickness, and expression of proliferating cell nuclear antigen and TJ proteins ZO-1 and OCLN in early-weaned piglets, and prevented E. coli K88-induced jejunum damage (172). Similarly, Lactobacillus fermentum CECT 5716 prevented maternal separation and WAS-induced intestinal barrier dysfunction in newborn rats, reducing small intestine permeability and increasing ZO-1 expression (173).

In humans, Lactobacillus plantarum WCFS1 administration into the duodenum was associated with an increase in of ZO-1 and OCLN in healthy subjects (174). In contrast, Lactobacillus GG significantly reduced the alteration of gastric (but not intestinal permeability induced by indomethacin administration in healthy subjects suggesting that probiotics are useful to enhance barrier function possibly in a location-specific manner (175).

Bifidobacterium lactis CNCM I-3446 induced a significant decrease of intestinal permeability in infants with NEC (176). In IBD patients, particularly in those with severe pouchitis, administration of a probiotic combination effectively prevented flare-ups (177), combination that has been shown to promote recovery from IFN- $\gamma$-induced intestinal barrier dysfunction (178).

Recently, beneficial effects of probiotics have also been shown to occur through the release of extracellular vesicles (EV). EV contain a vast number of active compounds and bacterial mediators that play a key role in bacteriahost interactions, but also between probiotics and other bacteria. In vitro, pretreatment with Akkermansia muciniphiladerived EV decreased IL-6 production from colon epithelial cells stimulated by pathogenic Escherichia coli EV (179). Akkermansia muciniphila-derived EV (179) also protected from DSS-induced colitis in C57BL/6 mice. Moreover, in high-fat dietinduced diabetic mice, Akkermansia muciniphila-derived EV administration enhanced tight junction function, reduced body weight gain and improve glucose tolerance in association with an increase in the expression of occludin, zonula occludens, and claudin-5 (180). In fact, in the same study, more Akkermansia muciniphila-derived EV were found in the fecal samples of healthy controls when compared with type 2 diabetes patients and Akkermansia muciniphila-derived EV treatment improved 
intestinal permeability in LPS-treated Caco-2 cells, by increasing the expression of occludin.

Vesicles secreted by Bacteroides fragilis have been shown to contain capsular polysaccharide, which induces immunomodulatory effects on dendritic cells and prevents experimental colitis through TLR2-signaling pathways (181). In Caco2 cells, B. fragilis EV significantly decreased TLR2 and slightly increased TLR4 mRNA levels along with an increase in anti-inflammatory cytokines and the inhibition of interferon (IFN)- $\gamma$ (182). Stimulation of bone marrow derived dendritic cells (BMDCs) with EV originated from another Gram-negative probiotic, Bacteroides vulgatus mpk, contributes to immune response silencing through induction of a tolerant BMDCs phenotype (183).

Escherichia coli Nissle 1917 (EcN) has also been shown to restore barrier function in experimental models of increased gut barrier permeability. Prophylactic administration of $\mathrm{EcN}$ resulted in reduced inflammation, and preservation of intestinal permeability in a DSS murine model of colitis (184). EcN treatment significantly upregulated the colonic expression of the tight junction proteins $\mathrm{ZO}-1$ and occludin, preserving the mucus- layer and restoring intestinal permeability. Oral administration of purified EcN EV before DSS intake, significantly reduced clinical symptoms and histological scores in a DSS-induced colitis mouse model (185). Similarly, in colonic cell lines, EcN EV promoted upregulation of ZO-1 and claudin-14, and induced IL-22 expression reinforcing the intestinal barrier (186).

However, few studies have specifically addressed intestinal permeability in vivo in humans. One study assessed the efficacy of a probiotic mix in intestinal permeability, immune function and in the prevention of multiple organ dysfunction syndrome in critically ill patients. They found that patients responded with a significantly larger increase in systemic IgA and IgG concentrations and in most of them, intestinal permeability decreased, compared to placebo or sonicates (187). Mujagic et al. evaluated the effects of Lactobacillus plantarum on small intestinal barrier function through the lactuloserhamnose ratio after intake of indomethacin, but there was no significant effect. However, in small intestinal biopsies, $L$. plantarum TIFN101 modulated gene transcription pathways related to cell-cell adhesion with high turnover of genes involved in tight- and adhesion junction protein synthesis and degradation (188). A recent meta-analysis, evaluated the effect of probiotics/synbiotics on serum levels of zonulin, as a measure of intestinal permeability, showing favorable effects although results should be interpreted with caution due to high heterogeneity (189). Another recent meta-analysis highlights also the potential beneficial role of probiotics in GI mucositis and the reduction of intestinal permeability and maintenance of the mucus layer (190).

Taken together, all these data suggest that probiotics enhance intestinal barrier tightness and integrity by several mechanisms, and that mucosal restoration positively impacts the clinical course of disease. However, specific studies measuring intestinal permeability through a validated method are needed to achieve more robust conclusions.

\section{Bioactive Pharmaceutical Molecules and Signaling Peptide-Based Therapeutic Strategies \\ Glucagon-Like Peptide 2}

Glucagon-like peptide 2 (GLP-2) (Figure 3) is an intestinal peptide derived from proglucagon that exerts its function through the GLP-2 receptor (GLP-2R), expressed predominantly in the intestinal tract $(191,192)$. Endogenous GLP-2 promotes intestinal growth after a fasting period or in response to enteritis (193). Exogenous GLP-2 is exerts profound effects expanding the crypt-villus epithelium through enhanced proliferation and survival, to increase nutrient digestion, absorption, and blood flow $(192,194,195)$.

GLP-2 also improves intestinal barrier function in both health conditions and disease models $(59,196,197)$, reducing paracellular transport of ions and small molecules, and dramatically inhibiting endocytic macromolecules uptake in mice (197). GLP-2 chronic administration enhances gut barrier function and decreases epithelial barrier permeability. In fact, GLP2 in mice model decreases the transcellular passage of ions, 51Cr-EDTA and fluorescein-isothiocyanate as well as the endocytosis of horseradish peroxidase (HRP), a marker of transcellular permeability (198-200). Following studies have demonstrated that this ability is GLP-2Rdependent, in association with increased TJ expression, most notably CLDN-3 and -7 (196, 199). In addition, rats receiving subcutaneous exogenous GLP-2 exhibited less intestinal structural damage, longer intestinal villi, and increased immunoglobulin (Ig)A expression, in a model of obstructive jaundice (201).

It has been widely reported the GLP-2 effect on increasing microvillus length, however, how this is achieved is poorly understood. Recently, Markovic et al. (202) demonstrated that the increase in microvillus length with GLP-2 treatment requires the intestinal epithelial insulin-like growth factor-1 receptor (IEIGF-1R) in mice. Villin, an actin-binding protein, is regulated by the GLP-2-IE-IGF-1R pathway. Villin has a well-established role in epithelial wound repair, with both insulin growth factor 1 and villin levels decreased in Crohn's disease (203, 204). These findings suggest a new mechanism by which GLP2 may attenuate Crohn's disease and/or other inflammatory pathologies. These results are consistent with previous research which has already shown the effects of GLP-2 through the IEIGF-1R modulating intestinal TJ proteins (199). In this regard, a study in pediatric patients with acute ileal $\mathrm{CD}$ showed that these patients have decreased post-prandial GLP-2 release, and increased intestinal permeability. Healing of $\mathrm{CD}$ was associated with the normalization of post-prandial GLP-2 release and intestinal permeability (205). More recently, an abnormal postprandial glucagon-like peptide 2 release has also been described in adult patients with Crohn's disease (206).

Finally, GLP-2 analog teduglutide has been successfully introduced in clinical practice as a new treatment for parenteral nutrition-dependent short bowel syndrome (207). It can effectively increase the residual intestinal absorption capacity through the induction of intestinal mucosa hypertrophy and 


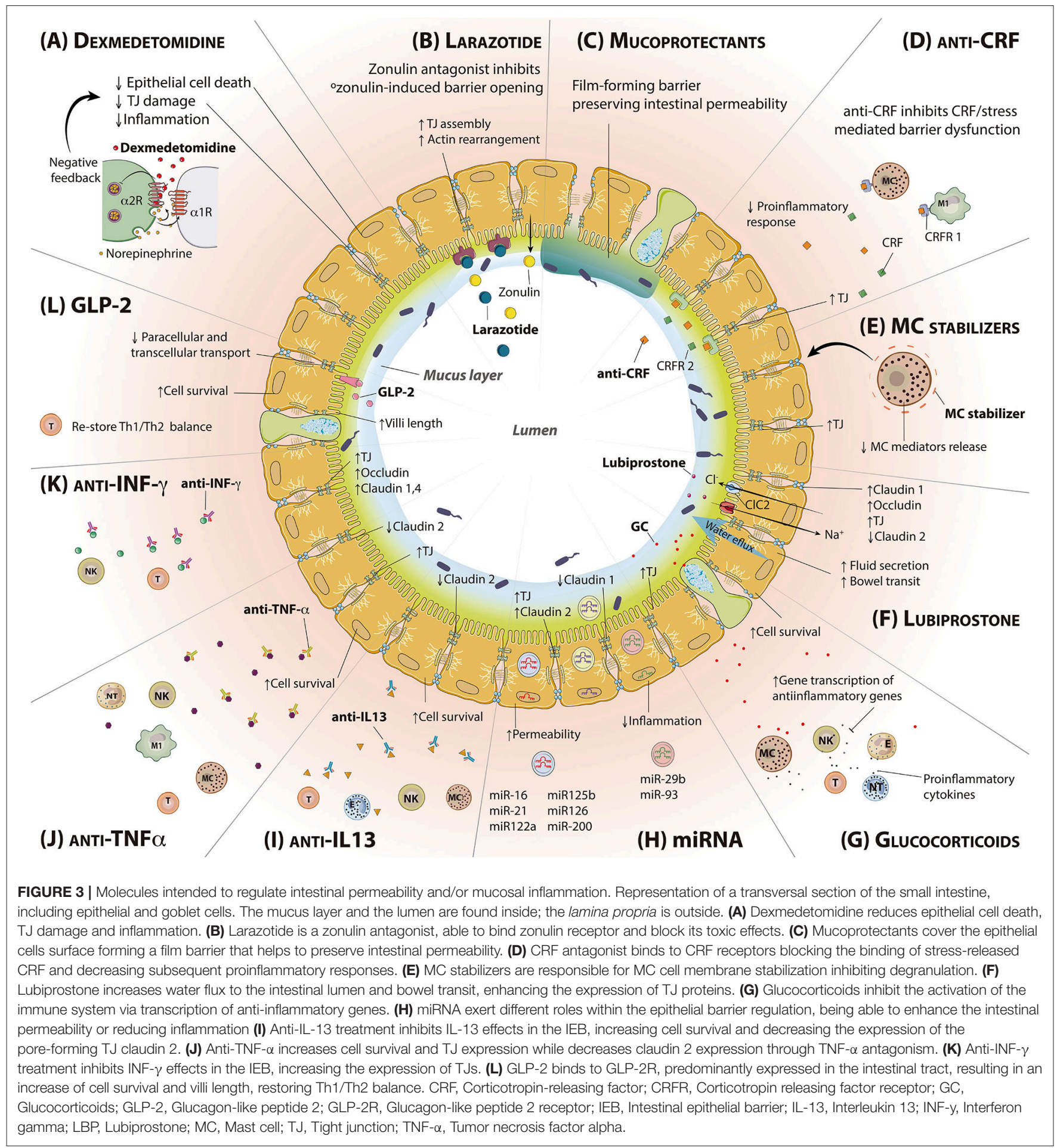

hyperplasia, the increase of intestinal perfusion and the reduction of intestinal motility and gastric acid secretion, achieving a reduction of parenteral nutrition $(208,209)$. Several cases of active Crohn's disease and short bowel syndrome successfully treated with teduglutide have been recently described (210-212). Yet, there are no systematic data about off-label teduglutide therapy in severely active CD since its fluctuating inflammatory activity can be considered at greater risk (213).

All these findings support GLP-2 treatment as a possible effective therapy for enhancing, maintaining, or recovering normal barrier function in intestinal disorders. However, to date, human studies evaluating the effect of GLP-2 on intestinal 
permeability do not exist. Nevertheless, teduglutide must be used with caution and discontinued in case of intestinal neoplasia because of its effect on intestinal epithelial proliferation.

\section{Corticotropin-Releasing Factor}

Corticotropin-releasing factor (CRF) is a signaling peptide (Figure 3), secreted both in the central nervous system and in the periphery, including the GI tract, which stimulates the secretion of adrenocorticotropic hormone from the pituitary gland in response to stress. CRF and related molecules such as urocortins 1,2 , and 3 have been extensively involved in the regulation of stress-mediated motor, sensory and permeability changes in the GI tract, in animal models and humans, acting via the G-Protein coupled CRF receptors (CRF-R) 1 and CRF-R2 (214-217).

Many authors have described the effects of stress on gut permeability. Studies in rats and pigs have shown that CRF-induced changes over the barrier function were equivalent to those triggered by stress. Among other alterations, CRF induces mucus layer thickening, enhanced conductance and transepithelial and paracellular macromolecular flux, TJ reorganization and activation of the immune system in the small intestine and colon (218-224). Consistent evidence indicates that many of these mechanisms are predominantly driven by the activation and degranulation of MCs (221, 223-225), although recent studies lay stress on eosinophils as potential contributors to the stress-mediated gut dysfunction, specifically in IBS-D patients (226). Opposite effects of CRF-R1 and CRF-R2 are observed on stress-mediated intestinal mucosal barrier function in pigs, with CRF-R2 preventing permeability changes and CRFR1 enhancing them (227).

Interestingly, chronic stress has shown how barrier impairment could be persistent if the stressor is repeated (222, 228-230). Vicario et al. reported increased gut epithelial permeability, hyperactivation of the hypothalamic-pituitaryadrenal axis and reversible inflammation in rats submitted to a repeated stress or CRF, developing visceral hypersensitivity afterwards (230). Similarly, CRF and sauvagine, a stress-like peptide, enhanced intestinal ion, and macromolecular flux, which could be inhibited by astressin, a potent non-specific CRF inhibitor, and doxantrazole, a MC stabilizer. The alterations of intestinal permeability evoked by various stressors or CRF are inhibited by peptide CRF receptor antagonists and selective CRF-R1 antagonists $(219,221-224,226,228-232)$ [for further review, see Taché et al. (217)]. Moreover, Nozu et al. have recently reported in a rat IBS model that imipramine dose-dependently inhibited visceral hypersensitivity, colonic hyperpermeability, and other GI effects of CRF or repeated stress through $\alpha 2$-adrenoceptors, dopamine and opioid receptors (233).

In healthy humans and IBS patients, functional studies also demonstrated that peripheral CRF largely reproduces the increased colonic motility, intestinal permeability, MC activation and visceral hypersensitivity observed in animals $(224,234)$. Changes in intestinal and colonic permeability were mediated by MC activation and reversed by disodium cromoglycate, another MC stabilizer (235). Nonetheless, despite raising high expectation early on, and several clinical assays performed with several CRF antagonists (236-240), unfortunately, to date, this has not been translated in clinical practice for the management of stressinduced IBS.

\section{Humanized Antibodies Against Tumor Necrosis Factor- $\alpha$}

Tumor necrosis factor- $\alpha$ (TNF- $\alpha$ ) (Figure 3) and myosinlight chain kinase (MLCK) are the main regulators of the leak paracellular pathway (102). TNF- $\alpha$ is a multifunctional pro-inflammatory cytokine that has wide effects on cells and structures related to the intestinal barrier function. One of the barrier-deteriorating effects likely comes from TNF- $\alpha$ 's ability to induce apoptosis (241). However, TNF$\alpha$ was found to deteriorate paracellular integrity even in the presence of an apoptosis blocker, suggesting additional mechanisms involved. Indeed, in vitro studies found that TNF- $\alpha$ modulates TJ structure by breaking strands of ZO1 and thus modifying the structure of the epithelial barrier (242). TNF- $\alpha$ stimulation could also increase permeability by inducing the expression of the pore-forming TJ protein CLDN2 (243). There is also evidence for TNF- $\alpha$ increasing paracellular permeability by activating long MLCK transcription, expression, enzymatic activity, and recruitment to the actomyosin ring (244-247). MLCK activation triggers perijunctional actomyosin ring contraction that leads to molecular reorganization of $\mathrm{TJ}$ structure, including OCLN endocytosis.

The use of monoclonal antibodies against TNF- $\alpha$ has shown mixed results, some proven successful in inducing remission in cases of IBD (248), but also at the cost of adverse events and high number of non-responders over time $(249,250)$. Few but promising evidence suggest targeting TNF- $\alpha$ can improve specific parts of the intestinal barrier function and endoscopic signs on the mucosal tissue, collectively termed mucosal healing (251)

Adalimumab is a monoclonal antibody against TNF- $\alpha$ shown to improve both IEB and clinical features in IBD patients (252256). Human colonic cell culture showed that simultaneous use of both TNF- $\alpha$ and interferon (IFN- $\gamma$ ) disrupted the epithelial barrier, leading to a significant drop in TEER (257), appearance of irregularities in the TJ structures, disruption of OCLN and increase phosphorylation of MLC. All of these effects were reversed upon administration of Adalimumab. When subjecting a 3D Caco-2 cell model to plasma from patients with active Crohn's disease, paracellular permeability increased via breakdown of ZO-1 and OCLN (258).

Infliximab, a chimeric monoclonal antibody against both membrane bound and soluble TNF- $\alpha$, has shown successful results in both patients with Crohn's disease and UC (256, 259261). Crohn's disease patients display an increased baseline permeability compared to healthy controls, that was normalized after 7-days course of infliximab, for a final 10-fold decrease of the lactulose/mannitol ratio. The effect of Infliximab on barrier function was also investigated by mounting non-inflamed colonic biopsies from Crohn's disease patients in Ussing chambers and in Caco-2 cells. The results showed a significant decrease in paracellular permeability and normalization of transmucosal permeability to near control levels for adherent invasive 
Escherichia coli (262). Efficacy of infliximab has not been wellstudied for other conditions characterized by intestinal barrier dysfunction. However, anti-TNF- $\alpha$ therapy is a common rescue medication for diarrheal conditions refractory to steroid therapy, including immune-related diarrhea after immune checkpoint inhibitor therapy (263) or microscopic colitis (264). A case-study of a refractory CD patient showed improvement in symptoms and intestinal histology after Infliximab treatment, suggesting a possible effect on the barrier function (265).

Inhibition of MLCK expression or enzymatic activity results in systemic toxicity making these molecules unsuitable as therapeutic targets for barrier control. However, recently a new molecule, termed divertin prevents MLCK1 recruitment to the acto-myosin ring without inhibiting enzymatic function. In this way, divertin restores TNF-induced barrier dysfunction and prevents disease progression in experimental chronic IBD (266).

Collectively, these results indicate that mucosal healing and clinical remission in IBD patients may be strongly related to the immunomodulatory effects from blocking TNF- $\alpha$, with improvements to the intestinal barrier function occurring as a secondary effects that synergistically improve the outcome.

\section{Interferon-Gamma (IFN- $\gamma$ )}

Interferon type II (IFN- $\gamma$ ) is widely known as a pro-inflammatory cytokine with potent effects on intestinal barrier function (267) (Figure 3). Studies performed in vitro have found IFN$\gamma$ to influence paracellular permeability by affecting structural properties of the epithelial barrier. It has been shown in colonic T84 cell lines that IFN- $\gamma$ can internalize the TJ proteins OCLN, CLDN-1, CLDN-4 and junctional adhesion molecule A, thereby decreasing TEER and increasing the passage of paracellular markers $(268,269)$. The internalization process was found to involve cytoskeletal contraction in a MLCK-independent manner (269), which separates it from the mechanisms of TNF- $\alpha$ through more direct effects on barrier integrity, even though the end result is similar. Modern in vitro techniques using intestinal organoids (3D cell culture models) have further verified the ability of IFN- $\gamma$ to disrupt the epithelial barrier function through TJ protein degradation and delocalization (270). A number of studies show a synergistic deleterious effect on intestinal barrier function from the combination of IFN- $\gamma$ and TNF- $\alpha(267,271)$. One of the mechanisms behind this synergistic effect could come from IFN- $\gamma$ 's ability to increase the expression of TNF receptor-2, as shown by restoration of barrier function when blocking TNF receptor-2 but not TNF receptor-1 (272). Viceversa, TNF- $\alpha$ has also been demonstrated to increase the IFN- receptor expression in vitro (16426148). IFN- $\gamma$ is seen increased in many intestinal conditions that also are characterized by gut barrier dysfunction, such as IBD and IBS $(273,274)$. Despite several attempts to create antibodies for IFN- $\gamma$ or its receptors (275), clinical applicability is difficult due to its ubiquity in cells and organs and its pleiotropic effects. Anyhow, a monoclonal antibody against IFN- $\gamma$, AMG 811 , is under development (276).

\section{Humanized Antibodies Against Interleukin-13}

IL-13 is a cytokine extensively involved in inflammatory reactions and mainly produced by T helper- 2 cells, MCs, eosinophils, and natural killer cells (277) (Figure 3). The effect of IL-13 on barrier function has not been widely studied but in vitro experiments using colonic epithelial cell lines have shown upregulation of the pore-forming TJ protein CLDN-2 together with an increase in paracellular permeability $(278,279)$. Activation of MLCK can lead to an increased production of mucosal IL-13 together with an upregulation of CLDN-2 in mice (279). Further on, IL-13 also shares with TNF- $\alpha$ the ability of inducing epithelial apoptosis and this effect can be enhanced by the stimulation of both cytokines simultaneously, hinting at a possible synergistic effect (280).

An increased expression of IL-13 has been found in the lamina propria mononuclear cells from Crohn's disease and ulcerative colitis (UC) patients (281). In the same study, stimulation with IL-13 displayed a decreased TEER in a cell culture model of HT29/B6 cells and by an increase in the pore-forming TJ CLDN2, while levels of both ZO-1 and OCLN were unaffected. In addition, they also found significantly increased permeability of the sugar probes lactulose and mannitol, and higher rate of apoptosis in vitro (281). Although information on mucosal IL-13 levels in patients with IBS is scarce, there are results showing serum levels of IL-13 being significantly increased in UC patients with IBS-like symptoms (282). However, the role of IL13 in the pathophysiology of inflammatory intestinal disorders is controversial as later clinical studies with monoclonal antibodies against IL-13 (tralokinumab, anrukinzumab) in UC fail to report convincing results $(277,283)$. These studies did not investigate any direct parameters of intestinal barrier function such as permeability or TJ gene/protein expression, thus it's possible that the anti-IL-13 agents could have had affected such parameters, mimicking the in vitro studies, but to an ineffective degree. The anti-IL-13 agent lebrikizumab seems to have positive effects on patients with atopic dermatitis, a chronic inflammatory skin condition characterized by skin-barrier defects. Even though the mechanisms behind improvement could speculatively be linked to restoration of skin barrier function, to our knowledge, no studies have yet elucidated such mechanisms $(284,285)$. It is likely the anti-inflammatory effects from inhibiting IL13 indirectly also could help to maintain barrier integrity to some extent. However, these results do not seem to suggest targeting only IL-13 is an effective option in treating conditions of intestinal barrier dysfunction. Since multiple cytokines can have deleterious effects on the barrier function, it's possible inhibiting several cytokines at the same time would have stronger effects.

\section{Larazotide}

Larazotide acetate, also known as AT-1001, is a synthetic peptide derived from the Vibrio cholerae zonula occludens toxin (ZO-T or zonulin) which behaves as a zonulin antagonist and proposed as permeability regulator (286) (Figure 3). Zonulin is released by intestinal epithelial cells after diet or microbiota stimuli. Zonulin-mediated detachment of the ZO-1 protein from the TJ protein complex has a direct effect in increasing intestinal permeability (287). Larazotide prevents TJ opening, being able to block zonulin receptors locally, by joining the receptors itself, decreasing TJ detachment and promoting TJ assembly and structural filaments rearrangement (288). Larazotide was developed for the treatment of CD (289) and later tested in 
type 1 diabetes, inflammatory bowel disease, Kawasaki disease, respiratory diseases (290), collagen-induced arthritis (291) and intestinal ischemic injury $(292,293)$.

Four clinical trials using larazotide acetate have been published, all in CD $(289,294-296)$. These studies confirmed its safety and efficacy for reducing gluten-induced symptoms as well as an interesting inverse dose effect, that is, greater reduction of symptoms with lower doses. Nevertheless, positive results cannot be linked to a reduction of small bowel permeability, measured by the lactulose-mannitol test, due to huge variability, leading to controversial results. A phase 3 trial is ongoing (ClinicalTrials.gov Identifier: NCT03569007) to test larazotide in lower doses in $\mathrm{CD}$ patients on a gluten-free diet. Hence, although some clinical benefit has been observed, a more accurate evaluation of larazotide effect on intestinal permeability is needed, not only in CD but also for other pathologies with paracellular intestinal barrier dysfunction.

\section{Lubiprostone}

Lubiprostone (LBP) is a prostaglandin E1-derivative able to bind and activate the chloride channel type $2(\mathrm{ClC}-2)$ located in the luminal side of the epithelium, improving bowel frequency and stool consistency in constipated-IBS patients (297-301) (Figure 3). Moreover, LBP has been reported to enhance intestinal barrier function, reversing IFN $\gamma$-induced decrease in TEER and the increase in fluorescein labeleddextran permeability and enhancing the expression of CLDN-1 in vitro (302).

LBP reduced the severity of colitis as well as intestinal permeability in both DSS and TNBS-induced colitis in murine models (303). Alternatively, when LBP was administered to ClC-2 knockout mice, the protective effect against DSS colitis was limited, suggesting a central role of chloride channels in the restoration of barrier function and TJ architecture driven by LBP (303). LBP also reduced mannitol flux in ischemiainjured intestine in ex vivo porcine models (304), and decreased chronic water avoidance stress-induced visceral hyperalgesia in rats, partly by down-regulation of OCLN and also up-regulation of CLDN-2 in rat colon crypts $(305,306)$. The potential of LBP to prevent small intestinal injury and increased permeability related to non-steroidal anti-inflammatory drugs has been reported in a rat model (307).

One study assessed the effect of LBP on human intestinal barrier function after administration of diclofenac, showing a significant reduction of lactulose-mannitol ratio compared to the control group (308). Unfortunately, the three randomized trials that support the use of LBP in IBS with constipation did not evaluate intestinal permeability as an endpoint.

\section{Dexmedetomidine}

Dexmedetomidine (DMM) (Figure 3) is a highly selective 2adrenoreceptor agonist, used as a sedative and anesthetic adjuvant. Interestingly, it also shows a protector role against barrier dysfunction and intestinal injury. However, the exact mechanisms are not completely elucidated, although it is able to accelerate intestinal wound healing by increasing intestinal epithelial cell proliferation (309). Pretreatment with DMM reduced intestinal injury in a rat model of intestinal ischemia (310), and also improved intestinal microcirculatory dysfunction and barrier dysfunction in endotoxemic rats (311) in association with a reduction of OCLN cleavage and bacterial influx into the spleen. After traumatic brain injury, GI system dysfunction and impairment of barrier function are common features (312). DMM was able to reduce systemic inflammatory cytokines and barrier dysfunction, and to improve villus structure in a rat model of brain injury (313). DMM has also proved to protect against heat stroke-induced inflammatory response and multi-organ dysfunction (314). DMM also demonstrated capacity to reverse burn-induced intestinal epithelial hyperpermeability by reducing inflammation and enhancing the expression and distribution of the TJ proteins ZO-1 and OCLN (315).

In humans, a randomized, double-blinded trial using either perioperative DMM or placebo in patients who underwent an hepatectomy not only showed a decrease in clinical relevant biomarkers of intestinal injury but also a reduction of intestinal failure scores at $72 \mathrm{~h}$ after surgery (316). In another randomized, double-blinded prospective study, DMM enhanced the recovery of GI and reduced intestinal injuries and permeability, reflected by decreased serum diamine oxidase and intestinal fatty acidbinding protein expression (317). A recent randomized doubleblinded prospective study, suggests DMM as a more suitable anesthetic for patients undergoing GI surgery as it is associated with a decrease in TNF- $\alpha$, and $D$-Lactate along with an increase in the activation of $\alpha 7 \mathrm{nAChR}$ (318).

\section{Mast Cell Stabilizers and Flavonoids}

Intestinal mast cells (MCs) (Figure 3) play an essential role in barrier function regulation and gut homeostasis as shown both in vitro, in animal models and in humans as reviewed elsewhere (216). MC activation leads to the release of a wide variety of proinflammatory and regulatory mediators, and many of them all have an effect on intestinal barrier as well as modulating immune response and enteric nervous system. Though the inhibition of MC activation has been extensively investigated, and many different approaches are possible (319-321), the use of MC stabilizers has gained some consideration in the management of several intestinal disorders in humans, mainly because its beneficial role in the regulation of IEB is based on a solid and vast literature in preclinical models (228, 322-332). Among MC stabilizers, only ketotifen and disodium cromoglycate (DSCG), have been translated to the clinic.

There are few studies exploring the effect of MC stabilizers in modulating IEB in humans. In one study, ketotifen was able to reestablish GI permeability in a small group of food allergy patients (333). In a trial with IBS patients, ketotifen reduced several IBS symptoms, although barrier function was not explored (334). Although preliminary, ketotifen has also shown significant benefits for the treatment of post-operative ileus (335), a condition that seems to be also related with dysfunction of IEB (336). DSCG reverted the increase of intestinal permeability triggered by CRF or stress in healthy volunteers (224). Previously, DSCG pretreatment reduced milkinduced in intestinal permeability, in children with cow's milk allergy $(337,338)$ or food allergy (339), and in patients with 
dyshidrotic eczema (340) but nor in atopic eczema (341), although these studies were performed in small groups. Several other studies have shown the potential utility of DSCG for IBS treatment (342-344), but again, little clinical evidence is available to support its use as a possible modulator of the IEB.

Flavonoids are natural substances with variable phenolic structures commonly present in fruits, vegetables, tea, wine, grains, bark, roots, stems, and flowers (345). Flavonoids present a natural antioxidant, antimicrobial, cytoprotective, and antiinflammatory activity (346). Multiple in vitro studies show the ability of several flavonoids, including 8-prenylnaringenin, anthocyanins, berberine, puerarin, genistein, kaempferol, naringenin, quercetin, and luteolin, among others, to restore barrier dysfunction, predominantly in a Caco-2 cells (347354). Moreover, it has been described their ability to increase the expression, assembling and production of different $T J$ proteins such as ZO-1 and 2, OCLN and CLDN 1, 3, and 4 through the activation of AMPK and the inhibition of NAPDH oxidase /NF- $\gamma \mathrm{B}$ and MLCK and MLC phosphorylation $(244,352,353,355-357)$. In vivo studies in rat, highlight the effect of flavonoids in the upregulation of several pathways involved in the expression of several TJ proteins $1(351,357,358)$ In humans, we are awaiting for ongoing clinical trials to determine the role of natural flavonoids in the management of IEB dysfunction (346).

\section{Glucocorticoids}

Glucocorticoids (GCs) (Figure 3) play an important role in maintaining homeostasis through anti-inflammatory and immunosuppressive actions (359), mediated mostly through GC receptors (360) GCs synthetic derivatives are essential in the clinical treatment of inflammatory and autoimmune diseases (361).

GCs are released after barrier disruption, in part to neutralize the effect of TNF, via inhibition of MLCK activity (362). In the same in vitro model, GCs triggered a time and dose-dependent increase in TEER in a GC receptor-dependent manner although no changes were observed in TJ architecture (362). GCs also regulated CLDN expression via MKP-1 in cell lines (363), but also in human and rat colon mucosal crypts (364). In addition, it has been described that GCs modulate the expression of several other molecules related with TJ polarization and development (365). An interaction between GCs and IL-10 p38 MAPK improved barrier integrity after TNF- $\alpha$ challenge in a Caco-2 model (366). GC receptor deficiency aggravated barrier integrity in an animal model of colitis (367).

GCs reduced intestinal permeability in a large number of patients, mostly in Crohn's disease $(368,369)$, but also in the rectum of collagenous colitis patients (370). In addition, the effect of GCs on permeability is not restricted to IEB because similar modulatory effects have been shown in lung epithelia (371) and the blood brain barrier (372). In addition, the use of GCs for treating intestinal inflammation during sepsis has been proposed to reduce intestinal barrier dysfunction (373). Finally, UC patients display decreased levels of the liver receptor homolog-1 (LRH-1) in the colon $(374,375)$. LRH-1 is involved in the replacement of the adrenal steroidogenic factor 1 and GC synthesis in the adrenal medulla (376). A recent study has shown how LRH-1 restoration reestablished epithelial integrity in mouse and human organoids as well as its overexpression protected mice from developing colitis (377).

\section{Mucoprotectors}

Mucoprotectants are compounds of different nature (insoluble salts, hemicellulose, tannic acid, gelatins...) with the ability of enhancing the intestinal barrier by creating a film-forming barrier over the intestinal mucosa (Figure 3), helping to reduce the effect of pathogens and to improve the function of the intestinal barrier (378). These compounds work intraluminally to modify enteric contents and may represent an alternative or complementary therapy for dealing with acute and chronic diarrheal disorders $(379,380)$.

\section{Xyloglucan}

Xyloglucan $(\mathrm{XG})$ is a water-soluble, high molecular weight branched polysaccharide hemicellulose. XG helps to reduce permeability changes, preserving TJ, and invasion by E. coli in Caco2/Goblet cells (381), and binding to MUC1, in mice exposed to DSS (382). XG is non-toxic and resistant to digestive enzymes, reaching the colon unaltered, where it is partially broken down to oligosaccharides by bacterial endo- $\beta$-glucanases, followed by bacterial fermentation of oligosaccharides $(383,384)$. The molecular structure of XG is known to possess mucomimetic and mucoadhesive properties (382). XG is often combined with gelatin or gelose to prolong its availability within the intestine, but showing similar protective effects as XG alone on barrier function in rats after Salmonella enterica and Enterococcus hirae infections (385). The combination of XG, pea proteins, tannins from grape xylo-oligosaccharides also offered protection against stress-induced visceral hypersensitivity and intestinal hyperpermeability in rats (380).

In humans, several clinical trials have shown the efficacy of XG in the treatment of acute diarrhea in children $(386,387)$ and adults (388), and also in chronic diarrhea in IBS patients, improving the majority of symptoms $(389,390)$. So far, these findings have not been linked to its ability to regulate IEB, and additional trials are needed to support this concept.

\section{Gelatine Tannate}

Gelatine tannate (GT) is a complex of tannic acid and gelatin which forms electrostatic bonds with mucin to create a proteinbased biofilm over the intestinal mucosa $(391,392)$. Gelatin is a collagen derivate, which is ingested as an insoluble powder at acidic $\mathrm{pH}$, that becomes a gelatin at $\mathrm{pH}>5.5$ (393). In the intestine, this complex increases the epithelial resistance against $E$. coli, contributing to restore the normal physiology of barrier function in Caco and Goblet cells ${ }^{\mathrm{TM}}$ (394). GT also helps to restore the mucus layer and to modulate the intestinal microbiota in the DSS model of murine colitis (395), and in Caco- 2 cells, where it prevents the release of TNF- $\alpha$ induced by LPS (396). Furthermore, tannins allow the precipitation of proinflammatory molecules from the intestinal mucus and their fecal elimination (396). Together, these observations may explain the protective effect of GT on intestinal barrier function. 
Several clinical trials have been performed with GT for acute diarrhea in children, and adults, with mixed results $(379,397$, 398). The combination of GT and tyndallized probiotics has been claimed as highly effective in the treatment of moderate and prolonged diarrhea, but clinical evidence awaits the results of an ongoing clinical trial (ISRCTN63068134). Similar to XG, additional evidence is needed to link the positive effects to the protective effect on IEB.

\section{Diosmectite}

Diosmectite is a medicinal clay (aluminum and magnesium silicate) frequently used as an adjuvant therapy in children and adults with acute diarrhea $(399,400)$, to reduce stool output, to provide symptomatic relief and to prevent dehydration (398). The mechanism of action is complex, but partly related to modifications of the rheological characteristics of the GI mucus barrier, to reduce penetration of toxins, adsorptive properties, reduction of intestinal permeability by increasing the expression of OCLN, CLDN-1, and ZO-1, and increased MUC2 expression. These mechanisms have been replicated mainly in Caco- 2 and HT-29 cell lines, and in rodent and piglets animal models in response to TNF, acetic acid or TNBS (401-405).

Diosmectite has been shown to improve acute and chronic diarrhea, based on a number of open and randomized doubleblind, placebo-controlled clinical trials, performed mostly in children with acute diarrhea, and highlighted in a recent Cochrane review (398). Nonetheless, the clinical benefit has not been associated with its barrier protective characteristics.

\section{Epigenetic and Exosome-Mediated Regulation of Intestinal Barrier Function}

In the last decade, exosomes (food and host-derived) and enclosed micro-RNA (miRNA)s' role as modulators of immune responses and IEB function has been widely reported. miRNAs are small (21-23 bp) non-coding RNAs that regulate gene expression either by binding to the $3^{\prime}$ untranslated region of their target mRNAs or via endonucleolytic mRNA cleavage, promoting post-transcriptional repression and influencing intestinal homeostasis $(406,407)$. miRNAs have been implicated in several GI physiologic and pathophysiologic mechanisms and studied widely in intestinal immune and inflammatory diseases, including IBS and IBD, though studies are highly heterogeneous.

Both in vitro and in vivo assays have recently shown that after IL-1 $\beta$ administration both Caco- 2 cells and enterocytes from mice with colitis display increased small intestinal TJ permeability, a rapid increase in miR200C-3p and reduced levels of OCLN mRNA and protein, meanwhile the antagomiR-200c prevented OCLN and permeability changes (408). Moreover, colon tissues and organoids from patients with UC had increased levels of IL-1 $\beta$ mRNA and miR200C-3p compared with healthy controls. In other studies, transfection of miR-21 in Caco- 2 cells also resulted in the loss of TJ as well as ultrastructural changes enhancing intestinal permeability through the degradation of RhoB and PTEN $(409,410)$. An increase of miR-21 and miR126 has been also observed in colon, feces and blood of UC, and CD patients $(409,411)$. In addition, increased expression of miR122a has been also noticed in Caco- 2 cells after TNF- $\alpha$ exposure, increasing barrier permeability through the degradation of OCLN mRNA (412).

By inactivating the endonuclease RNase Dicer, enzyme responsible of the pre-miRNAs cleavage and the following maturation to functional miRNAs (413), McKeena et al. showed altered expression of Cadherin 1 and Cathepsin B. Dicer1 mutants also displayed impaired epithelial barrier function, most probably due to the disorganization of the epithelial layer and the junctional complexes (414). Hence, the role of miR-144 in downregulating OCLN and ZO-1 expression and enhancing intestinal permeability has been reported in a rat model od IBS-D (415).

Other miRNAs, such as miR-93 and miR-29a/b seem to offer protective effects on barrier function. miRNA-93 is responsible of PTK6 downregulation in YAMC cells, reversing the effects in permeability caused by TNF- $\alpha$ and IFN- $\gamma$ (416). miR-29a and miR-29b prevented inflammation in mice after DSS-induced colitis when delivered with supercarbonate apatite nanoparticle (417). Increased levels of miR-29a have also been found in blood, small bowel and colon in IBS and colon in IBD patients $(113,418,419)$, but, as a matter of fact, its role is sometimes contradictory (420). miR-29a overexpression increased epithelial permeability by targeting glutamine synthetase gene (GLUL), alteration that has been previously associated with increased membrane permeability (113). Moreover, in IBS-D patients, increased levels of miRNA-29a and miRNA-29b have been described together with a reduction of CLDN1, ZO-1 and nuclear factor- $\mathrm{kB}$ repressing factor, while increased levels have also been observed in mice models of IBS or colitis $(113,419)$.

After showing a correlation between differential mRNA expression and ultrastructural changes in the epithelium of IBSD patients (421), the same group reported the ability of miR-16 and miR-125b to modulate barrier function in the jejunum of these patients through the regulation of claudin- 2 and cingulin expression, respectively (422). In a recent study, Martínez et al. reported several regulated miRNAS in the rectal mucosa of postinfectious-IBS patients along with downregulation of their target mRNAs involved in barrier function (423). Finally, MahurkarJoshi et al. (424) have reported decreased levels of miR-219a-5p and miR-338-3p in sigmoid biopsies in IBS, particularly in IBSC. Inhibition of miR-219a-5p resulted in altered expression of proteasome/barrier function genes and enhanced permeability of intestinal epithelial cells. Additionally, inhibition of miR-338-3p in cells caused alterations in the mitogen-activated protein kinase (MAPK) signaling pathway genes (424).

Not only host miRNA but also plant and bacterial-derived miRNAS have gained special attention for their potential role, yet disputed, as cross-kingdom gene expression regulators, influencing plant interactions with animals and microorganisms to regulate a number of physiological functions (425). In humans, diet would be a primary source of plant miRNA uptake, whereby have been termed as xeno-miRNAs (xenomiRs), moreover, effective detection and quantification of dietetically absorbed plant microRNAs in human plasma (426). Several mechanisms, including transmembrane miRNA carriers, receptor-facilitated endocytosis, phagocytosis, macropinocytosis, clathrin-mediated, caveolin-mediated, and clathrin and 
caveolin-independent endocytosis, paracellular diffusion, and luminal immune cell capture have been proposed to explain xenomiRs uptake by intestinal epithelial cells, though, to date, still unresolved $(425,427)$. Later, xenomiRs could be packaged into microvesicles (426) or associated with proteinase K-resistant complexes (428) to be transported and released into the bloodstream to reach out target tissues. It has been shown that absorption of more stable xenomiRs, such as miR-2911, could be promoted when intestinal permeability is enhanced, which may be of use for engineering delivery of dietary miRNA (429). Moreover, gut microbiota could be responsible for enhancing xenomiRs absorption, increasing their bioavailability by degrading the exosomes components (430).

Despite the well-known role of xenomiRs in shaping microbiota and modulating inflammation and immune activation $(410,430,431)$, including the down-regulation of TNF receptor (432), direct regulation of the epithelial barrier has not been reported (430). However, given TNF- $\alpha$ ability to modulate barrier permeability, xenomiRs could be indirectly involved in the regulation of IEB. In addition, several studies have shown the ability of plant-derived exosomes, enriched for diverse miRNAs, to contribute to intestinal barrier integrity (410, 433-435), though, again, a direct link could not be established and the effect on barrier function could be dependent on other non-xenomiRrelated mechanisms. Because some plant xenomiRs modulate the expression of enterocyte transporters (436), cytokines involved in barrier function such as TNF- $\alpha$ or IL- $1 \beta$, and activate $\mathrm{Wnt} / \beta$ catenin pathway (437), it remains plausible that xenomiRs could act as regulators of intestinal barrier permeability. Furthermore, gut microbiota, by enhancing xenomiRs absorption, may also regulate the expression of different miRNAs in IECs (438).

Therefore, considering miRNAs promising role on modulating intestinal barrier function, miRNA based therapeutic strategies are moving from bench to the bedside. Although with several limitations, regulation of miRNAs expression can be achieved by administering synthetic miRNAs or miRNAs expressing vectors or by anti-sense nucleotides (439). Their therapeutic application for barrier function and intestinal inflammation and cancer is under development though further research is needed (440-442).

\section{SUMMARY AND CONCLUSIONS}

This is an exciting time for intestinal permeability. We have gone from not recognizing the importance of intestinal permeability, no more than 30 years ago, to express now that most digestive and extradigestive disorders have something to do with it.
Probably, the truth lies somewhere between these two extremes. What is certain is that pathophysiological, functional and molecular knowledge has advanced enormously in that period of time, and with it, the search for better therapeutic options to manage intestinal permeability disorders. In this review, we have discussed the most relevant therapeutic approaches to improve intestinal permeability and barrier dysfunction. To move forward, more clinical trials, new molecules intended directly to fine tuning of intestinal permeability, differential treatments according to the affected intestinal segment, according to sex, according to age, and to many other variants are needed. In addition, it is important to recognize the role of other factors, such as immune activation and microbiota-related regulation of barrier defects in order to deal better with chronic inflammation in the gastrointestinal tract because presumably targeting only the barrier may not be sufficient to change the natural history of many of these conditions. The advancement in our knowledge of the intimate mechanisms and the inducing and predictive factors of changes in permeability will lead to the development of a better therapeutic approach in several digestive and also extradigestive diseases.

\section{AUTHOR CONTRIBUTIONS}

MF, MA-B, MA-G, JP-GM, XS-R, AH-P, EE, AG-C, DG, BL, and $C A-C$ reviewed scientific literature and collected data. MF, MA-B, MA-G, JP-GM, XS-R, AH-P, CA-C, and JS wrote the paper. MF, MA-B, and MA-G prepared the tables and figures. All authors critically reviewed and edited the manuscript in its final version and approved the final draft of the manuscript.

\section{FUNDING}

This work was supported in part by Fondo Europeo de Desarrollo Regional (FEDER), Fondo de Investigación Sanitaria and Centro de Investigación Biomédica en Red de Enfermedades Hepáticas y Digestivas (CIBEREHD), Instituto de Salud Carlos III, Subdirección General de Investigación Sanitaria, Ministerio de Economía y Competitividad, Ajuts per a la contractació de personal investigador FI-Agència de Gestió d'Ajuts Universitaris i de Recerca (AGAUR), Generalitat de Catalunya; The Swedish Research Council, and the European Commision. PI19/0164 (BL), FI20/00256 and 2020FI_B1 00127, 2019FI_B 00817 (MA-B); PI17/0190 (JS); CIBERehd CB06/04/0021 (JS and CA-C); dnr 2019-00653 (JP-GM); GA no:848228 (JS, CA-C, $\mathrm{EE}, \mathrm{AG}-\mathrm{C}$, and $\mathrm{BL}$ ). MF received support from FWO (Fonds Wetenschappelijk Onderzoek) grant G.093818 to P. Vanden Berghe, KU Leuven.

\section{REFERENCES}

1. Turner JR. Intestinal mucosal barrier function in health and disease. Nat Rev Immunol. (2009) 9:799-809. doi: 10.1038/nri2653

2. Khoshbin K, Camilleri M. Effects of dietary components on intestinal permeability in health and disease. Am J Physiol. (2020) 319:G589608. doi: 10.1152/ajpgi.00245.2020

3. Anderson JL, Hedin CR, Benjamin JL, Koutsoumpas A, Ng SC, Hart AL, et al. Dietary intake of inulin-type fructans in active and inactive Crohn's disease and healthy controls: a case-control study. J Crohn's Colitis. (2015) 9:1024-31. doi: 10.1093/ecco-jcc/jjv136

4. Farré R, Fiorani M, Rahiman SA, Matteoli G. Intestinal permeability, inflammation and the role of nutrients. Nutrients. (2020) 12:1185. doi: $10.3390 /$ nu12041185 
5. Camilleri M, Lyle BJ, Madsen KL, Sonnenburg J, Verbeke K, Wu GD. Role for diet in normal gut barrier function: developing guidance within the framework of food-labeling regulations. Am J Physiol. (2019) 317:G1739. doi: 10.1152/ajpgi.00063.2019

6. FAO-WHO. Nutrition and Labelling. Codexalimentarius. Rome: FAOWHO (2020).

7. Gill SK, Rossi M, Bajka B, Whelan K. Dietary fibre in gastrointestinal health and disease. Nat Rev Gastroenterol Hepatol. (2021) 18:10116. doi: 10.1038/s41575-020-00375-4

8. Dhingra D, Michael M, Rajput H, Patil RT. Dietary fibre in foods: a review. J Food Sci Technol. (2012) 49:255-66. doi: 10.1007/s13197-011-0365-5

9. Makki K, Deehan EC, Walter J, Bäckhed F. The impact of dietary fiber on gut microbiota in host health and disease. Cell Host Microbe. (2018) 23:705-15. doi: 10.1016/j.chom.2018.05.012

10. Wang X, Gibson GR. Effects of the in vitro fermentation of oligofructose and inulin by bacteria growing in the human large intestine. J Appl Bacteriol. (1993) 75:373-80. doi: 10.1111/j.1365-2672.1993.tb02790.x

11. Ramirez-Farias C, Slezak K, Fuller Z, Duncan A, Holtrop G, Louis P. Effect of inulin on the human gut microbiota: stimulation of Bifidobacterium adolescentis and Faecalibacterium prausnitzii. Br J Nutr. (2021) 101:54150. doi: 10.1017/S0007114508019880

12. Gibson GR, Scott KP, Rastall RA, Tuohy KM, Hotchkiss A, Dubert-Ferrandon A, et al. Dietary prebiotics: current status and new definition. Food Sci Technol Bull Funct Foods. (2010) 7:1-19. doi: 10.1616/1476-2137.15880

13. Wlodarska M, Kostic AD, Xavier RJ. An integrative view of microbiome-host interactions in inflammatory bowel diseases. Cell Host and Microbe. (2015) 17:577-91. doi: 10.1016/j.chom.2015.04.008

14. Badia R, Lizardo R, Martínez P, Brufau J. Oligosaccharide structure determines prebiotic role of $\beta$-galactomannan against Salmonella enterica ser. Typhimurium in vitro. Gut Microbes. (2013) 4:72-5. doi: 10.4161/gmic. 22728

15. Brufau MT, Campo-Sabariz J, Bou R, Carné S, Brufau J, Vilà B, et al. Salmosan, a $\beta$-Galactomannan-rich product, protects epithelial barrier function in Caco- 2 cells infected by Salmonella enterica Serovar enteritidis. $J$ Nutr. (2016) 146:1492-8. doi: 10.3945/jn.116.232546

16. Rodríguez-Cabezas ME, Gálvez J, Camuesco D, Lorente MD, Concha A, Martinez-Augustin $\mathrm{O}$, et al. Intestinal anti-inflammatory activity of dietary fiber (Plantago ovata seeds) in HLA-B27 transgenic rats. Clin Nutr. (2003) 22:463-71. doi: 10.1016/S0261-5614(03)00045-1

17. Morita T, Tanabe H, Sugiyama K, Kasaoka S, Kiriyama S. Dietary resistant starch alters the characteristics of colonic mucosa and exerts a protective effect on trinitrobenzene sulfonic acid-induced colitis in rats. Biosci Biotechnol Biochem. (2004) 68:2155-64. doi: 10.1271/bbb.6 8.2155

18. Ye MB, Lim BO. Dietary pectin regulates the levels of inflammatory cytokines and immunoglobulins in interleukin-10 knockout mice. J Agric Food Chem. (2010) 58:11281-6. doi: 10.1021/jf103262s

19. Bassaganya-Riera J, DiGuardo M, Viladomiu M, de Horna A, Sanchez S, Einerhand AWC, et al. Soluble fibers and resistant starch ameliorate disease activity in interleukin-10-deficient mice with inflammatory bowel disease. $J$ Nutr. (2011) 141:1318-25. doi: 10.3945/jn.111.139022

20. Nagy-Szakal D, Hollister EB, Luna RA, Szigeti R, Tatevian N, Smith CW, et al. Cellulose supplementation early in life ameliorates colitis in adult mice. PLoS ONE. (2013) 8:e0056685. doi: 10.1371/journal.pone. 0056685

21. Ogata M, Ogita T, Tari H, Arakawa T, Suzuki T. Supplemental psyllium fibre regulates the intestinal barrier and inflammation in normal and colitic mice. Br J Nutr. (2017) 118:661-72. doi: 10.1017/S00071145170 02586

22. Hung T Van, Suzuki T. Dietary fermentable fibers attenuate chronic kidney disease in mice by protecting the intestinal barrier. J Nutr. (2018) 148:55261. doi: 10.1093/jn/nxy008

23. Divani A, Bagherzadeh-Kasmani F, Mehri M. Plantago ovata in broiler chicken nutrition: performance, carcass criteria, intestinal morphology, immunity, and intestinal bacterial population. J Anim Physiol Anim Nutr. (2018) 102:e353-63. doi: 10.1111/jpn.12753
24. Maurer LH, Cazarin CBB, Quatrin A, Minuzzi NM, Costa EL, Morari J, et al. Grape peel powder promotes intestinal barrier homeostasis in acute TNBScolitis: a major role for dietary fiber and fiber-bound polyphenols. Food Res Int. (2019) 123:425-39. doi: 10.1016/j.foodres.2019.04.068

25. Tinh NTT, Sitolo GC, Yamamoto Y, Suzuki T. Citrus limon peel powder reduces intestinal barrier defects and inflammation in a colitic murine experimental model. Foods. (2021) 10:240. doi: 10.3390/foods 10020240

26. Wang G, Sun W, Pei X, Jin Y, Wang H, Tao W, et al. Galactooligosaccharide pretreatment alleviates damage of the intestinal barrier and inflammatory responses in LPS-challenged mice. Food Funct. (2021) 12:1569-79. doi: 10.1039/D0FO03020A

27. Alves JC, Santos A, Jorge P, Pitães A. The use of soluble fibre for the management of chronic idiopathic large-bowel diarrhoea in police working dogs. BMC Vet Res. (2021) 17:100. doi: 10.1186/s12917-021-02809-w

28. Wan J, Zhang J, Chen D, Yu B, Huang Z, Mao X, et al. Alterations in intestinal microbiota by alginate oligosaccharide improve intestinal barrier integrity in weaned pigs. J Funct Foods. (2020) 71:104040. doi: 10.1016/j.jff.2020.104040

29. Han R, Ma Y, Xiao J, You L, Pedisić S, Liao L. The possible mechanism of the protective effect of a sulfated polysaccharide from Gracilaria Lemaneiformis against colitis induced by dextran sulfate sodium in mice. Food Chem Toxicol. (2021) 149:112001. doi: 10.1016/j.fct.2021.112001

30. Fernández-Bañares F, Hinojosa J, Sánchez-Lombraña JL, Navarro E, Martínez-Salmerón JF, García-Pugés A, et al. Randomized clinical trial of plantago ovata seeds (dietary fiber) as compared with mesalamine in maintaining remission in ulcerative colitis. Am J Gastroenterol. (1999) 94:427-33. doi: 10.1111/j.1572-0241.1999.872_a.x

31. Lindsay JO, Whelan K, Stagg AJ, Gobin P, Al-Hassi HO, Rayment $\mathrm{N}$, et al. Clinical, microbiological, and immunological effects of fructooligosaccharide in patients with Crohn's disease. Gut. (2006) 55:34855. doi: 10.1136/gut.2005.074971

32. Benjamin JL, Hedin CRH, Koutsoumpas A, Ng SC, McCarthy NE, Hart AL, et al. Randomised, double-blind, placebo-controlled trial of fructo- oligosaccharides in active Crohn's disease. Gut. (2011) 60:9239. doi: 10.1136/gut.2010.232025

33. Brotherton CS, Taylor AG, Bourguignon C, Anderson JG. A highfiber diet may improve bowel function and health-related quality of life in patients with crohn disease. Gastroenterol Nurs. (2014) 37:20616. doi: 10.1097/SGA.0000000000000047

34. Halmos EP, Power VA, Shepherd SJ, Gibson PR, Muir JG. A diet low in FODMAPs reduces symptoms of irritable bowel syndrome. Gastroenterology. (2014) 146:67-75.e5. doi: 10.1053/j.gastro.2013.09.046

35. Ganda Mall JP, Löfvendahl L, Lindqvist CM, Brummer RJ, Keita V, Schoultz I. Differential effects of dietary fibres on colonic barrier function in elderly individuals with gastrointestinal symptoms. Sci Rep. (2018) 8:13404. doi: 10.1038/s41598-018-31492-5

36. Krawczyk M, Maciejewska D, Ryterska K, Czerwińka-Rogowska M, Jamioł-Milc D, Skonieczna-zydecka K, et al. Gut permeability might be improved by dietary fiber in individuals with nonalcoholic fatty liver disease (NAFLD) undergoing weight reduction. Nutrients. (2018) 10:1793. doi: 10.3390/nu10111793

37. Goyal O, Batta S, Nohria S, Kishore H, Goyal P, Sehgal R, et al. Low fermentable oligosaccharide, disaccharide, monosaccharide, and polyol diet in patients with diarrhea-predominant irritable bowel syndrome: a prospective, randomized trial. J Gastroenterol Hepatol. (2021) 36:210715. doi: 10.1111/jgh.15410

38. Desai MS, Seekatz AM, Koropatkin NM, Kamada N, Hickey CA, Wolter $\mathrm{M}$, et al. A dietary fiber-deprived gut microbiota degrades the colonic mucus barrier and enhances pathogen susceptibility. Cell. (2016) 167:133953.e21. doi: 10.1016/j.cell.2016.10.043

39. Macfarlane S, Macfarlane GT. Regulation of short-chain fatty acid production. Proc Nutr Soc. (2003) 62:67-72. doi: 10.1079/PNS2002207

40. Squires PE, Rumsey RDE, Edwards CA, Read NW. Effect of short-chain fatty acids on contractile activity and fluid flow in rat colon in vitro. Am J Physiol. (1992) 262:G813-7. doi: 10.1152/ajpgi.1992.262.5.G813

41. Peng L, He Z, Chen W, Holzman IR, Lin J. Effects of butyrate on intestinal barrier function in a caco-2 cell monolayer model of intestinal barrier. Pediatr Res. (2007) 61:37-41. doi: 10.1203/01.pdr.0000250014.92242.f3 
42. Suzuki T, Yoshida S, Hara H. Physiological concentrations of short-chain fatty acids immediately suppress colonic epithelial permeability. Br J Nutr. (2008) 100:297-305. doi: 10.1017/S0007114508888733

43. Peng L, Li ZR, Green RS, Holzman IR, Lin J. Butyrate enhances the intestinal barrier by facilitating tight junction assembly via activation of AMP-activated protein kinase in Caco-2 cell monolayers. J Nutr. (2009) 139:1619-25. doi: 10.3945/jn.109.104638

44. Huang XZ, Li ZR, Zhu L Bin, Huang HY, Hou LL, Lin J. Inhibition of p38 mitogen-activated protein kinase attenuates butyrate-induced intestinal barrier impairment in a Caco-2 cell monolayer model. J Pediatr Gastroenterol Nutr. (2014) 59:264-9. doi: 10.1097/MPG.0000000000000369

45. Jin UH, Cheng Y, Park H, Davidson LA, Callaway ES, Chapkin RS, et al. Short chain fatty acids enhance aryl hydrocarbon (Ah) responsiveness in mouse colonocytes and Caco-2 human colon cancer cells. Sci Rep. (2017) 7:10163. doi: 10.1038/s41598-017-10824-X

46. Feng Y, Wang Y, Wang P, Huang Y, Wang F. Short-chain fatty acids manifest stimulative and protective effects on intestinal barrier function through the inhibition of NLRP3 inflammasome and autophagy. Cell Physiol Biochem. (2018) 49:190-205. doi: 10.1159/000492853

47. Segers A, Desmet L, Thijs T, Verbeke K, Tack J, Depoortere I. The circadian clock regulates the diurnal levels of microbial short-chain fatty acids and their rhythmic effects on colon contractility in mice. Acta Physiol. (2019) 225:13193. doi: 10.1111/apha.13193

48. Yang R, Hu X, Xie X, Chen H, Fang H, Zhu L, et al. Propionic acid targets the TLR4/NF- $\mathrm{B}$ signaling pathway and inhibits LPS-induced intestinal barrier dysfunction: in vitro and in vivo studies. Front Pharmacol. (2020) 11:573475. doi: 10.3389/fphar.2020.573475

49. Nakkarach A, Foo HL, Song AAL, Mutalib NEA, Nitisinprasert S, Withayagiat U. Anti-cancer and anti-inflammatory effects elicited by short chain fatty acids produced by Escherichia coli isolated from healthy human gut microbiota. Microb Cell Fact. (2021) 20:36. doi: 10.1186/s12934-020-01477-z

50. Nozu T, Miyagishi S, Nozu R, Takakusaki K, Okumura T. Butyrate inhibits visceral allodynia and colonic hyperpermeability in rat models of irritable bowel syndrome. Sci Rep. (2019) 9:19603. doi: 10.1038/s41598-019-56132-4

51. Van Hung T, Suzuki T. Dietary fermentable fiber reduces intestinal barrier defects and inflammation in colitic mice1-3. J Nutr. (2016) 146:19709. doi: 10.3945/jn.116.232538

52. Yuan F, Tan W, Ren H, Yan L, Wang Y, Luo H. The effects of short-chain fatty acids on rat colonic hypermotility induced by water avoidance stress. Drug Des Devel Ther. (2020) 14:4671-84. doi: 10.2147/DDDT.S246619

53. Shaidullov IF, Sorokina DM, Sitdikov FG, Hermann A, Abdulkhakov SR, Sitdikova GF. Short chain fatty acids and colon motility in a mouse model of irritable bowel syndrome. BMC Gastroenterol. (2021) 21:37. doi: 10.1186/s12876-021-01613-y

54. Vinolo MAR, Rodrigues HG, Nachbar RT, Curi R. Regulation of inflammation by short chain fatty acids. Nutrients. (2011) 3:85876. doi: 10.3390/nu3100858

55. McNabney SM, Henagan TM. Short chain fatty acids in the colon and peripheral tissues: A focus on butyrate, colon cancer, obesity and insulin resistance. Nutrients. (2017) 9:1348. doi: 10.3390/nu9121348

56. Leonel AJ, Alvarez-Leite JI. Butyrate: Implications for intestinal function. Curr Opin Clin Nutr Metab Care. (2012) 15:4749. doi: 10.1097/MCO.0b013e32835665fa

57. Lei-Leston AC, Murphy AG, Maloy KJ. Epithelial cell inflammasomes in intestinal immunity and inflammation. Front Immunol. (2017) 8:1168. doi: 10.3389/fimmu.2017.01168

58. Gallotti B, Galvao I, Leles G, Quintanilha MF, Souza RO, Miranda VC, et al. Effects of dietary fibre intake in chemotherapy-induced mucositis in murine model. Br J Nutr. (2020) 126:853-64. doi: 10.1017/S000711452 0004924

59. Cani PD, Possemiers S, Van De Wiele T, Guiot Y, Everard A, Rottier $\mathrm{O}$, et al. Changes in gut microbiota control inflammation in obese mice through a mechanism involving GLP-2-driven improvement of gut permeability. Gut. (2009) 58:1091-103. doi: 10.1136/gut.2008.1 65886

60. Llewellyn SR, Britton GJ, Contijoch EJ, Vennaro OH, Mortha A, Colombel JF, et al. Interactions between diet and the intestinal microbiota alter intestinal permeability and colitis severity in mice. Gastroenterology. (2018) 154:103746.e2. doi: 10.1053/j.gastro.2017.11.030

61. Jiang T, Gao X, Wu C, Tian F, Lei Q, Bi J, et al. Apple-derived pectin modulates gut microbiota, improves gut barrier function, and attenuates metabolic endotoxemia in rats with diet-induced obesity. Nutrients. (2016) 8:126. doi: 10.3390/nu8030126

62. Mosenthal AC, Xu D, Deitch EA. Elemental and intravenous total parenteral nutrition diet-induced gut barrier failure is intestinal site specific and can be prevented by feeding nonfermentable fiber. Crit Care Med. (2002) 30:396402. doi: 10.1097/00003246-200202000-00022

63. Mao Y, Kasravi B, Nobaek S, Wang LQ, Adawi D, Roos G, et al. Pectin-supplemented enterai diet reduces the severity of methotrexateinduced enterocolitis in rats. Scand J Gastroenterol. (1996) 31:55867. doi: 10.3109/00365529609009128

64. Limketkai BN, Iheozor-Ejiofor Z, Gjuladin-Hellon T, Parian A, Matarese LE, Bracewell K, et al. Dietary interventions for induction and maintenance of remission in inflammatory bowel disease. Cochr Datab Syst Rev. (2019) 2:CD012839. doi: 10.1002/14651858.CD012839.pub2

65. Wilms E, Jonkers DMAE, Savelkoul HFJ, Elizalde M, Tischmann L, Vos $\mathrm{P}$ de, et al. The impact of pectin supplementation on intestinal barrier function in healthy young adults and healthy elderly. Nutrients. (2019) 11:1554. doi: 10.3390/nu11071554

66. Ganda-Mall JP, Fart F, Sabet JA, Lindqvist CM, Nestestog R, Hegge FT, et al. Effects of dietary fibres on acute indomethacin-induced intestinal hyperpermeability in the elderly: A randomised placebo controlled parallel clinical trial. Nutrients. (2020) 12:1-17. doi: 10.3390/nu12071954

67. Ho J, Nicolucci AC, Virtanen H, Schick A, Meddings J, Reimer RA, et al. Effect of prebiotic on microbiota, intestinal permeability, and glycemic control in children with type 1 diabetes. J Clin Endocrinol Metab. (2019) 104:4427-40. doi: 10.1210/jc.2019-00481

68. Olguin F, Araya M, Hirsch S, Brunser O, Ayala V, Rivera R, et al. Prebiotic ingestion does not improve gastrointestinal barrier function in burn patients. Burns. (2005) 31:482-8. doi: 10.1016/j.burns.2004.11.017

69. Russo F, Linsalata M, Clemente C, Chiloiro M, Orlando A, Marconi E, et al. Inulin-enriched pasta improves intestinal permeability and modifies the circulating levels of zonulin and glucagon-like peptide 2 in healthy young volunteers. Nutr Res. (2012) 32:940-6. doi: 10.1016/j.nutres.2012.09.010

70. Krumbeck JA, Rasmussen HE, Hutkins RW, Clarke J, Shawron K, Keshavarzian A, et al. Probiotic Bifidobacterium strains and galactooligosaccharides improve intestinal barrier function in obese adults but show no synergism when used together as synbiotics. Microbiome. (2018) 6:121. doi: 10.1186/s40168-018-0494-4

71. Rabbani GH, Teka T, Saha SK, Zaman B, Majid N, Khatun M, et al. Green banana and pectin improve small intestinal permeability and reduce fluid loss in Bangladeshi children with persistent diarrhea. Dig Dis Sci. (2004) 49:475-84. doi: 10.1023/B:DDAS.0000020507.25910.cf

72. Swanson GR, Siskin J, Gorenz A, Shaikh M, Raeisi S, Fogg L, et al. Disrupted diurnal oscillation of gut-derived Short chain fatty acids in shift workers drinking alcohol: possible mechanism for loss of resiliency of intestinal barrier in disrupted circadian host. Transl Res. (2020) 221:97109. doi: 10.1016/j.trsl.2020.04.004

73. Šuligoj T, Vigsnæs LK, Van den Abbeele P, Apostolou A, Karalis K, Savva GM, et al. Effects of human milk oligosaccharides on the adult gut microbiota and barrier function. Nutrients. (2020) 12:1-21. doi: 10.3390/nu12092808

74. Liu J, Chey WD, Haller E, Eswaran S. Low-FODMAP diet for irritable bowel syndrome: what we know and what we have yet to learn. Ann Rev Med. (2020) 71:303-14. doi: 10.1146/annurev-med-050218-013625

75. Manning LP, Yao CK, Biesiekierski JR. Therapy of IBS: is a low FODMAP diet the answer? Front Psychiatry. (2020) 11:865. doi: 10.3389/fpsyt.2020.00865

76. Linsalata M, Riezzo G, Orlando A, D'attoma B, Prospero L, Tutino V, et al. The relationship between low serum vitamin D levels and altered intestinal barrier function in patients with ibs diarrhoea undergoing a long-term low-fodmap diet: novel observations from a clinical trial. Nutrients. (2021) 13:1-18. doi: 10.3390/nu13031011

77. Ried K, Travica N, Dorairaj R, Sali A. Herbal formula improves upper and lower gastrointestinal symptoms and gut health in Australian adults with digestive disorders. Nutr Res. (2020) Apr 1 76:37-51. doi: 10.1016/j.nutres.2020.02.008 
78. Kiewiet MBG, González Rodríguez MI, Dekkers R, Gros M, Ulfman LH, Groeneveld A, et al. The epithelial barrier-protecting properties of a soy hydrolysate. Food Funct. (2018) 9:4164-72. doi: 10.1039/C8FO00913A

79. Kubota H, Chiba H, Takakuwa Y, Osanai M, Tobioka H, Kohama GI, et al. Retinoid $\mathrm{X}$ receptor $\alpha$ and retinoic acid receptor $\gamma$ mediate expression of genes encoding tight-junction proteins and barrier function in F9 cells during visceral endodermal differentiation. Exp Cell Res. (2001) 263:16372. doi: 10.1006/excr.2000.5113

80. Gubatan J, Moss AC. Vitamin D in inflammatory bowel disease: more than just a supplement. Curr Opin Gastroenterol. (2018) 34:21725. doi: 10.1097/MOG.0000000000000449

81. Cantorna MT, Snyder L, Arora J. Vitamin A and vitamin D regulate the microbial complexity, barrier function, and the mucosal immune responses to ensure intestinal homeostasis. Crit Rev Biochem Mol Biol. (2019) 54:18492. doi: 10.1080/10409238.2019.1611734

82. Schmidt DR, Holmstrom SR, Tacer KF, Bookout AL, Kliewer SA, Mangelsdorf DJ. Regulation of bile acid synthesis by fat-soluble vitamins A and D. J Biol Chem. (2010) 285:14486-94. doi: 10.1074/jbc.M110.116004

83. Li Y, Gao Y, Cui T, Yang T, Liu L, Li T, et al. Retinoic acid facilitates toll-like receptor 4 expression to improve intestinal barrier function through retinoic acid receptor beta. Cell Physiol Biochem. (2017) 42:1390406. doi: 10.1159/000479203

84. Zhao H, Zhang H, Wu H, Li H, Liu L, Guo J, et al. Protective role of $1,25(\mathrm{OH}) 2$ vitamin D3 in the mucosal injury and epithelial barrier disruption in DSS-induced acute colitis in mice. BMC Gastroenterol. (2012) May 30 12. doi: 10.1186/1471-230X-12-57

85. He C, Deng J, Hu X, Zhou S, Wu J, Xiao D, et al. Vitamin A inhibits the action of LPS on the intestinal epithelial barrier function and tight junction proteins. Food Funct. (2019) 10:1235-42. doi: 10.1039/C8FO01123K

86. Chen SW, Wang PY, Zhu J, Chen GW, Zhang JL, Chen ZY, et al. Protective effect of 1,25-dihydroxyvitamin D3 on lipopolysaccharide-induced intestinal epithelial tight junction injury in CaCo-2 cell monolayers. Inflammation. (2015) 38:375-83. doi: 10.1007/s10753-014-0041-9

87. Lee C, Lau E, Chusilp S, Filler R, Li B, Zhu H, et al. Protective effects of vitamin D against injury in intestinal epithelium. Pediatr Surg Int. (2019) 35:1395-401. doi: 10.1007/s00383-019-04586-y

88. Chen SW, Ma YY, Zhu J, Zuo S, Zhang JL, Chen ZY, et al. Protective effect of 1,25-dihydroxyvitamin D3 on ethanol-induced intestinal barrier injury both in vitro and in vivo. Toxicol Lett. (2015) 237:7988. doi: 10.1016/j.toxlet.2015.06.006

89. Kong J, Zhang Z, Musch MW, Ning G, Sun J, Hart J, et al. Novel role of the vitamin D receptor in maintaining the integrity of the intestinal mucosal barrier. Am J Physiol. (2007) 294:G208-16. doi: 10.1152/ajpgi.00398.2007

90. Xiao L, Cui T, Liu S, Chen B, Wang Y, Yang T, et al. Vitamin A supplementation improves the intestinal mucosal barrier and facilitates the expression of tight junction proteins in rats with diarrhea. Nutrition. (2019) 57:97-108. doi: 10.1016/j.nut.2018.06.007

91. Liu W, Chen Y, Golan MA, Annunziata ML, Du J, Dougherty U, et al. Intestinal epithelial vitamin D receptor signaling inhibits experimental coliti. J Clin Invest. (2013) 123:3983-96. doi: 10.1172/JCI65842

92. Jørgensen SP, Hvas CL, Agnholt J, Christensen LA, Heickendorff L, Dahlerup JF. Active Crohn's disease is associated with low vitamin D levels. J Crohn's Colitis. (2013) 7:e407-13. doi: 10.1016/j.crohns.2013.01.012

93. Yang L, Weaver V, Smith JP, Bingaman S, Hartman TJ, Cantorna MT. Therapeutic effect of vitamin d supplementation in a pilot study of crohn's patients. Clin Transl Gastroenterol. (2013) 4:e33. doi: 10.1038/ctg.2013.1

94. Abbasnezhad A, Amani R, Hasanvand A, Yousefi Rad E, Alipour M, Saboori S, et al. Association of serum vitamin D concentration with clinical symptoms and quality of life in patients with irritable bowel syndrome. J Am Coll Nutr. (2019) 38:327-33. doi: 10.1080/07315724.2018.1510349

95. Sadeghian M, Saneei P, Siassi F, Esmaillzadeh A. Vitamin D status in relation to Crohn's disease: meta-analysis of observational studies. Nutrition. (2016) 32:505-14. doi: 10.1016/j.nut.2015.11.008

96. Li XX, Liu Y, Luo J, Huang ZD, Zhang C, Fu Y. Vitamin D deficiency associated with Crohn's disease and ulcerative colitis: a meta-analysis of 55 observational studies. J Transl Med. (2019) 17:323. doi: 10.1186/s12967-019-2070-5
97. Miura K, Oshima T, Ito C, Horikawa T, Yamada M, Tomita T, et al. Vitamin $\mathrm{D}$ receptor is overexpressed in the duodenum of patients with irritable bowel syndrome. J Gastroenterol Hepatol. (2021) 36:951-8. doi: 10.1111/jgh.15225

98. Zhang YG, Wu S, Lu R, Zhou D, Zhou J, Carmeliet G, et al. Tight junction CLDN2 gene is a direct target of the Vitamin D receptor. Sci Rep. (2015) 5:10642. doi: 10.1038/srep10642

99. Chen H, Lu R, Zhang Y guo, Sun J. Vitamin D receptor deletion leads to the destruction of tight and adherens junctions in lungs. Tissue Barriers. (2018) 6:1-13. doi: 10.1080/21688370.2018.1540904

100. Zhang YG, Lu R, Xia Y, Zhou D, Petrof E, Claud EC, et al. Lack of Vitamin $\mathrm{D}$ receptor leads to hyperfunction of claudin-2 in intestinal inflammatory responses. Inflamm Bowel Dis. (2019) 25:97-110. doi: 10.1093/ibd/izy292

101. Raftery T, Martineau AR, Greiller CL, Ghosh S, McNamara D, Bennett K, et al. Effects of vitamin D supplementation on intestinal permeability, cathelicidin and disease markers in Crohn's disease: results from a randomised double-blind placebo-controlled study. United Eur Gastroenterol J. (2015) 3:294-302. doi: 10.1177/2050640615572176

102. Lingaraju A, Long TM, Wang Y, Austin JR, Turner JR. Conceptual barriers to understanding physical barriers. Semin Cell Dev Biol. (2015) 42:1321. doi: 10.1016/j.semcdb.2015.04.008

103. Rosenthal R, Günzel D, Theune D, Czichos C, Schulzke JD, Fromm M. Water channels and barriers formed by claudins. Ann N Y Acad Sci. (2017) 1397:100-9. doi: 10.1111/nyas.13383

104. DeMarco VG, Li N, Thomas J, West CM, Neu J. Glutamine and barrier function in cultured Caco-2 epithelial cell monolayers. J Nutr. (2003) 133:2176-9. doi: 10.1093/jn/133.7.2176

105. Li N, Lewis P, Samuelson D, Liboni K, Neu J. Glutamine regulates Caco-2 cell tight junction proteins. Am J Physiol. (2004) 287:G72633. doi: 10.1152/ajpgi.00012.2004

106. Li N, Neu J. Glutamine deprivation alters intestinal tight junctions via a PI3-K/Akt mediated pathway in caco-2 cells. J Nutr. (2009) 139:7104. doi: 10.3945/jn.108.101485

107. Beutheu S, Ghouzali I, Galas L, Déchelotte P, Coëffier M. Glutamine and arginine improve permeability and tight junction protein expression in methotrexate-treated Caco-2 cells. Clin Nutr. (2013) 32:863-9. doi: 10.1016/j.clnu.2013.01.014

108. White JS, Hoper M, Parks RW, Clements WDB, Diamond T. Glutamine improves intestinal barrier function in experimental biliary obstruction. Eur Surg Res. (2005) 37:342-7. doi: 10.1159/000090334

109. Sukhotnik I, Khateeb K, Mogilner JG, Helou H, Lurie M, Coran AG, et al. Dietary glutamine supplementation prevents mucosal injury and modulates intestinal epithelial restitution following ischemia-reperfusion injury in the rat. Dig Dis Sci. (2007) 52:1497-504. doi: 10.1007/s10620-006-9629-8

110. Sukhotnik I, Helou H, Mogilner J, Lurie M, Bernsteyn A, Coran $\mathrm{AG}$, et al. Oral arginine improves intestinal recovery following ischemia-reperfusion injury in rat. Pediatr Surg Int. (2005) 21:191-6. doi: 10.1007/s00383-004-1318-0

111. Wang B, Wu Z, Ji Y, Sun K, Dai Z, Wu G. L-glutamine enhances tight junction integrity by activating CaMK kinase 2-AMP-activated protein kinase signaling in intestinal porcine epithelial cells. J Nutr. (2016) 146:5018. doi: 10.3945/jn.115.224857

112. Li M, Oshima T, Ito C, Yamada M, Tomita T, Fukui H, et al. Glutamine blocks interleukin-13-induced intestinal epithelial barrier dysfunction. Digestion. (2021) 102:170-9. doi: 10.1159/000502953

113. Zhou QQ, Souba WW, Croce CM, Verne GN. MicroRNA-29a regulates intestinal membrane permeability in patients with irritable bowel syndrome. Gut. (2010) 59:775-84. doi: 10.1136/gut.2009.181834

114. Zhou QQ, Verne ML, Fields JZ, Lefante JJ, Basra S, Salameh H, et al. Randomised placebo-controlled trial of dietary glutamine supplements for postinfectious irritable bowel syndrome. Gut. (2019) 68:996-1002. doi: 10.1136/gutjnl-2017-315136

115. Zhou YP, Jiang ZM, Sun YH, Wang XR, Ma EL, Wilmore D. The effect of supplemental enteral glutamine on plasma levels, gut function, and outcome in severe burns: a randomized, double-blind, controlled clinical trial. $J$ Parenter Enter Nutr. (2003) 27:241-5. doi: 10.1177/0148607103027004241

116. Benjamin J, Makharia G, Ahuja V, Rajan KDA, Kalaivani M, Gupta SD, et al. Glutamine and whey protein improve intestinal permeability and 
morphology in patients with crohn's disease: a randomized controlled trial. Dig Dis Sci. (2012) 57:1000-12. doi: 10.1007/s10620-011-1947-9

117. Varasteh S, Braber S, Kraneveld AD, Garssen J, Fink-Gremmels J. L-Arginine supplementation prevents intestinal epithelial barrier breakdown under heat stress conditions by promoting nitric oxide synthesis. Nutr Res. (2018) 57:45-55. doi: 10.1016/j.nutres.2018.05.007

118. Chapman JC, Liu Y, Zhu L, Marc Rhoads J. Arginine and citrulline protect intestinal cell monolayer tight junctions from hypoxia-induced injury in piglets. Pediatr Res. (2012) 72:576-82. doi: 10.1038/pr.2012.137

119. Duggan C, Gannon J, Allan Walker W. Protective nutrients and functional foods for the gastrointestinal tract. Am J Clin Nutr. (2002) 75:789808. doi: $10.1093 /$ ajen/75.5.789

120. Hashimoto T, Perlot T, Rehman A, Trichereau J, Ishiguro H, Paolino M, et al. ACE2 links amino acid malnutrition to microbial ecology and intestinal inflammation. Nature. (2012) 487:477-81. doi: 10.1038/nature11228

121. Mou Q, Yang HS, Yin YL, Huang PF. Amino acids influencing intestinal development and health of the piglets. Animals. (2019) 9:302. doi: 10.3390/ani9060302

122. Gupta R, Yin L, Grosche A, Lin S, Xu X, Guo J, et al. An amino acid-Based oral rehydration solution regulates radiation-Induced intestinal barrier disruption in mice. J Nutr. (2020) 150:1100-8. doi: 10.1093/jn/nxaa025

123. Andreini C, Banci L, Bertini I, Rosato A. Counting the zincproteins encoded in the human genome. J Proteome Res. (2006) 5:196-201. doi: 10.1021/pr050361j

124. Ohashi W, Fukada T. Contribution of zinc and zinc transporters in the pathogenesis of inflammatory bowel diseases. J Immunol Res. (2019) 2019:8396878. doi: 10.1155/2019/8396878

125. Finamore A, Massimi M, Devirgiliis LC, Mengheri E. Zinc deficiency induces membrane barrier damage and increases neutrophil transmigration in Caco2 cells. J Nutr. (2008) 138:1664-70. doi: 10.1093/jn/138.9.1664

126. Miyoshi Y, Tanabe S, Suzuki T. Cellular zinc is required for intestinal epithelial barrier maintenance via the regulation of claudin- 3 and occludin expression. Am J Physiol. (2016) 311:G105-16. doi: 10.1152/ajpgi.00405.2015

127. Wang X, Valenzano MC, Mercado JM, Zurbach EP, Mullin JM. Zinc supplementation modifies tight junctions and alters barrier function of CACO-2 human intestinal epithelial layers. Dig Dis Sci. (2013) 58:7787. doi: 10.1007/s10620-012-2328-8

128. Shao Y, Wolf PG, Guo S, Guo Y, Rex Gaskins H, Zhang B. Zinc enhances intestinal epithelial barrier function through the PI3K/AKT/mTOR signaling pathway in Caco-2 cells. J Nutr Biochem. (2017) 43:1826. doi: 10.1016/j.jnutbio.2017.01.013

129. Wiegand S, Zakrzewski SS, Eichner M, Schulz E, Günzel D, Pieper R, et al. Zinc treatment is efficient against Escherichia coli $\alpha$-haemolysininduced intestinal leakage in mice. Sci Rep. (2017) 7:1-13. doi: 10.1038/srep 45649

130. Cohen L, Sekler I, Hershfinkel M. The zinc sensing receptor, ZnR/GPR39, controls proliferation and differentiation of colonocytes and thereby tight junction formation in the colon. Cell Death Dis. (2014) 5:e1307. doi: 10.1038/cddis.2014.262

131. Santos TS dos, Teng PY, Yadav S, Castro FL de S, Gould RL, Craig SW, et al. Effects of inorganic $\mathrm{Zn}$ and $\mathrm{Cu}$ supplementation on gut health in broiler chickens challenged with Eimeria spp. Front Vet Sci. (2020) 7:230. doi: 10.3389/fvets.2020.00230

132. Xu C, Qiao L, Ma L, Guo Y, Dou X, Yan S, et al. Biogenic selenium nanoparticles synthesized by lactobacillus casei ATCC 393 alleviate intestinal epithelial barrier dysfunction caused by oxidative stress via nrf2 signalingmediated mitochondrial pathway. Int J Nanomedicine. (2019) 14:4491502. doi: 10.2147/IJN.S199193

133. Wen ZS, Du M, Tang Z, Zhou TY, Zhang ZS, Song HH, et al. Low molecular seleno-aminopolysaccharides protect the intestinal mucosal barrier of rats under weaning stress. Int J Mol Sci. (2019) 20:5727. doi: 10.3390/ijms20225727

134. Lazzerini $M$, Wanzira $H$. Oral zinc for treating diarrhoea in children. Cochr Datab Syst Rev. (2016) 2016:CD005436. doi: 10.1002/14651858.CD005436.pub5

135. Fischer Walker CL, Black RE. Zinc for the treatment of diarrhoea: effect on diarrhoea morbidity, mortality and incidence of future episodes. Int $J$ Epidemiol. (2010) 39(SUPPL. 1):i63-9. doi: 10.1093/ije/dyq023
136. Alam AN, Sarker SA, Wahed MA, Khatun M, Rahaman MM. Enteric protein loss and intestinal permeability changes in children during acute shigellosis and after recovery: effect of zinc supplementation. Gut. (1994) 35:1707-11. doi: 10.1136/gut.35.12.1707

137. Raqib R, Roy SK, Rahman MJ, Azim T, Ameer SS, Chisti J, et al. Effect of zinc supplementation on immune and inflammatory responses in pediatric patients with shigellosis. Am J Clin Nutr. (2004) 79:44450. doi: 10.1093/ajcn/79.3.444

138. Mahmood A, FitzGerald AJ, Marchbank T, Ntatsaki E, Murray D, Ghosh $S$, et al. Zinc carnosine, a health food supplement that stabilises small bowel integrity and stimulates gut repair processes. Gut. (2007) 56:16875. doi: $10.1136 /$ gut.2006.099929

139. Kamada N, Chen GY, Inohara N, Núñez G. Control of pathogens and pathobionts by the gut microbiota. Nature Immunol. (2013) 14:68590. doi: $10.1038 /$ ni.2608

140. Jandhyala SM, Talukdar R, Subramanyam C, Vuyyuru H, Sasikala M, Reddy DN. Role of the normal gut microbiota. World J Gastroenterol. (2015) 21:8836-47. doi: 10.3748/wjg.v21.i29.8787

141. Jernberg C, Löfmark S, Edlund C, Jansson JK. Long-term impacts of antibiotic exposure on the human intestinal microbiota. Microbiology. (2010) 156:3216-23. doi: 10.1099/mic.0.040618-0

142. Seelbinder B, Chen J, Brunke S, Vazquez-Uribe R, Santhaman R, Meyer $A C$, et al. Antibiotics create a shift from mutualism to competition in human gut communities with a longer-lasting impact on fungi than bacteria. Microbiome. (2020) 8:133. doi: 10.1186/s40168-020-00899-6

143. Dethlefsen L, Huse S, Sogin ML, Relman DA. The pervasive effects of an antibiotic on the human gut microbiota, as revealed by deep 16s rRNA sequencing. PLoS Biol. (2008) 6:0060280. doi: 10.1371/journal.pbio.0060280

144. Modi SR, Collins JJ, Relman DA. Antibiotics and the gut microbiota. J Clin Invest. (2014) 124:4212-8. doi: 10.1172/JCI72333

145. Bohnhoff M, Miller CP. Enhanced susceptibility to salmonella infection in streptomycin-treated mice. J Infect Dis. (1962) 111:117-27. doi: 10.1093/infdis/111.2.117

146. Tulstrup MVL, Christensen EG, Carvalho V, Linninge C, Ahrné S, Højberg $\mathrm{O}$, et al. Antibiotic treatment affects intestinal permeability and gut microbial composition in wistar rats dependent on antibiotic class. PLoS ONE. (2015) 10:e0144854. doi: 10.1371/journal.pone.0144854

147. Feng Y, Huang Y, Wang Y, Wang P, Song H, Wang F. Antibiotics induced intestinal tight junction barrier dysfunction is associated with microbiota dysbiosis, activated NLRP3 inflammasome and autophagy. PLOS ONE. (2019) 14:0218384. doi: 10.1371/journal.pone.0218384

148. Palombo G, Merone M, Altomare A, Gori M, Terradura C, Bacco $\mathrm{L}$, et al. The impact of the intestinal microbiota and the mucosal permeability on three different antibiotic drugs. Eur J Pharm Sci. (2021) 164:105869. doi: 10.1016/j.ejps.2021.105869

149. Shayto RH, Mrad RA, Sharara AI. Use of rifaximin in gastrointestinal and liver diseases. (2016) 22:6638-51. doi: 10.3748/wjg.v22.i29.6638

150. Lopetuso LR, Napoli M, Rizzatti G, Gasbarrini A. The intriguing role of Rifaximin in gut barrier chronic inflammation and in the treatment of Crohn's disease. Expert Opin Investig Drugs. (2018) 27:54351. doi: 10.1080/13543784.2018.1483333

151. Ponziani FR, Zocco MA, D’Aversa F, Pompili M, Gasbarrini A. Eubiotic properties of rifaximin: disruption of the traditional concepts in gut microbiota modulation. World J Gastroenterol. (2017) 23:4491-9. doi: 10.3748/wjg.v23.i25.4491

152. Xu D, Gao J, Gillilland III M, Wu X, Song I, Kao JY, et al. Rifaximin alters intestinal bacteria and prevents stress-induced gut inflammation and visceral hyperalgesia in rats. Gastroenterology. (2014) 146:48496.e4. doi: $10.1053 /$ j.gastro.2013.10.026

153. Ontario L. Food and Agriculture Organization of the United Nations. World Health Organization. Available online at: http://www.fao.org/es/ESN/ Probio/probio.htm

154. Mennigen R, Bruewer M. Effect of probiotics on intestinal barrier function. Annals N $\quad Y$ Acad Sci. (2009) 1165:1839. doi: 10.1111/j.1749-6632.2009.04059.x

155. Collado MC, Meriluoto J, Salminen S. Role of commercial probiotic strains against human pathogen adhesion to intestinal mucus. Lett Appl Microbiol. (2007) 45:454-60. doi: 10.1111/j.1472-765X.2007.02212.x 
156. Putaala H, Salusjärvi T, Nordström M, Saarinen M, Ouwehand AC, Bech Hansen E, et al. Effect of four probiotic strains and Escherichia coli O157:H7 on tight junction integrity and cyclo-oxygenase expression. Res Microbiol. (2008) 159:692-8. doi: 10.1016/j.resmic.2008.08.002

157. Nébot-Vivinus M, Harkat C, Bzioueche H, Cartier C, PlichonDainese R, Moussa L, et al. Multispecies probiotic protects gut barrier function in experimental models. World J Gastroenterol. (2014) 20:6832-43. doi: 10.3748/wjg.v20.i22.6832

158. Laval L, Martin R, Natividad JN, F Chain FC, Miquel S, Desclée de Maredsous C, et al. Lactobacillus rhamnosus CNCM I-3690 and the commensal bacterium faecalibacterium prausnitzii A2-165 exhibit similar protective effects to induced barrier hyper-permeability in mice. Gut Microbes. (2015) 6:1-9. doi: 10.4161/19490976.2014.990784

159. Wang H, Gong J, Wang W, Long Y, Fu X, Fu Y, et al. Are there any different effects of Bifidobacterium, Lactobacillus and Streptococcus on intestinal sensation, barrier function and intestinal immunity in PI-IBS mouse model? PLoS ONE. (2014) Mar 3 9. doi: 10.1371/journal.pone.0090153

160. Patel RM, Myers LS, Kurundkar AR, Maheshwari A, Nusrat A, Lin PW. Probiotic bacteria induce maturation of intestinal claudin 3 expression and barrier function. Am J Pathol. (2012) 180:626-35. doi: 10.1016/j.ajpath.2011.10.025

161. Everard A, Belzer C, Geurts L, Ouwerkerk JP, Druart C, Bindels LB, et al. Cross-talk between Akkermansia muciniphila and intestinal epithelium controls diet-induced obesity. Proc Natl Acad Sci USA. (2013) 110:906671. doi: 10.1073/pnas.1219451110

162. Yan F, Cao H, Cover TL, Washington MK, Shi Y, Liu LS, et al. Colonspecific delivery of a probiotic-derived soluble protein ameliorates intestinal inflammation in mice through an EGFR-dependent mechanism. J Clin Invest. (2011) 121:2242-53. doi: 10.1172/JCI44031

163. Toumi R, Abdelouhab K, Rafa H, Soufli I, Raissi-Kerboua D, Djeraba $\mathrm{Z}$, et al. Beneficial role of the probiotic mixture ultrabiotique on maintaining the integrity of intestinal mucosal barrier in DSS-induced experimental colitis. Immunopharmacol Immunotoxicol. (2013) 35:4039. doi: 10.3109/08923973.2013.790413

164. Mennigen R, Nolte K, Rijcken E, Utech M, Loeffler B, Senninger N, et al. Probiotic mixture VSL\#3 protects the epithelial barrier by maintaining tight junction protein expression and preventing apoptosis in a murine model of colitis. Am J Physiol. (2009) 296:G1140-9. doi: 10.1152/ajpgi.90534.2008

165. Ewaschuk JB, Diaz H, Meddings L, Diederichs B, Dmytrash A, Backer J, et al. Secreted bioactive factors from Bifidobacterium infantis enhance epithelial cell barrier function. Am J Physiol. (2008) 295:G1025-34. doi: 10.1152/ajpgi.90227.2008

166. Ukena SN, Singh A, Dringenberg U, Engelhardt R, Seidler U, Hansen W, et al. Probiotic Escherichia coli Nissle 1917 inhibits leaky gut by enhancing mucosal integrity. PLoS ONE. (2007) Dec 12 2. doi: 10.1371/journal.pone.0001308

167. Kaur H, Gupta T, Kapila S, Kapila R. Protective effects of potential probiotic Lactobacillus rhamnosus (MTCC-5897) fermented whey on reinforcement of intestinal epithelial barrier function in colitis induced murine model. Food Funct. (2021) 12:6102-16 doi: 10.1039/D0FO02641G

168. Sandes S, Figueiredo N, Pedroso S, Sant'Anna F, Acurcio L, Abatemarco Junior M, et al. Weissella paramesenteroides WpK4 plays an immunobiotic role in gut-brain axis, reducing gut permeability, anxiety-like and depressivelike behaviors in murine models of colitis and chronic stress. Food Res Int. (2020) 137:109741. doi: 10.1016/j.foodres.2020.109741

169. Da Silva S, Robbe-Masselot C, Ait-Belgnaoui A, Mancuso A, MercadeLoubière M, Salvador-Cartier C, et al. Stress disrupts intestinal mucus barrier in rats via mucin O-glycosylation shift: Prevention by a probiotic treatment. Am J Physiol. (2014) 307:G420-9. doi: 10.1152/ajpgi.00290.2013

170. Ait-Belgnaoui A, Durand H, Cartier C, Chaumaz G, Eutamene $\mathrm{H}$, Ferrier L, et al. Prevention of gut leakiness by a probiotic treatment leads to attenuated HPA response to an acute psychological stress in rats. Psychoneuroendocrinology. (2012) 37:1885-95. doi: 10.1016/j.psyneuen.2012.03.024

171. Agostini S, Goubern M, Tondereau V, Salvador-Cartier C, Bezirard V, Lévèque $\mathrm{M}$, et al. A marketed fermented dairy product containing Bifidobacterium lactis CNCM I-2494 suppresses gut hypersensitivity and colonic barrier disruption induced by acute stress in rats. Neurogastroenterol Motil. (2012) 24:376-e172. doi: 10.1111/j.1365-2982.2011.01865.x

172. Wang Y, Yan X, Zhang W, Liu Y, Han D, Teng K, et al. Lactobacillus casei zhang prevents jejunal epithelial damage to early-weaned piglets induced by Escherichia coli $\mathrm{K} 88$ via regulation of intestinal mucosal integrity, tight junction proteins and immune factor expression. J Microbiol Biotechnol. (2019) 29:863-76. doi: 10.4014/jmb.1903.03054

173. Vanhaecke T, Aubert P, Grohard PA, Durand T, Hulin P, Paul-Gilloteaux $\mathrm{P}$, et al. L. fermentum CECT (5716) prevents stress-induced intestinal barrier dysfunction in newborn rats. Neurogastroenterol Motil. (2017) 29:13069. doi: 10.1111/nmo.13069

174. Karczewski J, Troost FJ, Konings I, Dekker J, Kleerebezem M, Brummer RJM, et al. Regulation of human epithelial tight junction proteins by Lactobacillus plantarum in vivo and protective effects on the epithelial barrier. Am J Physiol. (2010) 298:G851-9. doi: 10.1152/ajpgi.00327.2009

175. Gotteland M, Cruchet S, Verbeke S. Effect of lactobacillus ingestion on the gastrointestinal mucosal barrier alterations induced by indometacin in humans. Aliment Pharmacol Ther. (2001) 15:11-7. doi: 10.1046/j.1365-2036.2001.00898.x

176. Stratiki Z, Costalos C, Sevastiadou S, Kastanidou O, Skouroliakou M, Giakoumatou A, et al. The effect of a bifidobacter supplemented bovine milk on intestinal permeability of preterm infants. Early Hum Dev. (2007) 83:575-9. doi: 10.1016/j.earlhumdev.2006.12.002

177. Gionchetti P, Rizzello F, Venturi A, Brigidi P, Matteuzzi D, Bazzocchi G, et al. Oral bacteriotherapy as maintenance treatment in patients with chronic pouchitis: a double-blind, placebo-controlled trial. Gastroenterology. (2000) 119:305-9. doi: 10.1053/gast.2000.9370

178. Krishnan M, Penrose HM, Shah NN, Marchelletta RR, McCole DF. VSL\#3 probiotic stimulates $\mathrm{T}$-cell protein tyrosine phosphatase-mediated recovery of IFN- $\gamma$-induced intestinal epithelial barrier defects. Inflamm Bowel Dis. (2016) 22:2811-23. doi: 10.1097/MIB.0000000000000954

179. Kang C sung, Ban M, Choi EJ, Moon HG, Jeon JS, Kim DK, et al. Extracellular vesicles derived from gut microbiota, especially akkermansia muciniphila, protect the progression of dextran sulfate sodium-induced colitis. PLOS ONE. (2013) 8:e0076520. doi: 10.1371/journal.pone.0076520

180. Chelakkot C, Choi Y, Kim DK, Park HT, Ghim J, Kwon Y, et al. Akkermansia muciniphila-derived extracellular vesicles influence gut permeability through the regulation of tight junctions. Exp Mol Med. (2018) 50:282. doi: $10.1038 / \mathrm{emm} .2017 .282$

181. Shen Y, Giardino Torchia M, Lawson G, Karp C, Ashwell J, Mazmanian $\mathrm{S}$. Outer membrane vesicles of a human commensal mediate immune regulation and disease protection. Cell Host Microbe. (2012) 12:50920. doi: 10.1016/j.chom.2012.08.004

182. Ahmadi Badi S, Khatami S, Irani S, Siadat S. Induction effects of bacteroides fragilis derived outer membrane vesicles on toll like receptor 2, toll like receptor 4 genes expression and cytokines concentration in human intestinal epithelial cells. Cell J. (2019) 21:57-61. doi: 10.22074/cellj.2019.5750

183. Maerz J, Steimle A, Lange A, Bender A, Fehrenbacher B, Frick J. Outer membrane vesicles blebbing contributes to B. vulgatus mpk-mediated immune response silencing. Gut Microbes. (2018) 9:1-12. doi: 10.1080/19490976.2017.1344810

184. Souza E, Elian S, Paula L, Garcia C, Vieira A, Teixeira M, et al. Escherichia coli strain Nissle 1917 ameliorates experimental colitis by modulating intestinal permeability, the inflammatory response and clinical signs in a faecal transplantation model. J Med Microbiol. (2016) 65:20110. doi: 10.1099/jmm.0.000222

185. Fábrega M, Rodríguez-Nogales A, Garrido-Mesa J, Algieri F, Badía J, Giménez R, et al. Intestinal anti-inflammatory effects of outer membrane vesicles from Escherichia coli Nissle 1917 in DSS-experimental colitis in mice. Front Microbiol. (2017) 8:1274. doi: 10.3389/fmicb.2017.01274

186. Alvarez C, Badia J, Bosch M, Giménez R, Baldomà L. Outer membrane vesicles and soluble factors released by probiotic Escherichia coli Nissle 1917 and commensal ECOR63 enhance barrier function by regulating expression of tight junction proteins in intestinal epithelial cells. Front Microbiol. (2016) 7:1981. doi: $10.3389 /$ fmicb.2016.01981

187. Alberda C, Gramlich L, Meddings J, Field C, McCargar L, Kutsogiannis D, et al. Effects of probiotic therapy in critically ill patients: a randomized, 
double-blind, placebo-controlled trial. Am J Clin Nutr. (2007) 85:81623. doi: 10.1093/ajcn/85.3.816

188. Mujagic Z, De Vos P, Boekschoten M V., Govers C, Pieters HJHM, De Wit NJW, et al. The effects of Lactobacillus plantarum on small intestinal barrier function and mucosal gene transcription: a randomized double-blind placebo controlled trial. Sci Rep. (2017) 7:40128. doi: 10.1038/srep40128

189. Ahmadi AR, Sadeghian M, Alipour M, Taheri SA, Rahmani S, Abbasnezhad A. The effects of probiotic/synbiotic on serum level of zonulin as a biomarker of intestinal permeability: a systematic review and meta-analysis. Iran J Public Health. (2020) 49:1222-31. doi: 10.18502/ijph.v49i7.3575

190. Lima WG, Pessoa RM, Vital KD, Takenaka IKTM, Cardoso VN, Fernandes SOA. Effect of probiotics on the maintenance of intestinal homeostasis after chemotherapy: systematic review and meta-analysis of pre-clinical studies. Benef Microbes. (2020) 11:305-18. doi: 10.3920/BM2019.0142

191. Yusta B, Huang L, Munroe D, Wolff G, Fantaske R, Sharma S, et al. Enteroendocrine localization of GLP-2 receptor expression in humans and rodents. Gastroenterology. (2000) 119:744-55. doi: 10.1053/gast.2000.16489

192. Guan X, Karpen HE, Stephens J, Bukowski JT, Niu S, Zhang G, et al. GLP-2 receptor localizes to enteric neurons and endocrine cells expressing vasoactive peptides and mediates increased blood flow. Gastroenterology. (2006) 130:150-64. doi: 10.1053/j.gastro.2005.11.005

193. Shin ED, Estall JL, Izzo A, Drucker DJ, Brubaker PL. Mucosal adaptation to enteral nutrients is dependent on the physiologic actions of glucagon-like peptide-2 in mice. Gastroenterology. (2005) 128:1340-53. doi: 10.1053/j.gastro.2005.02.033

194. Rowland KJ, Brubaker PL. The "cryptic" mechanism of action of glucagonlike peptide-2. Am J Physiol Gastrointest Liver Physiol. (2011) 301: :G18. doi: 10.1152/ajpgi.00039.2011

195. Drucker DJ, Ehrlich P, Asa SL, Brubaker PL. Induction of intestinal epithelial proliferation by glucagon-like peptide 2. Proc Natl Acad Sci USA. (1996) 93:7911-6. doi: 10.1073/pnas.93.15.7911

196. Lee SJ, Lee J, Li KK, Holland D, Maughan H, Guttman DS, et al. Disruption of the murine Glp2r impairs paneth cell function and increases susceptibility to small bowel enteritis. Endocrinology. (2012) 153:114151. doi: 10.1210/en.2011-1954

197. Benjamin MA, McKay DM, Yang PC, Cameron H, Perdue MH. Glucagonlike peptide-2 enhances intestinal epithelial barrier function of both transcellular and paracellular pathways in the mouse. Gut. (2000) 47:1129. doi: 10.1136/gut.47.1.112

198. Cameron HL, Perdue MH. Stress impairs murine intestinal barrier function: improvement by glucagon-like peptide-2. J Pharmacol Exp Ther. (2005) 314:214-20. doi: 10.1124/jpet.105.085373

199. Dong CX, Zhao W, Solomon C, Rowland KJ, Ackerley C, Robine S, et al. The intestinal epithelial insulin-like growth factor-1 receptor links glucagonlike peptide-2 action to gut barrier function. Endocrinology. (2014) 155:3709. doi: 10.1210/en.2013-1871

200. Amato A, Baldassano S, Mulè F. GLP2: an underestimated signal for improving glycaemic control and insulin sensitivity. J Endocrinol. (2016) 229:R57-66. doi: 10.1530/JOE-16-0035

201. Chen J, Dong JT, Li XJ, Gu Y, Cheng ZJ, Cai YK. Glucagon-like peptide-2 protects impaired intestinal mucosal barriers in obstructive jaundice rats. World J Gastroenterol. (2015) 21:484-90. doi: 10.3748/wjg.v21.i2.484

202. Markovic MA, Brubaker PL. The roles of glucagon-like peptide-2 and the intestinal epithelial insulin-like growth factor-1 receptor in regulating microvillus length. Sci Rep. (2019) 9:13010. doi: 10.1038/s41598-019-4 9510-5

203. Roy S, Esmaeilniakooshkghazi A, Patnaik S, Wang Y, George SP, Ahrorov A, et al. Villin-1 and gelsolin regulate changes in actin dynamics that affect cell survival signaling pathways and intestinal inflammation. Gastroenterology. (2018) 154:1405-20.e2. doi: 10.1053/j.gastro.2017.12.016

204. Street ME, De’Angelis GL, Camacho-Hübner C, Giovannelli G, Ziveri MA, Bacchini PL, et al. Relationships between serum IGF-1, IGFBP-2, interleukin1 beta and interleukin-6 in inflammatory bowel disease. Horm Res. (2004) 61:159-64. doi: 10.1159/000075699

205. Robertson M, Sigalet D, Holst J, Meddings J, Wood J, Sharkey K. Intestinal permeability and glucagon-like peptide-2 in children with autism: a controlled pilot study. J Autism Dev Disord. (2008) 38:106671. doi: 10.1007/s10803-007-0482-1
206. Lucotti P, Lovati E, Lenti M, Valvo V, Sprio E, Aronico N, et al. Abnormal post-prandial glucagon-like peptide release in patients with Crohn's disease. Clin Res Hepatol Gastroenterol. (2021) 45:11. doi: 10.1016/j.clinre.2020.08.011

207. Borghini R, Caronna R, Donato G, Picarelli A. GLP-2 analog Teduglutide in active Crohn's disease and short bowel syndrome: confirmation of antiinflammatory role and future perspectives. Digest Liver Dis. (2020) 52:6867. doi: 10.1016/j.dld.2020.03.019

208. Jeppesen PB, Gilroy R, Pertkiewicz M, Allard JP, Messing B, O’Keefe SJ. Randomised placebo-controlled trial of teduglutide in reducing parenteral nutrition and/or intravenous fluid requirements in patients with short bowel syndrome. Gut. (2011) 60:902-14. doi: 10.1136/gut.2010.218271

209. Naberhuis JK, Tappenden KA. Teduglutide for safe reduction of parenteral nutrient and/or fluid requirements in adults: a systematic review. J Parent Enteral Nutr. (2016) 40:1096-105. doi: 10.1177/0148607115582063

210. Borghini R, Caronna R, Picarelli A, Corazziari ES. Results of 12 month rescue treatment with teduglutide in severely active and parenteral nutrition-dependent Crohn's disease. Turk J Gastroenterol. (2017) 28:734. doi: $10.5152 /$ tjg. 2016.0587

211. Al Draiweesh S, Ma C, Gregor JC, Rahman A, Jairath V. Teduglutide in patients with active Crohn's disease and short bowel syndrome. Inflamm Bowel Dis. (2019) 25:e109. doi: 10.1093/ibd/izz087

212. Chiplunker A, Ha C, Paski S. P108 teduglutide use in Crohn's disease: a case series. Gastroenterology. (2020) 158:S37. doi: 10.1053/j.gastro.2019.11.113

213. Brubaker PL. Glucagon-like peptide- 2 and the regulation of intestinal growth and function. In: Comprehensive Physiology. Hoboken, NJ: John Wiley \& Sons, Inc. (2018). p. 1185-210. doi: 10.1002/cphy.c170055

214. Liapakis G. Corticotropin Releasing Factor (CRF) and its receptors: from structure to function in health and disease (Part II). Curr Mol Pharmacol. (2018) 11:2-3. doi: 10.2174/187446721101180103122730

215. Taché $\mathrm{Y}$, Perdue MH. Role of peripheral CRF signalling pathways in stressrelated alterations of gut motility and mucosal function. Neurogastroenterol Motil. (2004) 16(SUPPL. 1):137-42. doi: 10.1111/j.1743-3150.2004.00490.x

216. Albert-Bayo M, Paracuellos I, González-Castro AM, Rodríguez-Urrutia A, Rodríguez-Lagunas MJ, Alonso-Cotoner C, et al. Intestinal mucosal mast cells: key modulators of barrier function and homeostasis. Cells. (2019) 8:135. doi: $10.3390 /$ cells 8020135

217. Tache Y, Larauche M, Yuan P-Q, Million M. Brain and gut CRF signaling: biological actions and role in the gastrointestinal tract. Curr Mol Pharmacol. (2017) 11:51-71. doi: 10.2174/1874467210666170224095741

218. Santos J, Saunders PR, Hanssen NPM, Yang PC, Yates D, Groot JA, et al. Corticotropin-releasing hormone mimics stress-induced colonic epithelial pathophysiology in the rat. Am J Physiol. (1999) 277:3919. doi: 10.1152/ajpgi.1999.277.2.G391

219. Saunders PR, Santos J, Hanssen NPM, Yates D, Groot JA, Perdue MH. Physical and psychological stress in rats enhances colonic epithelial permeability via peripheral CRH. Dig Dis Sci. (2002) 47:208-15. doi: 10.1023/A:1013204612762

220. Chatzaki E, Crowe PD, Wang L, Million M, Taché Y, Grigoriadis DE. CRF receptor type 1 and 2 expression and anatomical distribution in the rat colon. J Neurochem. (2004) 90:309-16. doi: 10.1111/j.1471-4159.2004.02490.x

221. Söderholm JD, Yang PC, Ceponis P, Vohra A, Riddell R, Sherman PM, et al. Chronic stress induces mast cell-dependent bacterial adherence and initiates mucosal inflammation in rat intestine. Gastroenterology. (2002) 123:1099-108. doi: 10.1053/gast.2002.36019

222. Söderholm JD, Yates DA, Gareau MG, Yang PC, MacQueen G, Perdue $\mathrm{MH}$. Neonatal maternal separation predisposes adult rats to colonic barrier dysfunction in response to mild stress. Am J Physiol. (2002) 283:125763. doi: 10.1152 /ajpgi.00314.2002

223. Wallon C, Söderholm JD. Corticotropin-releasing hormone and mast cells in the regulation of mucosal barrier function in the human colon. Ann N Y Acad Sci. (2009) 1165:206-10. doi: 10.1111/j.1749-6632.2009.04030.x

224. Vanuytsel T, Van Wanrooy S, Vanheel H, Vanormelingen C, Verschueren S, Houben E, et al. Psychological stress and corticotropin-releasing hormone increase intestinal permeability in humans by a mast cell-dependent mechanism. Gut. (2014) 63:1293-9. doi: 10.1136/gutjnl-2013-305690

225. Larauche M. Novel insights in the role of peripheral corticotropinreleasing factor and mast cells in stress-induced visceral 
hypersensitivity. Neurogastroenterol Motil. (2012) 24:2015. doi: 10.1111/j.1365-2982.2011.01867.x

226. Salvo-Romero E, Martínez C, Lobo B, Rodiño-Janeiro BK, Pigrau M, Sánchez-Chardi AD, et al. Overexpression of corticotropin-releasing factor in intestinal mucosal eosinophils is associated with clinical severity in diarrhea-predominant irritable bowel syndrome. Sci Rep. (2020) 10:113. doi: 10.1038/s41598-020-77176-x

227. Smith F, Clark JE, Overman BL, Tozel CC, Huang JH, Rivier JEF, et al. Early weaning stress impairs development of mucosal barrier function in the porcine intestine. Am J Physiol. (2010) 298:G352. doi: 10.1152/ajpgi.00081.2009

228. Moeser AJ, Klok C Vander, Ryan KA, Wooten JG, Little D, Cook $\mathrm{VL}$, et al. Stress signaling pathways activated by weaning mediate intestinal dysfunction in the pig. Am J Physiol. (2007) 292:17381. doi: 10.1152/ajpgi.00197.2006

229. Gareau MG, Jury J, Perdue MH. Neonatal maternal separation of rat pups results in abnormal cholinergic regulation of epithelial permeability. Am J Physiol. (2007) 293:198-203. doi: 10.1152/ajpgi.00392.2006

230. Vicario M, Alonso C, Guilarte M, Serra J, Martínez C, González-Castro AM, et al. Chronic psychosocial stress induces reversible mitochondrial damage and corticotropin-releasing factor receptor type- 1 upregulation in the rat intestine and IBS-like gut dysfunction. Psychoneuroendocrinology. (2012) 37:65-77. doi: 10.1016/j.psyneuen.2011.05.005

231. Ferrier L, Mazelin L, Cenac N, Desreumaux P, Janin A, Emilie D, et al. Stress-induced disruption of colonic epithelial barrier: role of interferon- $\gamma$ and myosin light chain kinase in mice. Gastroenterology. (2003) 125:795804. doi: 10.1016/S0016-5085(03)01057-6

232. Kiliaan AJ, Saunders PR, Bijlsma PB, Cecilia Berin M, Taminiau JA, Groot JA, et al. Stress stimulates transepithelial macromolecular uptake in rat jejunum. Am J Physiol. (1998) 275:1037-44. doi: 10.1152/ajpgi.1998.275.5.G1037

233. Nozu T, Miyagishi S, Ishioh $M$, Takakusaki K, Okumura $T$. Imipramine improves visceral sensation and gut barrier in rat models of irritable bowel syndrome. Eur J Pharmacol. (2020) 887:173565. doi: 10.1016/j.ejphar.2020.173565

234. Fukudo S, Nomura T, Hongo M. Impact of corticotropin-releasing hormone on gastrointestinal motility and adrenocorticotropic hormone in normal controls and patients with irritable bowel syndrome. Gut. (1998) 42:8459. doi: 10.1136/gut.42.6.845

235. Wallon C, Yang PC, Keita Å V., Ericson AC, McKay DM, Sherman PM, et al. Corticotropin-releasing hormone $(\mathrm{CRH})$ regulates macromolecular permeability via mast cells in normal human colonic biopsies in vitro. Gut. (2008) Jan 1 57:50-8. doi: 10.1136/gut.2006.117549

236. Bailey JE, Papadopoulos A, Diaper A, Phillips S, Schmidt ME, Van Der Ark P, et al. Preliminary evidence of anxiolytic effects of the CRF1 receptor antagonist R317573 in the $7.5 \%$ CO2 proof-of-concept experimental model of human anxiety. J Psychopharmacol. (2011) 25:1199206. doi: 10.1177/0269881111400650

237. Hubbard CS, Labus JS, Bueller J, Stains J, Suyenobu B, Dukes GE, et al. Corticotropin-releasing factor receptor 1 antagonist alters regional activation and effective connectivity in an emotional-arousal circuit during expectation of abdominal pain. J Neurosci. (2011) 31:12491500. doi: 10.1523/JNEUROSCI.1860-11.2011

238. Sagami Y, Shimada Y, Tayama J, Nomura T, Satake M, Endo Y, et al. Effect of a corticotropin releasing hormone receptor antagonist on colonic sensory and motor function in patients with irritable bowel syndrome. Gut. (2004) 53:958-64. doi: 10.1136/gut.2003.018911

239. Tayama J, Sagami Y, Shimada Y, Hongo M, Fukudo S. Effect of alpha-helical CRH on quantitative electroencephalogram in patients with irritable bowel syndrome. Neurogastroenterol Motil. (2007) 19:47183. doi: 10.1111/j.1365-2982.2007.00903.x

240. Schmidt ME, Andrews RD, Van Der Ark P, Brown T, Mannaert E, Steckler T, et al. Dose-dependent effects of the CRF1 receptor antagonist R317573 on regional brain activity in healthy male subjects. Psychopharmacology. (2010) 208:109-19. doi: 10.1007/s00213-009-1714-1

241. Schulzke JD, Bojarski C, Zeissig S, Heller F, Gitter AH, Fromm M. Disrupted barrier function through epithelial cell apoptosis. Ann N Y Acad Sci. (2006) 1072:288-99. doi: 10.1196/annals.1326.027
242. Schmitz H, Fromm M, Bentzel CJ, Scholz P, Detjen K, Mankertz J, et al. Tumor necrosis factor-alpha (TNFalpha) regulates the epithelial barrier in the human intestinal cell line HT-29/B6. J Cell Sci. (1999) 112:13746. doi: $10.1242 /$ jcs.112.1.137

243. Mankertz J, Amasheh M, Krug SM, Fromm A, Amasheh S, Hillenbrand B, et al. TNFalpha up-regulates claudin-2 expression in epithelial HT-29/B6 cells via phosphatidylinositol-3-kinase signaling. Cell Tissue Res. (2009) 336:67-77. doi: 10.1007/s00441-009-0751-8

244. Cao M, Wang P, Sun C, He W, Wang F. Amelioration of IFN- $\gamma$ and TNF- $\alpha$-induced intestinal epithelial barrier dysfunction by berberine via suppression of MLCK-MLC phosphorylation signaling pathway. PLoS ONE. (2013) 8:e0061944. doi: 10.1371/journal.pone.0061944

245. Ma TY, Boivin MA, Ye D, Pedram A, Said HM. Mechanism of TNF-\{alpha\} modulation of Caco-2 intestinal epithelial tight junction barrier: role of myosin light-chain kinase protein expression. Am J Physiol Gastrointest Liver Physiol. (2005) 288:G422-30. doi: 10.1152/ajpgi.00412.2004

246. Graham W V, Wang F, Clayburgh DR, Cheng JX, Yoon B, Wang Y, et al. Tumor necrosis factor-induced long myosin light chain kinase transcription is regulated by differentiation-dependent signaling events. Characterization of the human long myosin light chain kinase promoter. J Biol Chem. (2006) 281:26205-15. doi: 10.1074/jbc.M602164200

247. Ye D, Ma I, Ma TY. Molecular mechanism of tumor necrosis factor-alpha modulation of intestinal epithelial tight junction barrier. Am J Physiol Gastrointest Liver Physiol. (2006) 290:G496504. doi: 10.1152/ajpgi.00318.2005

248. Levin AD, Wildenberg ME, van den Brink GR. Mechanism of action of anti-TNF therapy in inflammatory bowel disease. J Crohns Colitis. (2016) 10:989-97. doi: 10.1093/ecco-jcc/jjw053

249. Fernandez-Ruiz M, Aguado JM. Risk of infection associated with anti-TNF-alpha therapy. Expert Rev Anti Infect Ther. (2018) 16:93956. doi: 10.1080/14787210.2018.1544490

250. Ben-Horin S, Chowers Y. Review article: loss of response to anti-TNF treatments in Crohn's disease. Aliment Pharmacol Ther. (2011) 33:98795. doi: 10.1111/j.1365-2036.2011.04612.x

251. Florholmen J. Mucosal healing in the era of biologic agents in treatment of inflammatory bowel disease. Scand J Gastroenterol. (2015) 50:4352. doi: $10.3109 / 00365521.2014 .977943$

252. Choi SY, Choi YO, Choe YH, Kang B. Potential utility of therapeutic drug monitoring of adalimumab in predicting short-term mucosal healing and histologic remission in pediatric Crohn's disease patients. J Korean Med Sci. (2020) 35:e114. doi: 10.3346/jkms.2020.35.e114

253. Hanauer SB, Sandborn WJ, Rutgeerts P, Fedorak RN, Lukas M, MacIntosh D, et al. Human anti-tumor necrosis factor monoclonal antibody (adalimumab) in Crohn's disease: the CLASSIC-I trial. Gastroenterology. (2006) 130:323-33; quiz 591. doi: 10.1053/j.gastro.2005.11.030

254. Sandborn WJ, Colombel JF, Panes J, Castillo M, Robinson AM, Zhou Q, et al. Exploring the use of adalimumab for patients with moderate Crohn's disease: subanalyses from induction and maintenance trials. J Crohns Colitis. (2013) 7:958-67. doi: 10.1016/j.crohns.2013.02.016

255. Papamichael K, Baert F, Tops S, Assche G V, Rutgeerts P, Vermeire S, et al. Post-induction adalimumab concentration is associated with shortterm mucosal healing in patients with ulcerative colitis. J Crohns Colitis. (2017) 11:53-9. doi: 10.1093/ecco-jcc/jjw122

256. Ungar B, Levy I, Yavne Y, Yavzori M, Picard O, Fudim E, et al. Optimizing anti-TNF-alpha therapy: serum levels of infliximab and adalimumab are associated with mucosal healing in patients with inflammatory bowel diseases. Clin Gastroenterol Hepatol. (2016) 14:5507.e2. doi: $10.1016 /$ j.cgh.2015.10.025

257. Fischer A, Gluth M, Pape UF, Wiedenmann B, Theuring F, Baumgart DC. Adalimumab prevents barrier dysfunction and antagonizes distinct effects of TNF-alpha on tight junction proteins and signaling pathways in intestinal epithelial cells. Am J Physiol Gastrointest Liver Physiol. (2013) 304:G9709. doi: 10.1152/ajpgi.00183.2012

258. Xu P, Elamin E, Elizalde M, Bours P, Pierik MJ, Masclee AAM, et al. Modulation of intestinal epithelial permeability by plasma from patients with crohn's disease in a three-dimensional cell culture model. Sci Rep. (2019) 9:2030. doi: 10.1038/s41598-018-38322-8 
259. Ricart E, Panaccione R, Loftus E V, Tremaine WJ, Sandborn WJ. Successful management of Crohn's disease of the ileoanal pouch with infliximab. Gastroenterology. (1999) 117:429-32. doi: 10.1053/gast.1999.0029900429

260. Grazie ML, Bagnoli S, Dragoni G, Caini S, Annese V, Innocenti T, et al. Infliximab is more effective than cyclosporine as a rescue therapy for acute severe ulcerative colitis: a retrospective single-center study. Ann Gastroenterol. (2021) 34:370-7. doi: 10.20524/aog.2021.0584

261. Suenaert P, Bulteel V, Lemmens L, Noman M, Geypens B, Van Assche G, et al. Anti-tumor necrosis factor treatment restores the gut barrier in Crohn's disease. Am J Gastroenterol. (2002) 97:20004. doi: 10.1111/j.1572-0241.2002.05914.x

262. Yakymenko O, Schoultz I, Gullberg E, Strom M, Almer S, Wallon C, et al. Infliximab restores colonic barrier to adherent-invasive E. coli in Crohn's disease via effects on epithelial lipid rafts. Scand J Gastroenterol. (2018) 53:677-84. doi: 10.1080/00365521.2018.1458146

263. Favara DM, Spain L, Au L, Clark J, Daniels E, DIem S, et al. Five-year review of corticosteroid duration and complications in the management of immune checkpoint inhibitor-related diarrhoea and colitis in advanced melanoma. ESMO Open. (2020) 5:585. doi: 10.1136/esmoopen-2019-000585

264. Esteve M, Mahadevan U, Sainz E, Rodriguez E, Salas A, Fernández-Bañares F. Efficacy of anti-TNF therapies in refractory severe microscopic colitis. $J$ Crohn's Colitis. (2011) 5:612-8. doi: 10.1016/j.crohns.2011.05.001

265. Gillett HR, Arnott ID, McIntyre M, Campbell S, Dahele A, Priest M, et al. Successful infliximab treatment for steroid-refractory celiac disease: a case report. Gastroenterology. (2002) 122:800-5. doi: 10.1053/gast.2002.31874

266. He WQ, Wang J, Sheng JY, Zha JM, Graham WV, Turner JR. Contributions of myosin light chain kinase to regulation of epithelial paracellular permeability and mucosal homeostasis. Int J Mol Sci. (2020) 21:993. doi: 10.3390/ijms21030993

267. Suzuki T. Regulation of intestinal epithelial permeability by tight junctions. Cell Mol Life Sci. (2013) 70:631-59. doi: 10.1007/s00018-012-1070-x

268. Bruewer M, Luegering A, Kucharzik T, Parkos CA, Madara JL, Hopkins $\mathrm{AM}$, et al. Proinflammatory cytokines disrupt epithelial barrier function by apoptosis-independent mechanisms. J Immunol. (2003) 171:616472. doi: 10.4049/jimmunol.171.11.6164

269. Bruewer M, Utech M, Ivanov AI, Hopkins AM, Parkos CA, Nusrat A. Interferon- $\gamma$ induces internalization of epithelial tight junction proteins via a macropinocytosis-like process. FASEB J. (2005) 19:923-33. doi: 10.1096/fj.04-3260com

270. Bardenbacher M, Ruder B, Britzen-Laurent N, Schmid B, Waldner M, Naschberger E, et al. Permeability analyses and three dimensional imaging of interferon gamma-induced barrier disintegration in intestinal organoids. Stem Cell Res. (2019) 35:101383. doi: 10.1016/j.scr.2019.101383

271. Wang F, Graham WV, Wang Y, Witkowski ED, Schwarz BT, Turner JR. Interferon- $\gamma$ and tumor necrosis factor- $\alpha$ synergize to induce intestinal epithelial barrier dysfunction by up-regulating myosin light chain kinase expression. Am J Pathol. (2005) 166:409-19. doi: 10.1016/S0002-9440(10)62264-X

272. Wang F, Schwarz BT, Graham WV, Wang Y, Su L, Clayburgh DR, et al. IFN- $\gamma$-induced TNFR2 expression is required for TNF-dependent intestinal epithelial barrier dysfunction. Gastroenterology. (2006) 131:115363. doi: 10.1053/j.gastro.2006.08.022

273. Niessner M, Volk BA. Altered Th1/Th2 cytokine profiles in the intestinal mucosa of patients with inflammatory bowel disease as assessed by quantitative reversed transcribed polymerase chain reaction (RT-PCR). Clin Exp Immunol. (1995) 101:428-35. doi: 10.1111/j.1365-2249.1995. tb03130.x

274. Barbaro MR, Di Sabatino A, Cremon C, Giuffrida P, Fiorentino M, Altimari $A$, et al. Interferon- $\gamma$ is increased in the gut of patients with irritable bowel syndrome and modulates serotonin metabolism. Am J Physiol. (2016) 310:G439-47. doi: 10.1152/ajpgi.00368.2015

275. Novick D, Fischer DG, Reiter Z, Eshhar Z, Rubinstein M. Monoclonal antibodies to the human interferon $\gamma$ receptor: blocking of the biological activities of interferon- $\gamma$ and purification of the receptor. J Interferon Res. (1989) 9:315-28. doi: 10.1089/jir.1989.9.315

276. Chen P, Vu T, Narayanan A, Sohn W, Wang J, Boedigheimer $\mathrm{M}$, et al. Pharmacokinetic and pharmacodynamic relationship of AMG 811, an anti-IFN- $\gamma$ IgG1 monoclonal antibody, in patients with systemic lupus erythematosus. Pharm Res. (2015) 32:640-53. doi: 10.1007/s11095-014-1492-2

277. Giuffrida P, Caprioli F, Facciotti F, Di Sabatino A. The role of interleukin13 in chronic inflammatory intestinal disorders. Autoimmun Rev. (2019) 18:549-55. doi: 10.1016/j.autrev.2019.03.012

278. Prasad S, Mingrino R, Kaukinen K, Hayes KL, Powell RM, MacDonald TT, et al. Inflammatory processes have differential effects on claudins 2, 3 and 4 in colonic epithelial cells. Lab Invest. (2005) 85:113962. doi: 10.1038/labinvest.3700316

279. Weber CR, Raleigh DR, Su L, Shen L, Sullivan EA, Wang Y, et al. Epithelial myosin light chain kinase activation induces mucosal interleukin13 expression to alter tight junction ion selectivity. J Biol Chem. (2010) 285:12037-46. doi: 10.1074/jbc.M109.064808

280. Heller F, Fromm A, Gitter AH, Mankertz J, Schulzke JD. Epithelial apoptosis is a prominent feature of the epithelial barrier disturbance in intestinal inflammation: effect of pro-inflammatory interleukin-13 on epithelial cell function. Mucosal Immunol. (2008) 1(Suppl 1):S5861. doi: $10.1038 / \mathrm{mi} .2008 .46$

281. Heller F, Florian P, Bojarski C, Richter J, Christ M, Hillenbrand B, et al. Interleukin-13 is the key effector Th2 cytokine in ulcerative colitis that affects epithelial tight junctions, apoptosis, and cell restitution. Gastroenterology. (2005) 129:550-64. doi: 10.1053/j.gastro.2005.05.002

282. Jonefjall B, Ohman L, Simren M, Strid H. IBS-like symptoms in patients with ulcerative colitis in deep remission are associated with increased levels of serum cytokines and poor psychological well-being. Inflamm Bowel Dis. (2016) 22:2630-40. doi: 10.1097/MIB.0000000000000921

283. Reinisch W, Panes J, Khurana S, Toth G, Hua F, Comer GM, et al. Anrukinzumab, an anti-interleukin 13 monoclonal antibody, in active UC: efficacy and safety from a phase IIa randomised multicentre study. Gut. (2015) 64:894-900. doi: 10.1136/gutjnl-2014-308337

284. Loh TY, Hsiao JL, Shi VY. Therapeutic potential of lebrikizumab in the treatment of atopic dermatitis. J Asthma Allergy. (2020) 13:10914. doi: $10.2147 /$ JAA.S211032

285. Goncalves F, Freitas E, Torres T. Selective IL-13 inhibitors for the treatment of atopic dermatitis. Drugs Context. (2021) 10:2021-1-7. doi: 10.7573/dic.2021-1-7

286. Sturgeon C, Fasano A. Zonulin, a regulator of epithelial and endothelial barrier functions, and its involvement in chronic inflammatory diseases. Tissue Barriers. (2016) 4:e1251384. doi: 10.1080/21688370.2016.1251384

287. Asmar R El, Panigrahi P, Bamford P, Berti I, Not T, Coppa G V., et al. Hostdependent zonulin secretion causes the impairment of the small intestine barrier function after bacterial exposure. Gastroenterology. (2002) 123:160715. doi: 10.1053/gast.2002.36578

288. Gopalakrishnan S, Durai M, Kitchens K, Tamiz AP, Somerville R, Ginski M, et al. Larazotide acetate regulates epithelial tight junctions in vitro and in vivo. Peptides. (2012) 35:86-94. doi: 10.1016/j.peptides.2012.02.015

289. Paterson BM, Lammers KM, Arrieta MC, Fasano A, Meddings JB. The safety, tolerance, pharmacokinetic and pharmacodynamic effects of single doses of AT-1001 in coeliac disease subjects: a proof of concept study. Aliment Pharmacol Ther. (2007) 26:757-66. doi: 10.1111/j.1365-2036.2007. 03413.x

290. Troisi J, Venutolo G, Terracciano C, Carri MD, Di Micco S, Landolfi A, et al. The therapeutic use of the zonulin inhibitor AT-1001 (Larazotide) for a variety of acute and chronic inflammatory diseases. Curr Med Chem. (2021) 28:5788-807. doi: 10.2174/0929867328666210104110053

291. Tajik N, Frech M, Schulz O, Schälter F, Lucas S, Azizov V, et al. Targeting zonulin and intestinal epithelial barrier function to prevent onset of arthritis. Nat Commun. (2020) 11:1995. doi: 10.1038/s41467-020-15831-7

292. Enomoto H, Yeatts J, Carbajal L, Krishnan BR, Madan JP, Laumas S, et al. In vivo assessment of a delayed release formulation of larazotide acetate indicated for celiac disease using a porcine model. PLoS ONE. (2021) 16:e0249179. doi: 10.1371/journal.pone.0249179

293. Slifer ZM, Hernandez L, Pridgen TA, Carlson AR, Messenger KM, Madan J, et al. Larazotide acetate induces recovery of ischemia-injured porcine jejunum via repair of tight junctions. PLoS ONE. (2021) 16:e0250165. doi: 10.1371/journal.pone.0250165

294. Leffler DA, Kelly CP, Abdallah HZ, Colatrella AM, Harris LA, Leon F, et al. A randomized, double-blind study of larazotide acetate to prevent 
the activation of celiac disease during gluten challenge. Am J Gastroenterol. (2012) 107:1554-62. doi: 10.1038/ajg.2012.211

295. Kelly CP, Green PHR, Murray JA, Dimarino A, Colatrella A, Leffler DA, et al. Larazotide acetate in patients with coeliac disease undergoing a gluten challenge: a randomised placebo-controlled study. Aliment Pharmacol Ther. (2013) 37:252-62. doi: 10.1111/apt.12147

296. Leffler DA, Kelly CP, Green PHR, Fedorak RN, Dimarino A, Perrow W, et al. Larazotide acetate for persistent symptoms of celiac disease despite a gluten-free diet: a randomized controlled trial. Gastroenterology. (2015) 148:1311-9.e6. doi: 10.1053/j.gastro.2015.02.008

297. Lembo AJ, Johanson JF, Parkman HP, Rao SS, Miner PB, Ueno R. Longterm safety and effectiveness of lubiprostone, a chloride channel (ClC-2) activator, in patients with chronic idiopathic constipation. Dig Dis Sci. (2011) 56:2639-45. doi: 10.1007/s10620-011-1801-0

298. Drossman DA, Chey WD, Johanson JF, Fass R, Scott C, Panas R, et al. Clinical trial: Lubiprostone in patients with constipation-associated irritable bowel syndrome - results of two randomized, placebo-controlled studies. Aliment Pharmacol Ther. (2009) 29:329-41. doi: 10.1111/j.1365-2036.2008.03881.x

299. Lacy BE, Chey WD. Lubiprostone: chronic constipation and irritable bowel syndrome with constipation. Expert Opin Pharmacother. (2009) 10:14352. doi: $10.1517 / 14656560802631319$

300. Johanson JF, Drossman DA, Panas R, Wahle A, Ueno R. Clinical trial: phase 2 study of lubiprostone for irritable bowel syndrome with constipation. Aliment Pharmacol Ther. (2008) 27:685-96. doi: 10.1111/j.1365-2036.2008.03629.x

301. Chang L, Chey WD, Drossman D, Losch-Beridon T, Wang M, Lichtlen $\mathrm{P}$, et al. Effects of baseline abdominal pain and bloating on response to lubiprostone in patients with irritable bowel syndrome with constipation. Aliment Pharmacol Ther. (2016) 44:1114-22. doi: 10.1111/apt.13807

302. Nishii N, Oshima T, Li M, Eda H, Nakamura K, Tamura A, et al. Lubiprostone induces claudin-1 and protects intestinal barrier function. Pharmacology. (2020) 105:102-8. doi: 10.1159/000503054

303. Jin Y, Pridgen TA, Blikslager AT. Pharmaceutical activation or genetic absence of ClC-2 alters tight junctions during experimental colitis. Inflamm Bowel Dis. (2015) 21:2747-57. doi: 10.1097/MIB.00000000000 00550

304. Moeser AJ, Nighot PK, Engelke KJ, Ueno R, Blikslager AT. Recovery of mucosal barrier function in ischemic porcine ileum and colon is stimulated by a novel agonist of the ClC-2 chloride channel, lubiprostone. Am J Physiol. (2007) 292:G647-56. doi: 10.1152/ajpgi.00183.2006

305. Zong Y, Zhu S, Zhang S, Zheng G, Wiley JW, Hong S. Chronic stress and intestinal permeability: lubiprostone regulates glucocorticoid receptormediated changes in colon epithelial tight junction proteins, barrier function, and visceral pain in the rodent and human. Neurogastroenterol Motil. (2019) 31:13477. doi: 10.1111/nmo.13477

306. Ghosh SS, Wang J, Yannie PJ, Ghosh S. Intestinal barrier dysfunction, LPS translocation, and disease development. J Endocr Soc. (2020) 4:bvz039. doi: 10.1210/jendso/bvz039

307. Hayashi S, Kurata N, Yamaguchi A, Amagase K, Takeuchi K. Lubiprostone prevents nonsteroidal anti-inflammatory druginduced small intestinal damage by suppressing the expression of inflammatory mediators via EP4 receptors. J Pharmacol Exp Ther. (2014) 349:470-9. doi: 10.1124/jpet.114.213991

308. Kato T, Honda Y, Kurita Y, Iwasaki A, Sato T, Kessoku T, et al. Lubiprostone improves intestinal permeability in humans, a novel therapy for the leaky gut: A prospective randomized pilot study in healthy volunteers. PLoS ONE. (2017) 12:e0175626. doi: 10.1371/journal.pone.0175626

309. Schaak S, Cussac D, Cayla C, Devedjian JC, Guyot R, Paris H, et al. Alpha 2 adrenoceptors regulate proliferation of human intestinal epithelial cells. Gut. (2000) 47:242-50. doi: 10.1136/gut.47.2.242

310. Zhang X-Y, Liu Z-M, Wen S-H, Li Y-S, Li Y, Yao X, et al. Dexmedetomidine administration before, but not after, ischemia attenuates intestinal injury induced by intestinal ischemia-reperfusion in rats. Anesthesiology. (2012) 116:1035-46. doi: 10.1097/ALN.0b013e3182503964

311. Yeh YC, Wu CY, Cheng YJ, Liu CM, Hsiao JK, Chan WS, et al. Effects of dexmedetomidine on intestinal microcirculation and intestinal epithelial barrier in endotoxemic rats. Anesthesiology. (2016) 125:35567. doi: $10.1097 /$ ALN. 0000000000001135
312. Hang C-H, Shi J-X, Li J-S, Wu W, Yin H-X. Alterations of intestinal mucosa structure and barrier function following traumatic brain injury in rats. World J Gastroenterol. (2003) 9:2776-81. doi: 10.3748/wjg.v9.i12.2776

313. Karaca O, Dogan G. The effects of dexmedetomidine in increased intestinal permeability after traumatic brain injury: an experimental study. Ulus Travma Acil Cerrahi Derg. (2019) 26:15-20. doi: 10.14744/tjtes.2019. 49768

314. Xia Z-N, Zong Y, Zhang Z-T, Chen J-K, Ma X-J, Liu Y-G, et al. Dexmedetomidine protects against multi-organ dysfunction induced by heatstroke via sustaining the intestinal integrity. Shock. (2017) 48:2609. doi: $10.1097 /$ SHK.0000000000000826

315. Qin C, Jiang Y, Chen X, Bian Y, Wang Y, Xie K, et al. Dexmedetomidine protects against burn-induced intestinal barrier injury via the MLCK/p-MLC signalling pathway. Burns. (2021) doi: 10.1016/j.burns.2021.01.017. [Epub ahead of print].

316. Wang ZX, Huang CY, Hua YP, Huang WQ, Deng LH, Liu KX. Dexmedetomidine reduces intestinal and hepatic injury after hepatectomy with inflow occlusion under general anaesthesia: a randomized controlled trial. Br J Anaesth. (2014) 112:1055-64. doi: 10.1093/bja/aeu132

317. Chen C, Huang P, Lai L, Luo C, Ge M, Hei Z, et al. Dexmedetomidine improves gastrointestinal motility after laparoscopic resection of colorectal cancer. A randomized clinical trial. (2016) 95:e4295. doi: 10.1097/MD.0000000000004295

318. Qi Y. Effect of dexmedetomidine on intestinal barrier in patients undergoing gastrointestinal surgery-a single-centre randomized clinical trial. Res Sq [preprint]. (2021). doi: 10.21203/rs.3.rs-150967/vl

319. Molderings GJ, Haenisch B, Brettner S, Homann J, Menzen M, Dumoulin FL, et al. Pharmacological treatment options for mast cell activation disease. Naunyn-Schmiedeberg's Arch Pharmacol. (2016) 389:671-94. doi: 10.1007/s00210-016-1247-1

320. Reber LL, Frossard N. Targeting mast cells in inflammatory diseases. Pharmacol Ther. (2014) 142:416-35. doi: 10.1016/j.pharmthera.2014.01.004

321. Siebenhaar F, Redegeld FA, Bischoff SC, Gibbs BF, Maurer M. Mast cells as drivers of disease and therapeutic targets. Trends Immunol. (2018) 39:15162. doi: 10.1016/j.it.2017.10.005

322. Hei Z qing, Gan X liang, Huang P jie, Wei J, Shen N, Gao W ling. Influence of Ketotifen, Cromolyn Sodium, and Compound 48/80 on the survival rates after intestinal ischemia reperfusion injury in rats. BMC Gastroenterol. (2008) 8:42. doi: 10.1186/1471-230X-8-42

323. Overman EL, Rivier JE, Moeser AJ. CRF induces intestinal epithelial barrier injury via the release of mast cell proteases and TNF-a. PLoS ONE. (2012) 7(6):e39935. doi: 10.1371/journal.pone.0039935

324. Keita Å V., Carlsson AH, Cigéhn M, Ericson AC, Mckay DM, Söderholm JD. Vasoactive intestinal polypeptide regulates barrier function via mast cells in human intestinal follicle-associated epithelium and during stress in rats. Neurogastroenterol Motil. (2013) 25:e406-17. doi: 10.1111/nmo.12127

325. Aguilera-Lizarraga J, Florens M V., Viola MF, Jain P, Decraecker L, Appeltans I, et al. Local immune response to food antigens drives meal-induced abdominal pain. Nature. (2021) 590:151-6. doi: 10.1038/s41586-020-03118-2

326. Weangsripanaval T, Murota K, Murakami Y, Kominami M, Kusudo T, Moriyama T, et al. Sodium cromoglycate inhibits absorption of the major soybean allergen, gly $\mathrm{m}$ bd $30 \mathrm{k}$, in mice and human intestinal Caco-2 cells $1 . J$ Nutr Nutritional Immunol. (2006) 136:2874-80. doi: 10.1093/jn/136.11.2874

327. McLamb BL, Gibson AJ, Overman EL, Stahl C, Moeser AJ. Early weaning stress in pigs impairs innate mucosal immune responses to enterotoxigenic E. coli challenge and exacerbates intestinal injury and clinical disease. PLoS ONE. (2013) 8:e59838. doi: 10.1371/journal.pone.0059838

328. Mereu A, Tedó G, Moeser AJ, Rimbach G, Ipharraguerre IR. Cromolynmediated improvement of intestinal barrier function is associated with enhanced piglet performance after weaning. BMC Vet Res. (2012) 11:274. doi: 10.1186/s12917-015-0588-1

329. Stein J, Ries J, Barrett KE. Disruption of intestinal barrier function associated with experimental colitis: possible role of mast cells. Am J Physiol. (1998) 274:G203-9. doi: 10.1152/ajpgi.1998.274.1.G203

330. Barreau F, Cartier C, Ferrier L, Fioramonti J, Bueno L. Nerve growth factor mediates alterations of colonic sensitivity and mucosal barrier induced by neonatal stress in rats. Gastroenterology. (2004) 127:52434. doi: 10.1053/j.gastro.2004.05.019 
331. Demaude J, Salvador-Cartier C, Fioramonti J, Ferrier L, Bueno L. Phenotypic changes in colonocytes following acute stress or activation of mast cells in mice: implications for delayed epithelial barrier dysfunction. Gut. (2006) 55:655-61. doi: 10.1136/gut.2005.078675

332. Ferrier L, Bérard F, Debrauwer L, Chabo C, Langella P, Buéno L, et al. Impairment of the intestinal barrier by ethanol involves enteric microflora and mast cell activation in rodents. Am J Pathol. (2006) 168:114854. doi: 10.2353/ajpath.2006.050617

333. Galluzzi L, Vitale I, Aaronson SA, Abrams JM, Adam D, Agostinis $\mathrm{P}$, et al. Molecular mechanisms of cell death: recommendations of the Nomenclature Committee on Cell Death 2018. Cell Death Differ. (2018) 25:486-541. doi: 10.1038/s41418-017-0012-4

334. Klooker TK, Braak B, Koopman KE, Welting O, Wouters MM, van der Heide $\mathrm{S}$, et al. The mast cell stabiliser ketotifen decreases visceral hypersensitivity and improves intestinal symptoms in patients with irritable bowel syndrome. Gut. (2010) 59:1213-21. doi: 10.1136/gut.2010.213108

335. The FO, Buist MR, Lei A, Bennink RJ, Hofland J, Van Den Wijngaard RM, et al. The role of mast cell stabilization in treatment of postoperative ileus: a pilot study. Am J Gastroenterol. (2009) 104:2257-66. doi: 10.1038/ajg.2009.268

336. Lee YJ, Hussain Z, Huh CW, Lee YJ, Park H. Inflammation, impaired motility, and permeability in a Guinea Pig model of postoperative ileus. $J$ Neurogastroenterol Motil. (2018) 24:147-58. doi: 10.5056/jnm17012

337. Van Elburg RM, Heymans HSA, De Monchy JGR. Effect of disodiumcromoglycate on intestinal permeability changes and clinical response during cow's milk challenge. Pediatr Allergy Immunol. (1993) 4:79-85. doi: 10.1111/j.1399-3038.1993.tb00071.x

338. Fält-Magnusson K, Kjellman N -I M, Odelram H, Sundqvist T, Magnusson $\mathrm{K}$-E. Gastrointestinal permeability in children with cow's milk allergy: effect of milk challenge and sodium cromoglycate as assessed with polyethyleneglycols (PEG 400 and PEG 1000). Clin Exp Allergy. (1986) 16:543-51. doi: 10.1111/j.1365-2222.1986.tb01993.x

339. Andre F, Andre C, Feknous M, Colin L, Cavagna S. Digestive permeability to different-sized molecules and to sodium cromoglycate in food allergy. Allergy Proc. (1991) 12:293-8. doi: 10.2500/108854191778879142

340. Pigatto PD, Gibelli E, Fumagalli M, Bigardi A, Morelli M, Altomare GF. Disodium cromoglycate versus diet in the treatment and prevention of nickel-positive pompholyx. Contact Dermatitis. (1990) 22:27-31. doi: 10.1111/j.1600-0536.1990.tb01501.x

341. Ventura A, Rinaldi S, Florean P AE. Intestinal permeability, atopic eczema and oral disodium cromoglycate - PubMed. Pediatric Medical e Chirurgica. (1991) 13:169-72.

342. Stefanini G, Prati E, Albini M, Piccinini G, Capelli S, Castelli E, et al. Oral disodium cromoglycate treatment on irritable bowel syndrome: an open study on 101 subjects with diarrheic type. Am J Gastroenterol. (1992) 8 7:55-7.

343. Stefanini GF, Saggioro A, Alvisi V, Angelini G, Capurso L, di Lorenzo G, et al. Oral cromolyn sodium in comparison with elimination diet in the irritable bowel syndrome, diarrheic type. Multicenter study of 428 patients. Scand J Gastroenterol. (1995) 30:535-41. doi: 10.3109/00365529509089786

344. Lobo B, Ramos L, Martínez C, Guilarte M, González-Castro AM, AlonsoCotoner C, et al. Downregulation of mucosal mast cell activation and immune response in diarrhoea-irritable bowel syndrome by oral disodium cromoglycate: A pilot study. United Eur Gastroenterol J. (2017) 5:88797. doi: 10.1177/2050640617691690

345. Panche AN, Diwan AD, Chandra SR. Flavonoids: an overview. J Nutr Sci. (2016) 5:41. doi: 10.1017/jns.2016.41

346. Bernardi S, Del Bo’ C, Marino M, Gargari G, Cherubini A, Andrés-Lacueva C, et al. Polyphenols and intestinal permeability: rationale and future perspectives. J Agric Food Chem. (2019) 68:1816-29. doi: 10.1021/acs.jafc.9b02283

347. Gil-Cardoso K, Ginés I, Pinent M, Ardévol A, Blay M, Terra X. Effects of flavonoids on intestinal inflammation, barrier integrity and changes in gut microbiota during diet-induced obesity. Nutr Res Rev. (2016) 29:23448. doi: 10.1017/S0954422416000159

348. Luescher S, Urmann C, Butterweck V. Effect of hops derived prenylated phenols on TNF- $\alpha$ induced barrier dysfunction in intestinal epithelial cells. $J$ Nat Prod. (2017) 80:925-31. doi: 10.1021/acs.jnatprod.6b00869
349. Valenzano MC, DiGuilio K, Mercado J, Teter M, To J, Ferraro B, et al. Remodeling of tight junctions and enhancement of barrier integrity of the CACO-2 intestinal epithelial cell layer by micronutrients. PLoS ONE. (2015) 10:e133926. doi: 10.1371/journal.pone.0133926

350. Azzini E, Maiani G, Garaguso I, Polito A, Foddai MS, Venneria E, et al. The potential health benefits of polyphenol-rich extracts from Cichorium intybus L. studied on caco-2 cells model. Oxid Med Cell Longev. (2016) 2016:1594616. doi: 10.1155/2016/1594616

351. Cremonini E, Mastaloudis A, Hester SN, Verstraeten S V., Anderson M, Wood SM, et al. Anthocyanins inhibit tumor necrosis alphainduced loss of Caco-2 cell barrier integrity. Food Funct. (2017) 8:291523. doi: 10.1039/C7FO00625J

352. Suzuki T, Tanabe S, Hara H. Kaempferol enhances intestinal barrier function through the cytoskeletal association and expression of tight junction proteins in Caco-2 cells 1-3. J Nutr. (2011) 141:87-94. doi: 10.3945/jn.110.125633

353. Noda S, Tanabe S, Suzuki T. Naringenin enhances intestinal barrier function through the expression and cytoskeletal association of tight junction proteins in Caco-2 cells. Mol Nutr Food Res. (2013) 57:201928. doi: 10.1002/mnfr.201300045

354. Amasheh M, Luettig J, Amasheh S, Zeitz M, Fromm M, Schulzke JD. Effects of quercetin studied in colonic HT-29/B6 cells and rat intestine in vitro. Ann N Y Acad Sci. (2012) 1258:100-7. doi: 10.1111/j.1749-6632.2012.06609.x

355. Park HY, Kunitake Y, Hirasaki N, Tanaka M, Matsui T. Theaflavins enhance intestinal barrier of Caco-2 Cell monolayers through the expression of AMPactivated protein kinase-mediated Occludin, Claudin-1, and ZO-1. Biosci Biotechnol Biochem. (2015) 79:130-7. doi: 10.1080/09168451.2014.951027

356. Contreras TC, Ricciardi E, Cremonini E, Oteiza PI. (-)-Epicatechin in the prevention of tumor necrosis alpha-induced loss of Caco-2 cell barrier integrity. Arch Biochem Biophys. (2015) 573:84-91. doi: 10.1016/j.abb.2015.01.024

357. Wang K, Jin X, Chen Y, Song Z, Jiang X, Hu F, et al. Polyphenol-rich propolis extracts strengthen intestinal barrier function by activating AMPK and ERK signaling. Nutrients. (2016) 8:272. doi: 10.3390/nu8050272

358. Yang G, Wang H, Kang Y, Zhu MJ. Grape seed extract improves epithelial structure and suppresses inflammation in ileum of IL-10-deficient mice. Food Funct. (2014) 5:2558-63. doi: 10.1039/C4FO00451E

359. Miller WL, Auchus RJ. The molecular biology, biochemistry, and physiology of human steroidogenesis and its disorders. Endocr Rev. (2011) 32:81151. doi: 10.1210/er.2010-0013

360. Escoter-Torres L, Caratti G, Mechtidou A, Tuckermann J, Uhlenhaut NH, Vettorazzi S. Fighting the fire: Mechanisms of inflammatory gene regulation by the glucocorticoid receptor. Front Immunol. (2019) 10:1859. doi: 10.3389/fimmu.2019.01859

361. Ahmed A, Schmidt C, Brunner T. Extra-adrenal glucocorticoid synthesis in the intestinal mucosa: Between immune homeostasis and immune escape. Front Immunol. (2019) 10:1438. doi: 10.3389/fimmu.2019.01438

362. Boivin MA, Ye D, Kennedy JC, Al-Sadi R, Shepela C, Ma TY. Mechanism of glucocorticoid regulation of the intestinal tight junction barrier. Am J Physiol. (2007) 292:G590. doi: 10.1152/ajpgi.00252.2006

363. Fischer A, Gluth M, Weege F, Pape U-F, Wiedenmann B, Baumgart DC, et al. Glucocorticoids regulate barrier function and claudin expression in intestinal epithelial cells via MKP-1. Am J Physiol Liver Physiol. (2014) 306:G218-28. doi: 10.1152/ajpgi.00095.2013

364. Zheng G, Victor Fon G, Meixner W, Creekmore A, Zong Y, Michael Dame MK, et al. Chronic stress and intestinal barrier dysfunction: glucocorticoid receptor and transcription repressor HES1 regulate tight junction protein Claudin-1 promoter. Sci Rep. (2017) 1 7:1-12. doi: 10.1038/s41598-017-04755-w

365. Lu L, Li T, Williams G, Petit E, Borowsky M, Walker WA. Hydrocortisone induces changes in gene expression and differentiation in immature human enterocytes. Am J Physiol. (2011) 300:425-32. doi: 10.1152/ajpgi.00011.2010

366. Lorén V, Cabré E, Ojanguren I, Domènech E, Pedrosa E, García-Jaraquemada $A$, et al. Interleukin-10 enhances the intestinal epithelial barrier in the presence of corticosteroids through p38 MAPK activity in Caco-2 monolayers: a possible mechanism for steroid responsiveness in ulcerative colitis. PLoS ONE. (2015) 10:2006-15063. doi: 10.1371/journal.pone.0130921

367. Muzzi C, Watanabe N, Twomey E, Meers GK, Reichardt HM, Bohnenberger $\mathrm{H}$, et al. The glucocorticoid receptor in intestinal epithelial cells alleviates 
colitis and associated colorectal cancer in mice. CMGH. (2021) 11:150518. doi: $10.1016 /$ j.jcmgh.2020.12.006

368. Miehsler W, Püspök A, Oberhuber G, Vogelsang H. Impact of different therapeutic regimens on the outcome of patients with Cronh's disease of the upper gastrointestinal tract. Inflamm Bowel Dis. (2001) 7:99105. doi: 10.1097/00054725-200105000-00004

369. Wild GE, Waschke KA, Bitton A, Thomson ABR. The mechanisms of prednisone inhibition of inflammation in Crohn's disease involve changes in intestinal permeability, mucosal TNF $\alpha$ production and nuclear factor kappa B expression. Aliment Pharmacol Ther. (2003) 18:30917. doi: 10.1046/j.1365-2036.2003.01611.x

370. Taha Y, Raab Y, Carlson M, Larsson A, Lördal M, Lööf L, et al. Steroids reduce local inflammatory mediator secretion and mucosal permeability in collagenous colitis patients. World J Gastroenterol. (2006) 12:70128. doi: $10.3748 /$ wjg.v12.i43.7012

371. Kielgast F, Schmidt H, Braubach P, Winkelmann VE, Thompson KE, Frick M, et al. Glucocorticoids regulate tight junction permeability of lung epithelia by modulating claudin 8. Am J Respir Cell Mol Biol. (2016) 54:70717. doi: $10.1165 / \mathrm{rcmb} .2015-00710 \mathrm{C}$

372. Salvador E, Shityakov S, Förster C. Glucocorticoids and endothelial cell barrier function. Cell Tissue Res. (2014) 355:597605. doi: 10.1007/s00441-013-1762-z

373. Van Looveren K, Wallaeys C, Libert C. Potential of glucocorticoids to treat intestinal inflammation during sepsis. Curr Opin Pharmacol. (2020) 53:1-7. doi: 10.1016/j.coph.2019.12.005

374. Coste A, Dubuquoy L, Barnouin R, Annicotte JS, Magnier B, Notti M, et al. LRH-1-mediated glucocorticoid synthesis in enterocytes protects against inflammatory bowel disease. Proc Natl Acad Sci USA. (2007) 104:13098103. doi: 10.1073/pnas.0702440104

375. Bouguen G, Langlois A, Djouina M, Branche J, Koriche D, Dewaeles $\mathrm{E}$, et al. Intestinal steroidogenesis controls PPAR $\gamma$ expression in the colon and is impaired during ulcerative colitis. Gut. (2015) 64:90110. doi: 10.1136/gutjnl-2014-307618

376. Mueller M, Cima I, Noti M, Fuhrer A, Jakob S, Dubuquoy L, et al. The nuclear receptor LRH-1 critically regulates extra-adrenal glucocorticoid synthesis in the intestine. J Exp Med. (2006) 203:205762. doi: 10.1084/jem.20060357

377. Bayrer JR, Wang H, Nattiv R, Suzawa M, Escusa HS, Fletterick RJ, et al. LRH-1 mitigates intestinal inflammatory disease by maintaining epithelial homeostasis and cell survival. Nat Commun. (2018) 9:4055. doi: 10.1038/s41467-018-06137-w

378. Alonso-Cotoner C, Abril-Gil M, Albert-Bayo M, Mall J-PG, Sito EE, González-Castro A, et al. The role of purported mucoprotectants in dealing with irritable bowel syndrome, functional diarrhea, and other chronic diarrheal disorders in adults. Adv Ther. (2021) 38:205476. doi: 10.1007/s12325-021-01676-z

379. Aloi M, Mennini M. Efficacy of gelatin tannate for acute diarrhea in children: A systematic review and meta-analysis. J Comp Effect Res. (2019) 8:91102. doi: $10.2217 /$ cer-2018-0115

380. Eutamene H, Beaufrand C, Harkat C, Theodorou V. The role of mucoprotectants in the management of gastrointestinal disorders. Expert Rev Gastroenterol Hepatol. (2018) 12:8390. doi: 10.1080/17474124.2018.1378573

381. Piqué N, Gómez-Guillén M del C, Montero MP. Xyloglucan, a plant polymer with barrier protective properties over the mucous membranes: an overview. Int J Mol Sci. (2018) 19:673. doi: 10.3390/ijms19030673

382. Periasamy S, Lin CH, Nagarajan B, Sankaranarayanan NV, Desai UR, Liu MY. Mucoadhesive role of tamarind xyloglucan on inflammation attenuates ulcerative colitis. J Funct Foods. (2018) 47:1-10. doi: 10.1016/j.jff.2018. 05.035

383. Mishra A, Malhotra AV. Tamarind xyloglucan: a polysaccharide with versatile application potential. J Mater Chem. (2009) 19:8528-36. doi: 10.1039/b911150f

384. Hartemink R, Van Laere KMJ, Mertens AKC, Rombouts FM. Fermentation of xyloglucan by intestinal bacteria. Anaerobe. (1996) 2:223-30. doi: 10.1006/anae.1996.0031

385. Esposito E, Campolo M, Casili G, Lanza M, Franco D, Filippone A, et al. Protective effects of xyloglucan in association with the polysaccharide gelose in an experimental model of gastroenteritis and urinary tract infections. Int J Mol Sci. (2018) 19:1844. doi: 10.3390/ijms19071844

386. Pleea Condratovici C, Bacarea V, Piqué N. Xyloglucan for the treatment of acute gastroenteritis in children: Results of a randomized, controlled, clinical trial. Gastroenterol Res Pract. (2016) 2016:6874207. doi: 10.1155/2016/6874207

387. Santos J, Musta V, Luca CM, Belei OA, Cambrea SC. Randomized, placebo-controlled trial of xyloglucan and gelose for the treatment of acute diarrhea in children. Expert Rev Gastroenterol Hepatol. (2021) 15:32531. doi: $10.1080 / 17474124.2021 .1833715$

388. Gnessi L, Bacarea V, Marusteri M, Piqué N. Xyloglucan for the treatment of acute diarrhea: Results of a randomized, controlled, open-label, parallel group, multicentre, national clinical trial. BMC Gastroenterol. (2015) 15:153. doi: 10.1186/s12876-015-0386-Z

389. Trifan A, Burta O, Tiuca N, Petrisor DC, Lenghel A, Santos J. Efficacy and safety of Gelsectan for diarrhoea-predominant irritable bowel syndrome: a randomised, crossover clinical trial. United Eur Gastroenterol J. (2019) 7:1093-101. doi: 10.1177/2050640619862721

390. Alexea O, Bacarea V, Piqué N. The combination of oligo- and polysaccharides and reticulated protein for the control of symptoms in patients with irritable bowel syndrome: Results of a randomised, placebocontrolled, double-blind, parallel group, multicentre clinical trial. United Eur Gastroenterol J. (2016) 4:455-65. doi: 10.1177/2050640615615050

391. Lopetuso L, Scaldaferri G, Bruno G, Petito V, Franceschi F, Gasbarrini A. The therapeutic management of gut barrier leaking: the emerging role for mucosal barrier protectors. Eur Rev Med Pharmacol Sci. (2015) 19:1068-76.

392. Freli V, Moreira da Silva R, Pescio P. New insights into the mechanism of action of gelatine tannate for acute diarrhoea. Part 1: film-forming effect. Arch Pediatrie. (2013) 20:549. doi: 10.1016/j.arcped.2013.02.038

393. Esteban Carretero J, Durbán Reguera F, López-Argüeta Álvarez S, López Montes J. A comparative analysis of response to vs. ORS + gelatin tannate pediatric patients with acute diarrhea. Rev Esp Enfermedades Dig. (2009) 101:41-8. doi: 10.4321/S1130-01082009000100005

394. De Servi B, Ranzini F, Piqué N. Effect of Utipro $\AA$ (containing gelatinxyloglucan) against Escherichia coli invasion of intestinal epithelial cells: results of an in vitro study. Future Microbiol. (2016) 11:6518. doi: $10.2217 / \mathrm{fmb}-2016-0022$

395. Scaldaferri F, Lopetuso LR, Petito V, Cufino V, Bilotta M, Arena V, et al. Gelatin tannate ameliorates acute colitis in mice by reinforcing mucus layer and modulating gut microbiota composition: emerging role for 'gut barrier protectors' in IBD? United Eur Gastroenterol J. (2014) 2:11322. doi: $10.1177 / 2050640614520867$

396. Souza SMC, Aquino LCM, Milach AC, Bandeira MAM, Nobre MEP, Viana GSB. Antiinflammatory and antiulcer properties of tannins from Myracrodruon urundeuva Allemão (Anacardiaceae) in rodents. Phyther Res. (2007) 21:220-5. doi: 10.1002/ptr.2011

397. Ruszczyński M, Urbańska M, Szajewska H. Gelatin tannate for treating acute gastroenteritis: a systematic review. Ann Gastroenterol. (2014) 27:121-4.

398. Pérez-Gaxiola G, Cuello-García CA, Florez ID, Pérez-Pico VM. Smectite for acute infectious diarrhoea in children. Cochrane Database Syst Rev. (2018) 2018:CD011526. doi: 10.1002/14651858.CD011526.pub2

399. Szajewska H, Hoekstra JH, Sandhu B. Management of acute gastroenteritis in Europe and the impact of the new recommendations: a multicenter study. J Pediatr Gastroenterol Nutr. (2000) 30:522-7. doi: 10.1097/00005176-200005000-00011

400. Dupont C, Foo JLK, Garnier P, Moore N, Mathiex-Fortunet H, SalazarLindo E. Oral diosmectite reduces stool output and diarrhea duration in children with acute watery diarrhea. Clin Gastroenterol Hepatol. (2009) 7:456-62. doi: 10.1016/j.cgh.2008.12.007

401. González R, Sánchez De Medina F, Martínez-Augustin O, Nieto A, Gálvez J, Risco S, et al. Anti-inflammatory effect of diosmectite in hapten-induced colitis in the rat. Br J Pharmacol. (2004) 141:95160. doi: $10.1038 /$ sj.bjp. 0705710

402. Song ZH, Ke YL, Xiao K, Jiao LF, Hong QH, Hu CH. Diosmectite-zinc oxide composite improves intestinal barrier restoration and modulates TGF- $\beta 1$, ERK1/2, and Akt in piglets after acetic acid challenge. J Anim Sci. (2015) 93:1599-607. doi: 10.2527/jas.2014-8580 
403. Mahraoui L, Heyman M, Droy-Lefaix MT, Desjeux JF, Mahraoui M Heyman J F Desjeux PL, Desjeux J-F. Apical effect of diosmectite on damage to the intestinal baffler induced by basal tumour necrosis factor-cx INSERM U290 Hopital St Lazare 107 rue du Fg St Denis 75010. Gut. (1997) 40:33943. doi: 10.1136/gut.40.3.339

404. Buccigrossi V, Russo C, Guarino A, De Freitas MB, Guarino A. Mechanisms of antidiarrhoeal effects by diosmectite in human intestinal cells. Gut Pathog. (2017) 9:23. doi: 10.1186/s13099-017-0172-2

405. Theodorou V, Fioramonti J, Droy-Lefaix MT, Plique O, Buéno L. Protective action of diosmectite treatment on digestive disturbances induced by intestinal anaphylaxis in the guinea-pig. Aliment Pharmacol Ther. (1994) 8:295-9. doi: 10.1111/j.1365-2036.1994.tb00291.x

406. Bartel DP. MicroRNAs: target recognition and regulatory functions. Cell. (2009) 136:215-33. doi: 10.1016/j.cell.2009.01.002

407. Fabian MR, Sonenberg N, Filipowicz W. Regulation of mRNA translation and stability by microRNAs. Ann Rev Biochem. (2010) 79:351-79. doi: 10.1146/annurev-biochem-060308-103103

408. Rawat M, Nighot M, Al-Sadi R, Gupta Y, Viszwapriya D, Yochum G, et al. IL1B increases intestinal tight junction permeability by up-regulation of MIR200C-3p, which degrades occludin mRNA. Gastroenterology. (2020) 159:1375-89. doi: 10.1053/j.gastro.2020.06.038

409. Yang Y, Ma Y, Shi C, Chen H, Zhang H, Chen N, et al. Overexpression of miR-21 in patients with ulcerative colitis impairs intestinal epithelial barrier function through targeting the Rho GTPase RhoB. Biochem Biophys Res Commun. (2013) 434:746-52. doi: 10.1016/j.bbrc.2013.03.122

410. Zhang M, Viennois E, Prasad M, Zhang Y, Wang L, Zhang Z, et al. Edible ginger-derived nanoparticles: a novel therapeutic approach for the prevention and treatment of inflammatory bowel disease and colitis-associated cancer. Biomaterials. (2016) 101:321-40. doi: 10.1016/j.biomaterials.2016.06.018

411. Thorlacius-Ussing G, Schnack Nielsen B, Andersen V, Holmstrøm K, Pedersen AE. Expression and Localization of miR-21 and miR-126 in mucosal tissue from patients with inflammatory bowel disease. Inflamm Bowel Dis. (2017) 23:739-52. doi: 10.1097/MIB.0000000000001086

412. Ye D, Guo S, Alsadi R, Ma TY. MicroRNA regulation of intestinal epithelial tight junction permeability. Gastroenterology. (2011) 141:132333. doi: 10.1053 /j.gastro.2011.07.005

413. Bartel DP. MicroRNAs: genomics, biogenesis, mechanism, and function. Cell. (2004) 116:281-97. doi: 10.1016/S0092-8674(04)00045-5

414. McKenna LB, Schug J, Vourekas A, McKenna JB, Bramswig NC, Friedman JR, et al. MicroRNAs control intestinal epithelial differentiation, architecture, and barrier function. Gastroenterology. (2010) 139:1654. doi: 10.1053/j.gastro.2010.07.040

415. Hou Q, Huang Y, Zhu S, Li P, Chen X, Hou Z, et al. MiR-144 increases intestinal permeability in IBS-D rats by targeting OCLN and ZO1. Cell Physiol Biochem. (2018) 44:2256-68. doi: 10.1159/000486059

416. Haines RJ, Beard RS, Eitner RA, Chen L, Wu MH. TNF $\alpha / \operatorname{IFN} \gamma$ mediated intestinal epithelial barrier dysfunction is attenuated by microRNA-93 downregulation of PTK6 in mouse colonic epithelial cells. PLOS ONE. (2016) 11:154351. doi: 10.1371/journal.pone.0154351

417. Fukata T, Mizushima T, Nishimura J, Okuzaki D, Wu X, Hirose H, et al. The supercarbonate apatite-MicroRNA complex inhibits dextran sodium sulfateinduced colitis. Mol Ther. (2018) 12:658-71. doi: 10.1016/j.omtn.2018.07.007

418. Wu F, Zikusoka M, Trindade A, Dassopoulos T, Harris ML, Bayless TM, et al. MicroRNAs are differentially expressed in ulcerative colitis and alter expression of macrophage inflammatory peptide- $2 \alpha$. Gastroenterology. (2008) 135:68. doi: 10.1053/j.gastro.2008.07.068

419. Zhu H, Xiao X, Shi Y, Wu Y, Huang Y, Li D, et al. Inhibition of miRNA29a regulates intestinal barrier function in diarrhea-predominant irritable bowel syndrome by upregulating ZO-1 and CLDN1. Exp Ther Med. (2020) 20:9284. doi: 10.3892/etm.2020.9284

420. Chao G, Wang Y, Zhang S, Yang W, Ni Z, Zheng X. MicroRNA29a increased the intestinal membrane permeability of colonic epithelial cells in irritable bowel syndrome rats. Oncotarget. (2017) 8:8582837. doi: 10.18632/oncotarget.20687

421. Martínez C, Lobo B, Pigrau M, Ramos L, González-Castro AM, Alonso C, et al. Diarrhoea-predominant irritable bowel syndrome: an organic disorder with structural abnormalities in the jejunal epithelial barrier. Gut. (2013) 62:1160-8. doi: 10.1136/gutjnl-2012-302093

422. Martínez C, Rodiño-Janeiro B, Lobo B, Stanifer M, Klaus B, Granzow $\mathrm{M}$, et al. miR-16 and miR-125b are involved in barrier function dysregulation through the modulation of claudin-2 and cingulin expression in the jejunum in IBS with diarrhoea. Gut. (2017) Sep 1 66:1597610. doi: 10.1136/gutjnl-2016-311477

423. Martínez C, Lasitschka F, Thöni C, Wohlfarth C, Braun A, Granzow $\mathrm{M}$, et al. Comparative expression profiling in the intestine of patients with Giardia-induced postinfectious functional gastrointestinal disorders. Neurogastroenterol Motil. (2020) 32:13868. doi: 10.1111/nmo.13868

424. Mahurkar-Joshi S, Rankin CR, Videlock EJ, Soroosh A, Verma A, Khandadash A, et al. The colonic mucosal micrornas, MicroRNA-219a-5p, and MicroRNA-338-3p are downregulated in irritable bowel syndrome and are associated with barrier function and MAPK signaling. Gastroenterology. (2021) 160:2409-22.e19. doi: 10.1053/j.gastro.2021.02.040

425. $\mathrm{Li} \mathrm{Z}, \mathrm{Xu} \mathrm{R}, \mathrm{Li} \mathrm{N}$. MicroRNAs from plants to animals, do they define a new messenger for communication? Nutr Metab. (2018) 15:121. doi: 10.1186/s12986-018-0305-8

426. Liang H, Zhang S, Fu Z, Wang Y, Wang N, Liu Y, et al. Effective detection and quantification of dietetically absorbed plant microRNAs in human plasma. $J$ Nutr Biochem. (2015) 26:505-12. doi: 10.1016/j.jnutbio.2014.12.002

427. Witwer KW, Hirschi KD. Transfer and functional consequences of dietary microRNAs in vertebrates: concepts in search of corroboration. BioEssays. (2014) 36:394-406. doi: 10.1002/bies.201300150

428. Yang J, Hotz T, Broadnax L, Yarmarkovich M, Elbaz-Younes I, Hirschi KD. Anomalous uptake and circulatory characteristics of the plant-based small RNA MIR2911. Sci Reports. (2016) 6:1-9. doi: 10.1038/srep26834

429. Yang J, Elbaz-Younes I, Primo C, Murungi D, Hirschi KD. Intestinal permeability, digestive stability and oral bioavailability of dietary small RNAs. Sci Rep. (2018) 8:10253. doi: 10.1038/s41598-01828207-1

430. Díez-Sainz E, Lorente-Cebrián S, Aranaz P, Riezu-Boj JI, Martínez JA, Milagro FI. Potential mechanisms linking food-derived microRNAs, gut microbiota and intestinal barrier functions in the context of nutrition and human health. Front Nutr. (2021) 8:586564. doi: 10.3389/fnut.2021. 586564

431. Zhang H, Li Y, Liu Y, Liu H, Wang H, Jin W, et al. Role of plant MicroRNA in cross-species regulatory networks of humans. BMC Syst Biol. (2016) 10:60. doi: 10.1186/s12918-016-0292-1

432. Aquilano K, Ceci V, Gismondi A, De Stefano S, Iacovelli F, Faraonio $\mathrm{R}$, et al. Adipocyte metabolism is improved by TNF receptortargeting small RNAs identified from dried nuts. Commun Biol. (2019) 2:317. doi: 10.1038/s42003-019-0563-7

433. Ju S, Mu J, Dokland T, Zhuang X, Wang Q, Jiang H, et al. Grape exosome-like nanoparticles induce intestinal stem cells and protect mice from DSS-induced colitis. Mol Ther. (2013) 21:1345-57. doi: 10.1038/mt. 2013.64

434. Mu J, Zhuang X, Wang Q, Jiang H, Deng Z-B, Wang B, et al. Interspecies communication between plant and mouse gut host cells through edible plant derived exosome-like nanoparticles. Mol Nutr Food Res. (2014) 58:156173. doi: 10.1002/mnfr.201300729

435. Rahimi, Rahimi E, Amirkhani Z, Salehi R. Leucine-rich repeat-containing gprotein coupled receptor 5 gene overexpression of the rat small intestinal progenitor cells in response to orally administered grape exosome-like nanovesicles. Adv Biomed Res. (2018) 7:125. doi: 10.4103/abr.abr_114_18

436. Fujita D, Arai T, Komori H, Shirasaki Y, Wakayama T, Nakanishi T, et al. Apple-derived nanoparticles modulate expression of organic-aniontransporting polypeptide (OATP) 2B1 in Caco-2 Cells. Mol Pharm. (2018) 15:5772-80. doi: 10.1021/acs.molpharmaceut.8b00921

437. Li M, Chen T, He J-J, Wu J-H, Luo J-Y, Ye R-S, et al. Plant MIR167e$5 \mathrm{p}$ inhibits enterocyte proliferation by targeting $\beta$-catenin. Cells. (2019) 8:1385. doi: $10.3390 /$ cells8111385

438. Nakata K, Sugi Y, Narabayashi H, Kobayakawa T, Nakanishi Y, Tsuda $\mathrm{M}$, et al. Commensal Microbiota-induced microRNA modulates intestinal epithelial permeability through the small GTPase ARF4. J Biol Chem. (2017) 292:15426-33. doi: 10.1074/jbc.M117.788596 
439. Ishida M, Selaru FM, Edu S. miRNA-based therapeutic strategies. Curr Anesth Rep. (2013) 1:63-70. doi: 10.1007/s40139-0120004-5

440. Wang C, Chen J. microRNAs as therapeutic targets in intestinal diseases. ExRNA. (2019) 1:1-12. doi: 10.1186/s41544-019-0026-9

441. Hossian AKMN, Mackenzie GG, Mattheolabakis G. miRNAs in gastrointestinal diseases: can we effectively deliver RNA-based therapeutics orally? Nanomedicine. (2019) 14:2873-89. doi: 10.2217/nnm-2019-0180

442. Zhang L, Cheng J, Fan XM. MicroRNAs: New therapeutic targets for intestinal barrier dysfunction. World J Gastroenterol. (2014) 20:581825. doi: $10.3748 /$ wjg.v20.i19.5818

Conflict of Interest: CA-C discloses past scientific collaboration with Noventure S.L. JS has served as consultant for Noventure and discloses present and past recent scientific collaborations with Salvat, Norgine, Alfa-Sigma, Cosmo, Adare, Devintecpharma, Pileje and Danone that do not constitute a conflict of interest in developing the content of the present manuscript.

The remaining authors declare that the research was conducted in the absence of any commercial or financial relationships that could be construed as a potential conflict of interest.
Publisher's Note: All claims expressed in this article are solely those of the authors and do not necessarily represent those of their affiliated organizations, or those of the publisher, the editors and the reviewers. Any product that may be evaluated in this article, or claim that may be made by its manufacturer, is not guaranteed or endorsed by the publisher.

Citation: Fortea M, Albert-Bayo M, Abril-Gil M, Ganda Mall J-P, Serra-Ruiz X, Henao-Paez A, Expósito E, González-Castro AM, Guagnozzi D, Lobo B, AlonsoCotoner C and Santos J (2021) Present and Future Therapeutic Approaches to Barrier Dysfunction. Front. Nutr. 8:718093. doi: 10.3389/fnut.2021.718093

Copyright (C) 2021 Fortea, Albert-Bayo, Abril-Gil, Ganda Mall, Serra-Ruiz, Henao-Paez, Expósito, González-Castro, Guagnozzi, Lobo, Alonso-Cotoner and Santos. This is an open-access article distributed under the terms of the Creative Commons Attribution License (CC BY). The use, distribution or reproduction in other forums is permitted, provided the original author $(s)$ and the copyright owner(s) are credited and that the original publication in this journal is cited, in accordance with accepted academic practice. No use, distribution or reproduction is permitted which does not comply with these terms. 